\title{
ADAPTATION OF CANADIAN FORCES MEMBERS AND THEIR SPOUSES TO THE DEMANDS OF MILITARY LIFE: THE ROLE OF SOCIAL AND ORGANIZATIONAL SUPPORT
}

\author{
A thesis submitted to \\ the Faculty of Graduate Studies and Research \\ in Partial Fulfillment of the requirements for the degree \\ Doctor of Philosophy
}

by

Sanela Dursun

Department of Psychology

Carleton University

October 2009

C2009 Sanela Dursun 
Library and Archives

Canada

Published Heritage

Branch

395 Wellington Street

Ottawa ON K1A ON4

Canada
Bibliothèque et

Archives Canada

Direction du

Patrimoine de l'édition

395, rue Wellington

Ottawa ON K1A ON4

Canada
Your file Votre référence
ISBN: 978-0-494-63853-8
Our file Notre référence
ISBN: $978-0-494-63853-8$
NOTICE:

The author has granted a nonexclusive license allowing Library and Archives Canada to reproduce, publish, archive, preserve, conserve, communicate to the public by telecommunication or on the Internet, loan, distribute and sell theses worldwide, for commercial or noncommercial purposes, in microform, paper, electronic and/or any other formats.

The author retains copyright ownership and moral rights in this thesis. Neither the thesis nor substantial extracts from it may be printed or otherwise reproduced without the author's permission.

\section{AVIS:}

L'auteur a accordé une licence non exclusive permettant à la Bibliothèque et Archives Canada de reproduire, publier, archiver, sauvegarder, conserver, transmettre au public par télécommunication ou par l'Internet, prêter, distribuer et vendre des thèses partout dans le monde, à des fins commerciales ou autres, sur support microforme, papier, électronique et/ou autres formats.

L'auteur conserve la propriété du droit d'auteur et des droits moraux qui protège cette thèse. $\mathrm{Ni}$ la thèse ni des extraits substantiels de celle-ci ne doivent être imprimés ou autrement reproduits sans son autorisation.
In compliance with the Canadian Privacy Act some supporting forms may have been removed from this thesis.

While these forms may be included in the document page count, their removal does not represent any loss of content from the thesis.
Conformément à la loi canadienne sur la protection de la vie privée, quelques formulaires secondaires ont été enlevés de cette thèse.

Bien que ces formulaires aient inclus dans la pagination, il n'y aura aucun contenu manquant. 


\section{Abstract}

Perhaps more than in any other kind of organization, the interaction between work and family among military personnel has a pervasive influence on the lifestyle of its enlisted members and their families. The aim of this study was to assess the impact of military lifestyle demands on military families and the crossover effect of spousal support on CF members' personal well-being, as well as impacts on the organization. Study 1 ( $N$ $=2684$ ) focused on understanding the impact of spousal support on serving members' well-being (psychological distress and life satisfaction) and organizational outcomes (commitment, morale turnover intentions). Regression analyses indicated the influential role that spousal support, especially instrumental support played for both CF members' personal well-being, and organizational outcomes. Given the importance of spouses' support for the CF members' career, Study $2(N=1644)$ evaluated the factors that contributed to the well-being of the military spouses, as well as the factors that influenced their willingness to support the military career of the serving member. Regression analyses indicated that spousal appraisals of the impact of the military lifestyle on their family and career appeared to be key to mediating the impact of deployment related stressors (e.g., children's distress) on spousal well-being. Although it was suggested that coping styles would emanate from particular appraisals, it appears that appraisals and coping worked in conjunction with one another in a reciprocal manner. Such bidirectionality was also evident when considering the role of support perceptions in appraisals and coping, and how these factors influenced well-being. This dynamic pattern of relations has implications for promoting well-being among military spouses and facilitating their adaptation to the military lifestyle. 


\section{Acknowledgments}

I gratefully acknowledge the support of several people without whom I could have never completed this dissertation. First and foremost, I am indebted to my supervisor, Dr. Kimberly Matheson - thank you for your continual guidance, invaluable expertise and support through this endeavor. Your academic brilliance made working with you the most inspiring and enriching experience.

Next, I would like to thank Dr. Hymie Anisman and Dr. Tzvetanka DobrevaMartinova for their insightful comments and suggestions at the proposal stage of this research. Special thank you to my external committee members, Dr. Steven Murphy and Dr. Joseph Rochford for their expertise and time. Thank you also to Ms. Etelle Bourassa for her administrative proficiency and her consideration and kindness.

I am also grateful to the Director General Military Personnel Research and Analysis, Ms. Susan Truscott for her instrumental support over the years of my doctoral programme, as well as to LCol Dan Dunlop for sponsoring this project. A special thank you to the members of the Canadian Forces and their spouses who participated in this research and continue to serve their country in spite of all else.

I thank my friends and coworkers who offered encouragement and moral support. My sincere appreciation goes to my family (especially my in-laws) for their love, patience, understanding and invaluable support. Last, but certainly not least, my deepest gratitude to my husband Mirko and our children, Ana and Luka, whose unconditional love and support gave me the strength to balance work, school and family. 


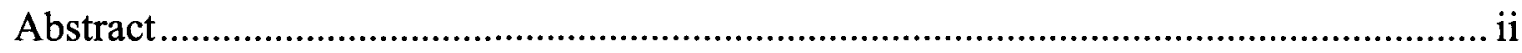

Acknowledgments ............................................................................................ iii

List of Tables ................................................................................................... vii

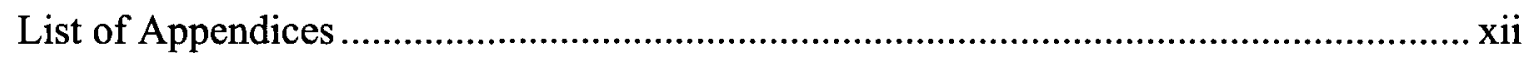

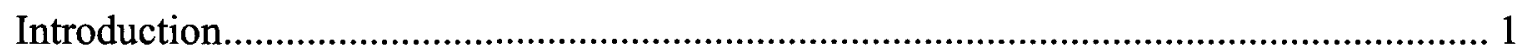

Changing Face of the Canadian Forces ......................................................... 5

Military Life and Organizational Outcomes ...................................................... 7

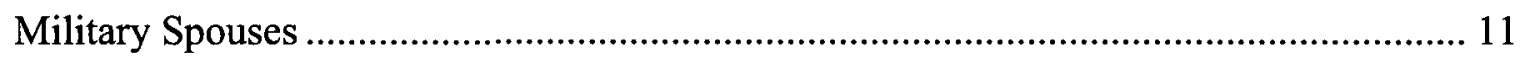

Coping Resources in the Relation between Stressors and Individual and Organizational

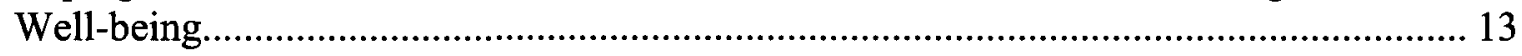

Role of Social Support on Well-being ................................................................ 13

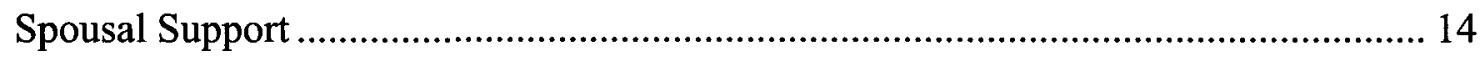

Spousal Support and Organizational Outcomes ................................................. 17

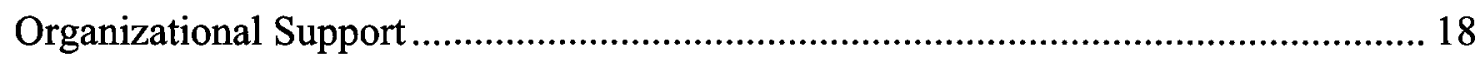

Potential Mediators in the Relations between Stressors and Well-being ...................... 19

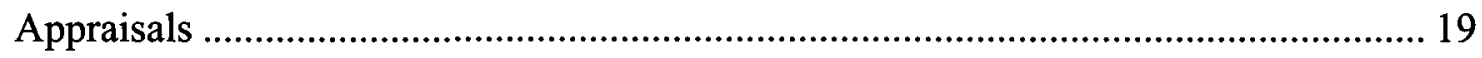

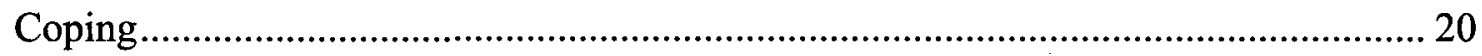

Overview of the Present Investigation .......................................................... 24

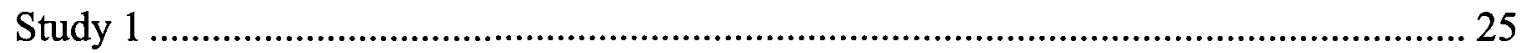

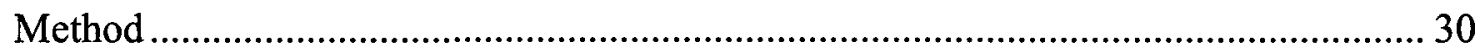

Participants and Procedure......................................................................... 30

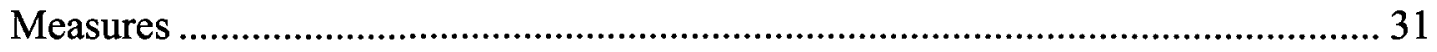

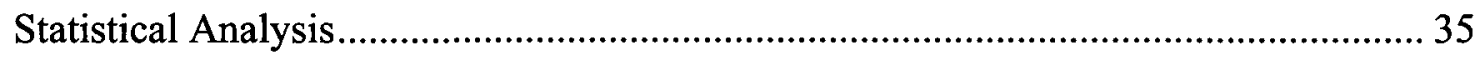




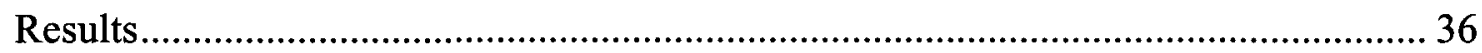

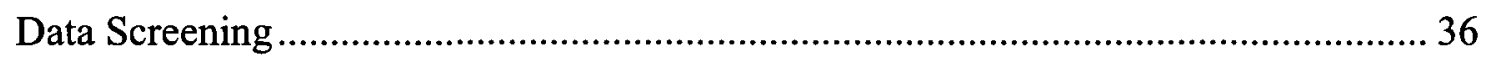

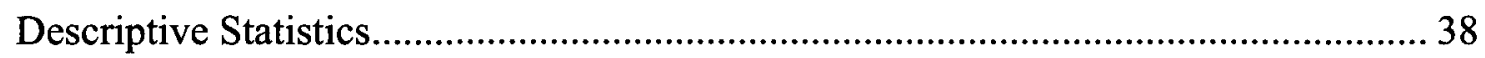

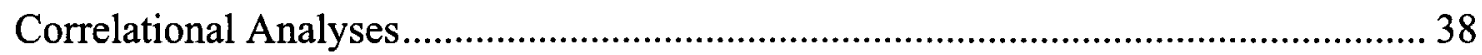

Role of Individual Well-being in Mediating the Relations between Spousal Support for Military Career and Organizational Outcomes .............................................................. 41

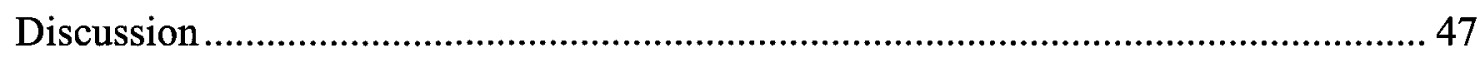

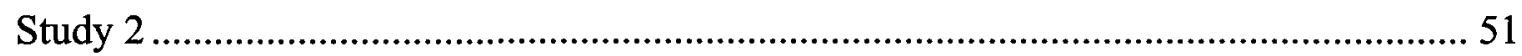

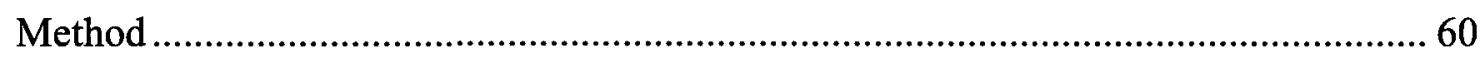

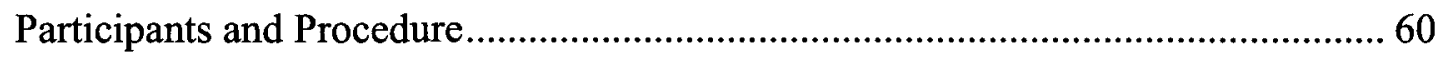

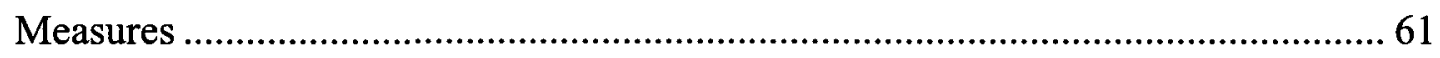

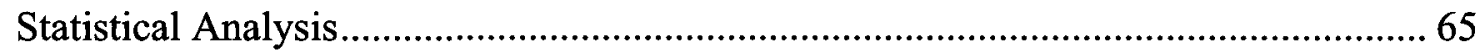

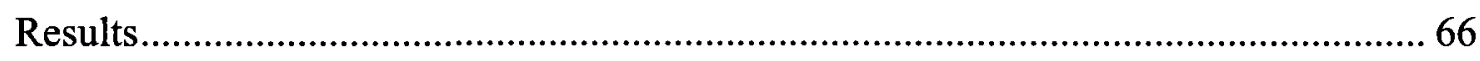

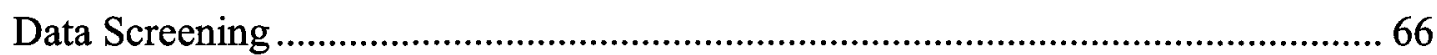

Mediated Analyses................................................................................................. 73

Role of Appraisals in Mediating the Relations between Stressors and Well-

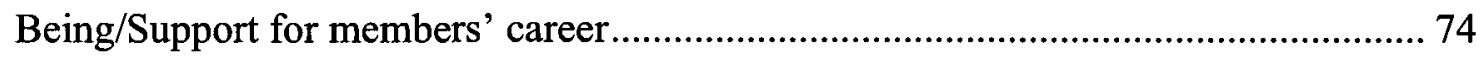

Role of Coping in Mediating the Relation between Appraisals and Well-being.......... 86 Role of Appraisals in Mediating the Relations between Social Support and Well-being

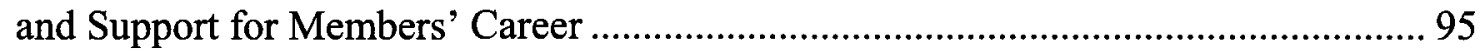

Role of Coping in Mediating the Relations between Social Support and Well-being and Support for Members' Career ..................................................................................... 106

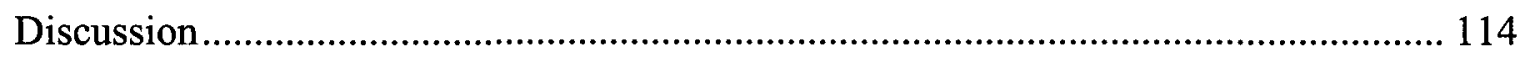

Deployment Stressors, Appraisals and Spousal Well-being...................................... 115 


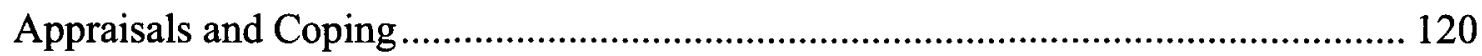

Social Support, Appraisals and Well-being .............................................................. 123

Social Support and Coping …………............................................................... 125

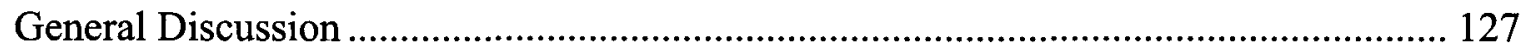

Theoretical and Methodological Contributions ....................................................... 134

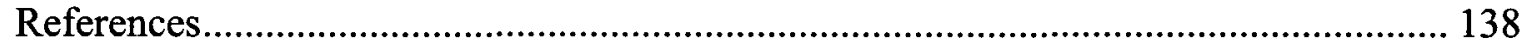


List of Tables

Table 1. Descriptive Statistics for the Variables in the Study..................................... 37

Table 2. Intercorrelations among Variables......................................................... 40

Table 3. Direct and Indirect (through Well-being Indicators) Effects of Support for

Career on Organizational Commitment: Results of Bootstrap Analysis. 43

Table 4. Direct and Indirect (through Well-being Indicators) Effects of Support for

Career on Personal Morale: Results of Bootstrap Analysis.. 45

Table 5. Direct and Indirect (through Well-being Indicators) Effects of Support for

Career on Turnover Intention: Results of Bootstrap Analysis. 47

Table 6. Descriptive Statistics and Correlations among the Coping Dimensions..... 68

Table 7. Correlations between Appraisal Dimensions and Coping Styles. 69

Table 8. Means and Standard Deviations on Social Support and Coping Styles across

Deployment Groups 70

Table 9. Means and Standard Deviations on Well-Being Indicators and Support for Military Career across Deployment Groups 72

Table 10. Means and Standard Deviations on Deployment Stressors and Appraisal Dimensions across Deployment Groups 73

Table 11. Direct and Indirect (through Appraisals) Effects of Parenting Stressors on Psychological Distress: Results of Bootstrap Analysis 75

Table 12. Direct and Indirect (through Appraisals) Effects of Relationship Stressors on Psychological Distress: Results of Bootstrap Analysis 77

Table 13. Direct and Indirect (through Appraisals) Effects of Parenting Stressors on Satisfaction with Life: Results of Bootstrap Analysis 78 
Table 14. Direct and Indirect (through Appraisals) Effects of Relationship Stressors on Satisfaction with Life: Results of Bootstrap Analysis 79

Table 15. Direct and Indirect (through Appraisals) Effects of Parenting Stressors on Support for Members' Career: Results of Bootstrap Analysis 80

Table 16. Direct and Indirect (through Appraisals) Effects of Relationship Stressors on Support for Members' Career: Results of Bootstrap Analysis 81

Table 17. Moderating effect of Deployment Phase on the Relation between Parenting Stressors and Support for Career (through Threat appraisal) 85

Table 18. Moderating effect of Deployment Phase on the relation between Relationship Stressors and Support for Career (through Threat appraisal) 86

Table 19. Direct and Indirect (through Coping) Effects of Appraisal of Threat on Psychological Distress: Results of Bootstrap Analysis 88

Table 20. Direct and Indirect (through Coping) Effects of Appraisal of Controllability on Psychological Distress: Results of Bootstrap Analysis 90

Table 21. Direct and Indirect (through Coping) Effects of Appraisal of Threat on Satisfaction with Life: Results of Bootstrap Analysis 92

Table 22. Direct and Indirect (through Coping) Effects Appraisal of Controllability on

Satisfaction with Life: Results of Bootstrap Analysis 93

Table 23. Direct and Indirect (through Appraisals) Effects of Spousal Support on Psychological Distress: Results of Bootstrap Analysis 97

Table 24. Direct and Indirect (through Appraisals) Effects of Spousal Support on Satisfaction with Life: Results of Bootstrap Analysis 98 
Table 25. Direct and Indirect (through Appraisals) Effects of Organizational Support on Satisfaction with Life: Results of Bootstrap Analysis 100

Table 26. Direct and Indirect (through Appraisals) Effects of Spousal Support on Support for Members' Career: Results of Bootstrap Analysis 102

Table 27. Moderating Effect of Deployment Phase on the Relation between Spousal Support and Support for Career (through Threat Appraisal) 105

Table 28. Direct and Indirect (through Coping) Effects of Spousal Support on Psychological Distress: Results of Bootstrap Analysis 108

Table 29. Direct and Indirect (through Appraisals) Effects of Spousal Support on Satisfaction with Life: Results of Bootstrap Analysis 110

Table 30. Direct and Indirect (through Coping) Effects of Organizational Support on Satisfaction with Life: Results of Bootstrap Analysis

Table C1. Descriptive statistics for the variables in Study 2. 187

Table C2. Intercorrelations among Predictors and Outcomes in Study 2 187 


\section{List of Figures}

Figure 1. Proposed Model of the Relations between Stress, Social Support, Coping and Appraisal.

Figure 2. Mediating Effects of Individual Well-being on the Relation between Spousal

Support and Organizational Well-being

Figure 3. Mediating Effects of Well-being Indicators on the Relation between Spousal

Support for Military Career and Organizational Outcomes.....

Figure 4. Proposed Model of the Relations between Stress, Social Support, Appraisals,

Coping and Well-being

Figure 5. Mediating Effects of Appraisals on the Relation between Stressors and Well-

being and Support for Military's Career.

Figure 6. Path Diagram depicting the Mediating Effects of Appraisals on the Relation

between Stressors and Well-being and Support for $C F$.

Figure 7. Mediating Effects of Coping on the Relation between Stress Appraisals and

Well-being

Figure 8. Path Diagram depicting the Mediating Effects of Coping on the Relation

between Appraisals and Well-being Indicators

Figure 9. Mediating Effects of Appraisals on the Relation between Social Support and

Well-being. 96

Figure 10. Path Diagram depicting the Mediating Effects of Appraisals on the Relation

between Spousal Support and Well-being indicators and Support for CF. 103

Figure 11. Path Diagram depicting the Mediating Effects of Appraisals on the Relation between Organizational Support and Satisfaction with life 104 
Figure 12. Mediating Effects of Coping on the Relation between Social Support and Wellbeing.. 106

Figure 13. Path Diagram depicting the Mediating Effects of Coping on the Relation between Spousal Support and Well-being Indicators 113

Figure 14. Path Diagram depicting the Mediating Effects of Coping on the Relation between Organizational Support and Satisfaction with life 


\section{List of Appendices}

Appendix A: Study 1 Measures ............................................................... 170

Appendix B: Measures New to Study 2 ...................................................... 179

Appendix C: Descriptive statistics for the variables in Study 2.......................... 185 
Introduction

Many organizations have come to recognize the importance of family life in promoting workplace productivity and organizational well-being. Employees who enjoy a happy and healthy family life are likely to be more committed, focused, and effective at work than those experiencing daily concerns revolving around stressful family matters (Kossek \& Ozeki, 1998; Smith-Major, Klein, \& Ehrhart, 2002). Similarly, conflicts between individuals' work and non-work lives have been linked to a variety of negative consequences not only for the individual (Frone, 2000), but also for the organization (Jex, 1998). For example, employees who experience work-family conflict report lower levels of general well-being (Frone, 2000; Frone, Russell \& Cooper, 1992; Thomas \& Ganster, 1995), lower levels of job satisfaction (Adams, King \& King, 1996), higher levels of burnout (Burke, 1988), more alcohol use and poorer health (Allen, Herst, Bruck, \& Sutton, 2000; Frone, Russell \& Barnes, 1996), and as a result, the organization experiences increased turnover and decreased performance (Jex, 1998). Much of the research on work and family life points to the bi-directional relationship between these two domains (Frone et al., 1992). Kanter's (1977) seminal work on the "myth of separate worlds" gave rise to a considerable body of research that shared the understanding that experiences inside the workplace interacted with experiences outside the workplace, commonly referred to as the "spillover effect".

Perhaps more than in any other kind of organization, the interaction between work and family among military personnel has a pervasive influence on the lifestyle of its enlisted members and their families. Unlike most organizations, a military member's family is highly involved in the culture and organization of the military (Wisecarver, 
Cracraft, \& Heffner, 2006). As well, the unique demands of military service, including operational deployments, risk of injury or death, frequent separation from the family, and postings can significantly disrupt family life (Castro, Bienvenu, Huffman, \& Adler, 2001). These realities, combined with isolation from traditional sources of support such as extended families, close friends and stable community relationships (Black, 1993) are associated with personal and interpersonal stress for some military families. While there are other occupations that share specific characteristics of the military lifestyle, the military is almost unique in its combination of requirements (Segal, 1989).

The aim of this study was to assess the impact of military lifestyle demands on military families and the crossover effects of spousal support or lack of spousal support on Canadian Forces (CF) members. To do so, two studies were conducted. Study 1 examined the role of spouses of CF members in promoting members' well-being, and associated implications for positive organizational outcomes. To the extent that spouses provided a vital resource promoting service members' well-being, readiness, performance and ability to carry out the mission, it was crucial to understand how families can maintain and even enhance spousal resiliency during and after military deployments and separations. Therefore, Study 2 focused on the well-being of the military spouses, and evaluated the relation between factors associated with the demands of military service and deployments in particular, and the well-being and quality of life of military spouses ${ }^{1}$. Specifically, it examined the effects of stressors across the deployment phases, the role of social support and mediating effects of appraisals and coping styles on spousal wellbeing, life satisfaction and their willingness to support members' career.

\footnotetext{
${ }^{1}$ In order to be as concise as possible, the term "spouse" is used to refer to both married and common-law partners. The term "families" refers to both traditional and non-traditional families, including extended and binuclear families.
} 
To assess the impact of military lifestyle demands on military families, it may be useful to adopt a stress and coping perspective. This approach emphasizes the cognitivemotivational-relational concepts of subjective appraisals and coping, and a processcentered holistic outlook regarding individuals' well-being (Lazarus, 2000). From the perspective of the transactional model of stress and coping (Lazarus \& Folkman, 1984), military lifestyle demands include various stressors, which the individual appraises and responds to. The processes of appraisal and coping mediate the relation between the experienced stressors and the individual's well-being. As important as the appraisal itself are the external resources that the individual has to deal with the stressors. Among other resources (e.g., financial, informational), external resources refer to the different dimensions of social support. There is fairly consistent evidence regarding the role of social support in influencing individuals' appraisals of the stressors, abilities to cope, and adjustment to stressful situations (House, Landis, \& Umberson, 1988; Katz, 2002; Tak \& McCubbin, 2002). The general model employed in the present studies (Figure 1) illustrates the relations between stressor experiences, social support, appraisals, coping, and well-being. 


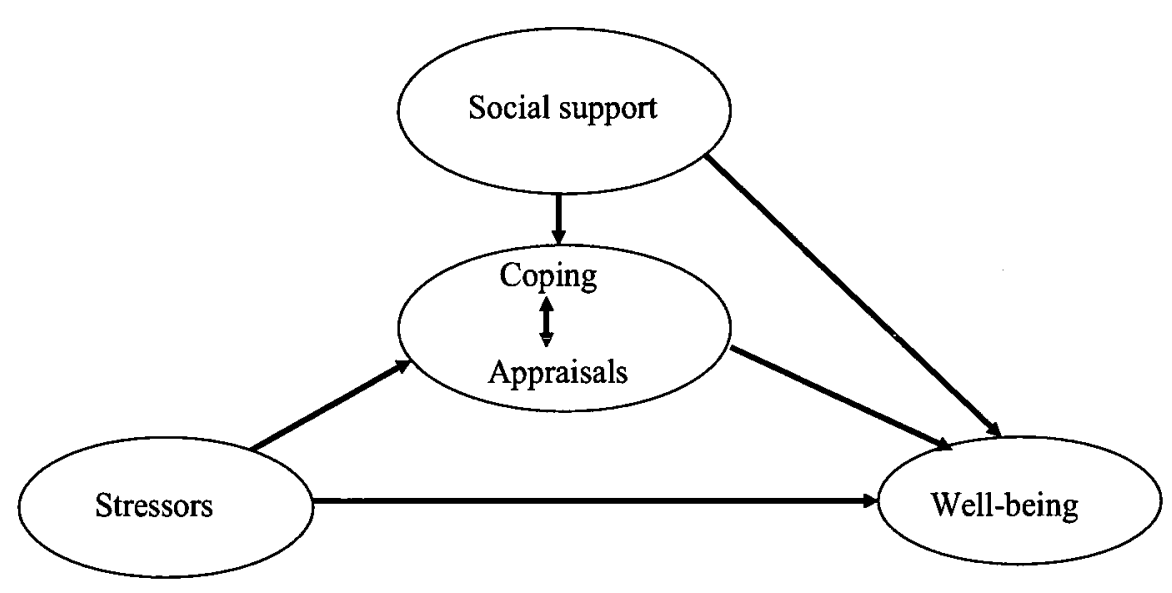

Figure 1. Proposed Model of the Relations between Stress, Social Support, Coping and Appraisal

Despite the attention given to the various components of the stress process and the interrelations among them, these components and their interrelations have not been extensively studied in a military family environment. A major reason possibly lies in the restricted availability and accessibility of data coming from samples of military members and their families. Therefore, a purpose of this study was to broaden and refine our conceptual understanding of the coping process by testing a prospective model of coping that examined these central mediating mechanisms in the coping process in a military environment. This study also aimed to explore factors specific to the military context that 
might be the most potent in influencing the effects of stressors experienced by military families on well-being.

Finally, the study aimed to assess shifts in the model predictors at different stages of the deployment cycle. There has been hardly any examination of the influence of multiple stress factors and coping on psychological distress, life satisfaction and willingness to support members' career in military spouses. Since there is a gap in the understanding of the stress of deployment on military families, this study examined the model depicted in Figure 1 across stages of the deployment cycle.

\section{Changing Face of the Canadian Forces}

Family patterns of Canadian military personnel have changed dramatically since the1970s. Most notable has been the increased numbers of married military members. During the 1980s, following the promulgation of the Canadian Human Rights Act and the Charter of Rights and Freedoms, the Canadian Forces removed the restrictive age eligibility requirements for entry, thus permitting older Canadians to join the military. A recent study of Service Providers in the Canadian Forces identified an emerging trend of increasing numbers of older members, who are frequently already married (or in common-law relationships) (Sudom \& Dursun, 2006). Since the 1970s, the proportion of recruits that are not single when they joined the $\mathrm{CF}$ increased considerably, from $6 \%$ in 1968 to $16 \%$ in 1996 , to $28 \%$ in 2008 . Indeed, $62 \%$ of the CF population was married as of February 2009 (HRMS, 2009).

The Canadian military is increasingly involved in multinational peacekeeping and humanitarian assistance missions, with the most recent involving a combat role in Afghanistan. The greater number of deployments, combined with the increased likelihood 
of CF members having families, means that family separation has become an important stressor that members have to contend with. Families have to be prepared to manage life in the absence of at least one spouse, potentially making it difficult for them to adjust to military life (Burnam, Meredith, Sherbourne, Valdez, \& Vernez, 1992). The present role of the Canadian Forces in Afghanistan, and the increased danger associated with this mission in particular, has created additional stress for serving members and their families.

Along with the changes in the demographics and the deployment pressures on the Canadian Forces, there have been significant changes in the Canadian society with respect to how families function. Of particular interest are changes over the past few decades with regard to gender roles. Although women in general still have disproportional responsibility for raising children, men increasingly share this role (Eagle, Miles, \& Icenogle, 1997). The switch from traditional complementary roles, wherein men assumed bread-winning responsibilities and women were primary caretakers for children, to a role-symmetrical model in which men and women can be equally involved in earning and caring, has accentuated the importance of fathers within the lives of their children, not only in terms of the provision of resources, but also with respect to their presence and day-to-day involvement (Pleck, 1997). These changing norms clearly have implications for the tensions between military work and members' domestic responsibilities (Pleck, 1997). Further changes of social norms include an increase in dual earner/dual career families. Often, the spouses of the military members are left to manage day-to-day family activities in addition to their work outside the home. But frequent relocations and separations due to deployment compromise the capacity of 
the military spouses to develop and maintain their own careers, thus contributing to family tensions associated with military life.

Changes in the missions of the Canadian Forces, as well as family patterns, gender roles, and general societal and economic trends have prompted the Canadian military to shift strategies for attracting and retaining service members. Recognizing the importance of the family, the military is branding itself as "we recruit a member, but retain a family". To live up to this, personnel research in the military has begun to address how particular organizational outcomes, such as recruitment and retention, are affected by family-related factors.

\section{Military Life and Organizational Outcomes}

As noted earlier, prior to the 1980 s, family issues were not of particular concern to the military because many of its members were single. The saying, "If the military wanted you to have a wife, it would have issued you one" rang true. By the late 1980's, Segal (1986) characterized the military as a "greedy" institution because of its tremendous demands for the loyalty and commitment of service members, and of their families (Segal, 1986). Family members were expected to adapt and to place their unconditional support behind the service member in his/her efforts to successfully accomplish the military mission (Segal, 1989; Stanley, Segal, \& Laughton, 1990). Military life places unique and extremely intense demands on its members and their families, including frequent separation and eventual reunions, relocations, risks of injury or death, long hours, changeable work schedules, isolation from civilian society, and an overarching culture that is still heavily masculine (i.e., valuing hierarchy, dominance, power and control of emotions; Segal, \& Harris, 1993). Military institutions challenge 
families in ways that would be unimaginable in most civilian occupations. The increasing awareness among military leaders of the importance of the family has triggered an interest in how factors related to the family might be associated with organizational effectiveness in the military. The key components of organizational effectiveness in the military include organizational outcomes such as organizational commitment, personal morale, readiness and intention to leave the CF (Villeneuve, Dobreva-Martinova, Little, \& Izzo, 2000).

Organizational commitment is a multidimensional construct, defined as "the relative strength of an individual's identification with and involvement in a particular organization" (Mowday, Porter, \& Steers, 1982, p.27). Strongly committed military personnel report higher job satisfaction (Martin \& O'Laughlin, 1984), adjust more readily to military life, report higher levels of psychological well-being (Rosen \& Martin, 1996), and are less likely to indicate an intention to leave the military (Allen, 2003; Gade, Tiggle, \& Schumm, 2003). Finally, highly committed soldiers also exhibit higher taskrelated knowledge (Gade, et al., 2003), suggesting a link between commitment and objective indicators of operational effectiveness. There is some empirical evidence for a link between family support variables and the work commitment of military personnel (Bourg \& Segal, 1999; Orthner \& Pittman, 1986). In particular, it was found that work commitment is the result of gratifications received from several sources, including one's job and family. Married service members who believed that their children and spouses were adjusting well to organizational demands reported greater family support for career commitment. This, in turn, led to increases in levels of organizational commitment for service members (Orthner \& Pittman, 1986). 
Morale can be conceptualized as both an individual and a collective phenomenon (Gal, 1986). Thus, morale may be a state of mind of an individual (e.g., dedication, willingness to sacrifice), or of a group (e.g., collective enthusiasm toward achieving goals). Individual morale (also referred to in the literature as professional morale) involves appraisals of the self, such as confidence and pride, whereas group morale involves aspects of group readiness, teamwork, and effectiveness (Murphy, Farley, Dobreva-Martinova, \& Gingras, 1997). There is some evidence showing that service members' morale can be influenced by their spouses' attitudes toward the military (Rosen, Moghadam, \& Vaitkus, 1989). Specifically, spouses' perceptions of unit leadership had a significant impact on soldiers' personal morale. It was found that for junior enlisted soldiers, this influence was indirect; that is, a spouse's attitudes toward her husband's unit influenced his perception of a satisfactory interface between the Army and the family, which, in turn, influenced his morale. The officers, on the other hand were more directly influenced by their spouses' attitudes (Rosen et al., 1989).

Operational readiness is defined as the degree to which an individual is psychologically prepared to deploy and/or conduct operations and to withstand the mental challenges with the operation, including separation from family and other support groups (Sharpe \& English, 2006). In this regard, the preparedness of an individual member's family to deal with the rigors of a deployment is also considered a part of operational readiness (Sharpe \& English, 2006). Even though a few studies demonstrate a link between family factors and readiness, attempts to identify the family factors that influence readiness have been limited and operationally inconsistent (e.g., Kirkland \& 
Katz, 1989; Oliver, 1991; Orthner \& Pittman, 1986; Pliske, 1988; Vernez \& Zellman, 1987).

Turnover intent has been a focus of considerable research, including in a military environment (e.g. Fricker, 2002; Hosek \& Totten, 1998; Hosek \& Totten, 2002; Sticha, Sadaca, DiFazio, \& Knerr, 1999). Several U.S. studies found that personal domains, such as marriage and relationships with children influenced reenlistment decisions (White, Baker, \& Wolosin, 1999; Wilcove, Schwerin, \& Wolosin, 2003). It has been suggested that the spouse's preference/support for the service member's career and reenlistment has an important impact on whether the member will remain in the service (Etheridge, 1989; Lakhani, 1995; Orthner, 1990; Seboda \& Szoc, 1984). Furthermore, it has been found that perceived unit support for family issues had a direct effect on the soldier's commitment (Bourg \& Segal, 1999).

The organizational outcomes described above, namely, organizational commitment, personal morale, operational readiness and turnover intent, are key components of organizational effectiveness in the military (Villeneuve et al., 2000). These outcomes have become even more pressing for the Canadian Forces in the past decade with the higher operational tempo that the Canadian military has been experiencing. As there is some empirical evidence that family factors may have an impact on all four organizational outcome variables, further research on the impact of the demands of military service on members and their families is needed to identify emerging patterns. Most of the studies reviewed above, despite the richness of some of the data sets described, only reported the percentages of respondents answering a given way with some basic statistical tests (e.g. Chi-square or t-tests). While many variables were 
measured, the essential interconnectedness among these variables was not always evident. Specifically, the mechanisms by which family factors and organizational outcomes are related have not been studied.

\section{Military Spouses}

The military lifestyle and operational tempo permeates almost every aspect of the lives of members and of their spouses (Bowen, 1989). Military spouses face a number of unique stressors as they attempt to meet the demands placed upon them by the military institution. Elements of the military lifestyle which influence the well-being of family members include frequent relocations, temporary housing, un- or under-employment, separations, some of which may last six months or longer, deployments to hostile situations, and the long and often unpredictable work hours of military personnel. Any combination of these factors may be associated with a deterioration of functioning for military spouses. Perhaps the most significant among these stressors is the separation of military family members due to operational deployments (Westhius, 1999).

Military deployments and duty-related separations are defining experiences for military members and their families. There is no dispute that deployment and duty-related separations are challenging for families and that stress is a normative response during military separations (Martin, Vaitkus, Johnson, Mikolajek, \& Ray, 1996). There is a distinct stage process that families go through when a member is deployed, reflecting the pre-deployment phase, the deployment phase, and the post-deployment phase (Kelley, 1994; Pincus, House, Christensen, \& Adler, 2001; Van Breda, 1999). Not surprisingly, what is perceived as stressful before a deployment differs from what is perceived as stressful during or after a deployment. Just prior to deployment, conflicts in the family 
are at their peak, and anxiety, apprehension and sadness seem to be the most common feelings (Adler, Vaitkus, \& Martin, 1996; VanBreda, 2001). During the deployment phase, many spouses continue to experience a period of emotional destabilization and disorganization (Ender 2006; MacDermid, Olson, \& Weiss, 2002; Pincus et al., 2001) characterized by reports of sadness, depression, disorientation, anxiety, loneliness, feeling overwhelmed, numbness, anger, and relief (Pincus et al., 2001; Wexler \& McGrath, 1991). There are also physical reactions such as sleep disturbances and other physical health complaints (Frankel, Snowden, \& Nelson, 1992; Wood, Scarville, \& Gravino, 1995; Wright, Burrell, Schroeder, \& Thomas, 2006).

Intuitively, the post-deployment stage ought to represent a relief from distress. However, this stage carries the strain of reunion. Numerous studies highlight homecoming problems, such as marital conflict and estrangement, behavioural changes in children, and mental health issues in both military members (Hoge et al., 2004; Grieger et al., 2006) and their spouses (Pincus et al., 2001). Although, researchers differ in their views on which deployment phase is the most stressful for the spouses, they are unequivocal in the belief that deployment places both the deployed member and the spouse remaining at home under considerable stress.

Research conducted on military families often adopts an external focus that assesses how the military organization and community service might intervene to help spouses cope and adjust, rather than the internal resources and coping abilities individuals themselves bring to the experience of deployment separations (Wright et al., 2006). However, social support, spouses' appraisal of stressful situations and their coping styles may all play a role in how well they adapt to the various stages of deployment. 
Coping Resources in the Relation between Stressors and Individual and Organizational Well-being

\section{Role of Social Support on Well-being}

Supportive relationships are viewed as a coping resource enhancing an individual's well-being in the face of stressful experiences (Wills, 1985). Social support has been postulated both as a main effect that influences psychological well-being (Cohen \& Wills, 1985), and as a moderator of the relation between encountering stressors and psychological well-being (Antonovsky, 1974).

The Main-Effect model states that perceived social support is beneficial to the health and well-being of individuals, irrespective of the amount of stress they are experiencing. It has been suggested that well-being (e.g., self-esteem, sense of belonging), in this instance, may simply be the by-product of individuals carrying out their social roles (Thoits, 1986). In contrast, the Stress-Buffering Model postulates that perceived social support benefits individuals primarily during times of high stress by bolstering and restoring self-esteem and sense of belonging during such times. Both, the Main-Effect (Elal \& Krespi, 1999) and Stress-Buffering models (Parry \& Shapiro, 1986) have received empirical support, but the validity of either model appears to be contingent upon such factors as the sources of social support and the nature of the stressors and strains (Ganster, Fusilier, \& Mayes, 1986).

Social support can be operationalized in a number of ways, each of which may promote well-being and/or increase resistance to health problems. Social support can be defined through the number or quality of support behaviours that are received (received support). It can also be thought of as the perception of the general availability and 
adequacy of the support that is provided (perceived support) (Sarason, Sarason, \& Pierce, 1990). Studies comparing measures of received versus perceived support indicate that perceived support correlates more strongly with mental and physical health outcomes than does received support (Barrera, 1986; Dunkel- Schetter \& Bennett, 1990; Sarason et al., 1990; Wethington \& Kessler, 1986). Furthermore, it has been suggested that received support may improve outcomes only if it modifies perceived support (Haber, Cohen, Lucas \& Baltes, 2007).

The contention that received support predicts outcomes less consistently than perceived support has contributed to the emergence of social cognitive perspectives on the health effects of social support. According to these perspectives, perceived support is based on subjective and sometimes idiosyncratic evaluative processes, rather than specific support behaviours (Kaul \& Lakey, 2003). Such evaluative judgments will vary across individuals and relationships, and objectively identifiable supportive behaviours could be interpreted differently by different individuals. For some individuals, these supportive behaviours will be very beneficial, whereas those same behaviours could be perceived as irrelevant by others. In effect, the health-enhancing effects of social support stem directly from the quality of support behaviour in the environment, as determined by the match between the needs of the support recipient and the type of support provided (Lakey \& Cohen, 2000). In a way, the level of perceived support could represent an evaluative judgment of how much received support meets the needs of the recipient.

\section{Spousal Support}

Prominent among sources of social support is spousal support, and some researchers have gone so far as to use marital status as a partial or complete index of 
support (Coyne \& DeLongis, 1986). Indeed, perceived spousal support has been found to have a direct positive relation to general well-being (Dehle, Larsen \& Landers, 2001). Such support has been also found to play a stress-buffering role against the negative outcomes of family-work conflict (Beutell \& Greenhaus, 1983; Suchet \& Barling, 1986). To fully understand why and how some people thrive in the face of stress while others fail, it is important to examine how stress is coped with within the context of intimate relationships.

Two forms of spousal support, emotional and instrumental, have been conceptualized and empirically tested (Adams et al., 1996). Emotional support includes caring behaviours such as the provision of trust, empathy, love, and genuine concern for the welfare of the partner. Instrumental support is defined as helping behaviors such as giving time, skill or advice. Instrumental spousal support eases the burden of family demands and enables individuals to devote more time to work, whereas emotional spousal support enhances feelings of self-efficacy both at home and at work (Parasuraman, Purohit, \& Godshalk, 1996). House (1981) suggested that these two domains of support - emotional and instrumental - represent two of the functions of interpersonal transactions. Empirical studies have provided confirmation that social support comes in many different forms, and may involve expression of empathy and intimacy, and affirmations of beliefs, actions, or practical matters such as direct instrumental help like doing household chores (Leavy, 1983). Cohen and McKay (1984) proposed that the type of support (e.g. emotional, instrumental) which will be most effective in a particular situation depends on the stressor prevalent in that situation. 
Research involving deployed soldiers revealed that those who reported higher rates of family problems at home (i.e., lower perceived support) had more psychological symptoms and were less resistant to combat stress syndrome (Teitelbaum, 1992). As well, McCreary, Thompson and Pasto (2003) found that family concerns were associated with all measured dimensions of psychological well-being among the Canadian Forces personnel preparing to deploy on a peacekeeping mission.

A strong impact of perceived spousal support could be expected for military spouses during both deployment and re-integration phases. During deployment, spouses often experience loneliness, depression, anxiety, anger, and physical illness (Blount, Curry, \& Lubin, 1992; Wood et al., 1995). Losing emotional spousal support during the separation period of deployment might, to some extent, account for some of these negative outcomes. Even though physically separated, the perception of spousal support might ameliorate some negative effects of the separation. Although, no study was found that measured the impact of perceived spousal support on health outcomes of spouses during deployment, some studies found that frequency of communication with home (Desivilya \& Gal, 1996) and perceived marital stability (Wood et al., 1995) enhanced coping with deployment for both military members and their spouses. Similarly, during the re-integration period, couples who seemed to have the most problems with reunions were those who already had a strained relationship and lack of social support (Schumm, Bell, Ender, \& Rice 2004).

In sum, perceived support may have both direct and indirect effects on the relation between stressor experiences and well-being. In this regard, perceived spousal support may take precedence over other sources of social support. Although descriptive in nature, 
research with military spouses underlines the importance of the quality of the marital relationship and spousal support as a resource against the negative effects of deployment stressors on spouses' well-being, both during the deployment and the re-integration phases of deployment (Schumm et al., 2004; Wood et al., 1995).

\section{Spousal Support and Organizational Outcomes}

To date, most studies on spousal support have focused on how such support affects individual well-being (Day \& Chamberlaine, 2006; Poortman, 2005; Presser, 2000), and have largely ignored work-related outcomes. However, personal domains, such as marriage and relationship-specific social support can influence such outcomes. Of the studies that do exist, family factors were examined in terms of the fit between the military and family and/or spousal support for military members' career, as opposed to relationship-specific social support. In particular, support for members' career has been linked to greater job commitment (Orthner \& Pittman, 1986), morale (Rosen et al., 1989), performance and readiness (e.g. Segal \& Harris, 1993), and retention and reenlistment of military personnel (Bourg \& Segal, 1999; Etheridge, 1989; Lakhani, 1995; Orthner, 1990; Seboda \& Szoc, 1984; White et al., 1999; Wilcove et al., 2003).

Some of the factors that may influence spousal support for members' careers, include perceived unit support for family issues and integration of the family into the military community (Burrell, Durand, \& Fortado, 2003). Furthermore, research has found that a spouse's perceptions of the degree to which the military is supportive of families affected her (these studies looked at military wives only) satisfaction with military life, her support for her husband's military career, and her willingness to tolerate deployment separations (Segal \& Harris, 1993). Thus, to better understand the antecedents of spousal 
support for members' career, it is necessary to consider the role of military organization and perceived organizational support.

\section{Organizational Support}

Generally, if employees perceive that the organization cares about them and recognizes their contributions, they tend to be more satisfied with various aspects of their employment (Stamper \& Johlke, 2003; Yueng-Hsiang, Shaw, \& Chen, 2004) and diligence, commitment, and innovation increases (Eisenberger, Huntington, Hutchison, \& Sowa, 1986; Eisenberger, Fasolo, \& Davis-LaMastro, 1990; Shore \& Tetrick, 1991). Soldiers who reported higher perceived organizational support were more likely to report higher family adjustment to Army life (Rohall, Segal \& Segal, 1999). Exchange relationships can also be developed between the organization and spouses of military members, with the spouses committing to support members' careers, and the organization committing to support the military families. Perceptions of organizational support for families has been found to be as important for perceived work-family conflict as the presence of formal family-friendly supports (Allen, 2001).

Although the relation between organizational support and the health and wellbeing of military members is well-established, to date, research exploring the impact of military organizational support sources on spousal health and well-being has been quite limited. Of the work that does exist, the perception of unit-level support was found to translate into greater adaptation (Pittman, Kerpelman, \& McFadyen, 2004). Thus, perceived organizational support is an important consideration in the overall evaluation of the spouses' adjustment to the demands of military life and their subsequent support for members' careers. 
Potential Mediators in the Relations between Stressors and Well-being Appraisals

Lazarus and Folkman (1984) argue that an individual's experience of stress and the stress response are the result of the individual's interaction with the environment and interpretation of the stressors. The environment produces stressors and the individual interprets and finds ways to deal with them. Clearly, not all individuals are affected in the same way by a given stimulus. An appraisal process model focuses on individuals' subjective evaluation of the stressor, rather than on the stimulus per se (Folkman \& Lazarus, 1980, 1985; Lazarus, 1981, 2000; Lazarus \& Folkman, 1984).

According to the transactional model, appraisal is a process of evaluating and categorizing the personal implications of events and comprises two phases, primary and secondary appraisal (Folkman \& Lazarus, 1980). Each person makes a primary appraisal of a potentially stressful event. An event is stressful if it is perceived as likely to equal or exceed the resources of the person to adapt to the demand. This primary appraisal involves evaluating the stressor threatening, challenging, or harmful to one's well-being (Lazarus \& Folkman, 1984). If the stressor is appraised as a potential threat, secondary appraisal occurs involving an evaluation of what can be done in a situation, and whether the individual has adequate resources and coping skills to contend with it. Empirical studies of the effects of stress on well-being have generally supported these links (Roseman, 1991; Smith \& Lazarus, 1993; Terry, Callan, \& Sartori, 1996; Ysseldyk, Matheson, \& Anisman, 2009).

In relation to perceptions of event controllability, there is a substantial amount of 
evidence suggesting that the belief that one has control over a stressor reduces its impact on both physiological and psychological indices of well-being (Lazarus, 1984) and facilitates the adoption of effective coping strategies (Terry, 1994; Terry et al., 1996). This occurs presumably because the perception that an event is amenable to personal control reduces the level of threat associated with the situation and provides a clear basis for the development of problem-oriented coping responses.

As well as appraising the situation in terms of controllability, people's efficacy expectancies or, in other words, their expectancies concerning the likelihood that they can perform the behaviours necessary to deal with the event (secondary appraisals), also need to be taken into account. Spouses who doubt their ability to respond to the demands of military life and separations are likely to focus attention on their feelings of incompetence, which will be accompanied by feelings of psychological distress and a failure to deal with the situation. In contrast, efficacious individuals are unlikely to be distressed by feelings of inadequacy and, for this reason, are expected to persist in their efforts to manage the situation (Terry, 1992). Thus, in assessing the impact of stressors, it is essential to consider that people may respond differently to the same stimulus owing to the appraisal process (Folkman \& Lazarus, 1991)

\section{Coping}

Coping and appraisals are intricately related and influence one another during an experience with a stressor. When a stressor is encountered, an individual appraises it in terms of its relevance to his or her well-being, as well as in relation to the coping strategies available to deal with the stressor. Coping refers to the thoughts and behaviours that people utilize in response to stressor situations (Lazarus \& Folkman, 1984). An 
important distinction between coping efforts is whether they are aimed at transforming the stressful situation itself (problem-focused coping), or are aimed at altering the emotional responses induced by the situation (emotion-focused coping). Problem-focused strategies include concrete problem-solving efforts, such as improving one's knowledge regarding the sources and implications of the crisis. Emotion-focused strategies comprise both deliberately chosen instrumental actions to alleviate negative emotional distress (e.g., exercise or substance use), as well as responses that reflect a perception that the experience is beyond personal control (e.g., denial or wishful thinking). Within the broad problem- and emotion-focused coping categorizations are a variety of specific strategies that can be used to deal with stressors. For example, emotion-focused coping includes strategies such as emotional expression, emotional containment, passive resignation, withdrawal, denial or blame (Matheson \& Anisman, 2003). Likewise, these investigators suggested that cognitive restructuring, religion and/or humor may be considered within the problem-solving category, primarily because they are focused on altering the relation between the individual and the situation.

Problem-focused efforts are typically considered to be more adaptive than emotion-focused strategies, given that the latter are more closely aligned with depressive mood states (Matheson \& Anisman, 2003). Numerous studies have demonstrated that the use of problem-focus coping strategies are generally associated with improved psychological well-being (Dunkel-Schetter, Feinstein, Taylor, \& Falke, 1992; Holahan \& Moos, 1987; Terry, Tonge, \& Callan 1995). Indeed, when a situation is perceived as controllable, problem-focused coping has been found to be the most effective in reducing stress and is strongly associated with positive psychological outcomes, such as lower 
depression and better adjustment (Valentiner, Holahan, \& Moos, 1994; Vitaliano, DeWolfe, Mainro, Russo, \& Katon 1990). The use of emotion-focused coping might predominate when the situation is appraised as uncontrollable or threatening and has been linked to poorer well-being (e.g., Carver, Scheier, \& Weintraub, 1989; Lazarus, 1999; Kobasa, Maddi, \& Kahn, 1982; Matheson \& Anisman 2003; Ysseldyk et al., 2009). It is possible, however, that any strategy may be useful depending on the circumstances in which it is used. For example, denial, which is usually labeled as maladaptive, may serve to avoid overload in a crisis (Tamres, Janicki, \& Helgeson 2002).

Military spouses and coping. The specific coping styles that spouses use are also likely to play a significant role in their ability to deal with the stress caused by separation due to the military members' deployment. Spouses who function most effectively during times of separation appear to be those who use active coping styles, such as actively seeking social support and increasing the quality and quantity of family communication (Figley, 1993). However, it has also been found that different coping styles, such as religiosity, are of help to some families in dealing with separation (Hunter, 1982). Thus, for the military spouses who realize that they have no choice regarding separation and that repeated separations are part of the military life, emotion-focused coping may help to lessen the experienced stress. For example, for a spouse of a deployed member, daydreaming could serve adaptive functions in managing loneliness. Although the use of avoidant strategies may appear adaptive when they provide short-term benefits in terms of reducing distress, they could become problematic when they are the exclusive coping strategy employed, and they prevent the use of more effective strategies (Matheson, Skomorovsky, Fiocco, \& Anisman, 2007). If daydreaming impacts the individual's 
ability to deal with daily stressors, such as managing a household, taking care of the children, and so on, then the use of such strategies is likely counterproductive.

Coping strategies also change from one stressful phase to another and lumping them together might result in a false picture of the coping process (Lazarus, 1993). For example, some coping strategies that are adaptive during deployment (e.g., improving knowledge regarding running a household and developing alternative sources of social support) may interfere with couples' functioning after deployment (McCubbin \& Dahl, 1976). After deployment spouses may resent the loss of independence and service members may be insecure about their places in this reconfigured system (Blount et al., 1992; Drummet, Coleman, \& Cable, 2003; Logan, 1987; Pincus et al., 2001; Stafford \& Grady, 2003).

Social support, appraisals and coping. It has been suggested that social support may alter appraisals of a stressor such that it is perceived as less threatening (Cohen \& McKay, 1984). One of the ways that social support may protect people from the potentially damaging effects of exposure to stress is through its effects on mediating appraisal and coping processes (Lazarus \& DeLongis, 1983; Lazarus \& Folkman, 1984). For people with support, fewer situations should tax or exceed their resources and consequently, less stress should be experienced. Even when people do experience stress, having close others to rely upon should make it less likely that they will cope ineffectively and thus have a negative psychological or health outcome. In the case of military spouses, support may reinforce spousal perceptions that she/he will be successful in coping with the separation, thus reducing feelings of hopelessness and increase feelings of effectiveness. 
Lazarus and Folkman (1984) indicated that social support is an important resource that precedes and influences coping. However, the effects of social support may depend upon appraisals of the situation. For example, when stressors were perceived as controllable, social support facilitated adaptive coping, but when stressors were appraised as uncontrollable, support was not associated with the coping strategy that was used to deal with the stressor (Valentiner et al., 1994). Finally, although appraisals may influence the type of coping strategy used (e.g., Chang \& Strunk, 1999), coping and appraisals likely operate in a dynamic, reciprocal fashion such that the outcomes of engaging in a coping activity may in turn modify one's appraisals of a situation (Folkman \& Lazarus, 1985).

\section{Overview of the Present Investigation}

The aim of this study was to assess the impact of military lifestyle demands on military families and the crossover effect of spousal support on CF members' and organizational well-being. To do so, two studies were conducted. Study 1 focused on understanding the impact of spousal support on serving members' well-being and organizational outcomes. To the extent that spouses provide vital support that enhances members' well-being, readiness, performance and ability to carry out the mission, it was also important to identify the factors that promote the well-being of the spouses, such that they are capable of providing the support that is necessary for the functioning of the military member. Thus, Study 2 focused on the well-being of the military spouses, and evaluated the relation between factors associated with the demands of military service, and deployments in particular, and the well-being and quality of life of military spouses. 


\section{Study 1}

As was noted earlier, previous research has found a positive association between spousal support and serving members' well-being (Dehle et al., 2001; McCubbin, 1998; Teitelbaum, 1992). It has been suggested that spousal support is also related to important organizational outcomes, such as service members' readiness, performance and ability to carry out the mission (Wilcove et al., 2003). Furthermore, research conducted with military samples has shown a strong link between serving members' well-being and organizational outcomes such as views of the leadership (Halverson, Bliese, Moore, \& Castro, 1995), several aspects of individual readiness (Burnam et al., 1992), and the performance in the military working environment (Tucker, Sinclair, \& Thomas, 2005). Although direct relations between the work-family interface and work, family and individual outcomes have been documented in past research (Frone, 2000; Frone et al., 1992; Thomas \& Ganster, 1995), insufficient attention has been given to the mechanisms that may explain these relationships. Therefore, Study 1 focused on these mechanisms and examined whether the relation between spousal support and organizational outcomes was mediated by members' well-being. It was our expectation that in doing so, one of the mechanisms by which spouses might influence organizational outcomes may be elucidated.

Several studies have found significant effects of family factors on organizational outcomes (Bourg \& Segal, 1999; Etheridge, 1989; Lakhani, 1995; Nice, 1981; Orthner, 1990; Orthner \& Pittman, 1986; Rosen \& Durand, 1995; Rosen et al., 1989). The majority of these studies used military-family fit or spousal support for the military career as predictors of organizational outcomes. While these aspects of spousal support are 
definitely important, they do not include the more emotional type of spousal support that has been found important for psychological well-being. As was described earlier, two main types of spousal support might be considered: emotional support and instrumental support. Therefore, Study 1 sought to expand the understanding of the role of spousal support by including different dimensions of spousal support.

The first dimension included in this study, operationalized as a general perception of spousal supportive behaviours (e.g. showing respect, listening, spending the time together; being romantic) tapped into emotional support. Generally, it has been recognized that perceived provision of emotionally supportive behaviours in marriage is related to various health and mental health outcomes (Beach, Fincham, Katz \& Bradbury, 1996). Similarly, military research shows that low levels of emotional social support contributed to serious clinical conditions such as PTSD and combat stress reactions (Dirkzwager, Bramsen, \& van der Ploeg, 2003; Solomon \& Mikulincer, 1990). Most soldiers appear to view family and friends as their most significant source of emotional support (Solomon, Margalit, Waysman, \& Bleich, 1991). The second dimension, operationalized as marital satisfaction, while tapping into emotional support as well, is more indirect. Although marital satisfaction is related to spousal support (Dehle et al., 2001; Julien, Chartrand, Simard, Bouthiller, \& Begin, 2003), a strong and satisfying marriage might, in itself, serve as an important source of social support that is not necessarily tied to specific spousal support behaviours. There is an ample evidence of a relation between marital satisfaction and both major depression (e.g., Beach, Martin, Blum, \& Roman, 1993; Johnson \& Jacob, 1997) and depressive symptoms (e.g., Arseltine \& Kessler, 1993; Beach \& O'Leary, 1993; Cohan \& Bradbury, 1997; Tower \& 
Kasl, 1995). A recent meta-analysis found a positive relation between marital quality and individual well-being (Proulx, Helms, and Buehler, 2007). Based on these findings, it seems likely that the spousal support reflected in relationship satisfaction would be linked to member's well-being.

Finally, a third dimension of spousal support was included in Study 1 and attempted to tap into a more instrumental type of social support, namely, support for the military career. It was hypothesized that spouses who are supportive of the military career would be more willing to "carry the weight" of the family demands, such as occasional single parenting or household responsibilities. Taking on these types of responsibilities constitutes the provision of instrumental support.

Despite the continued recognition that work-family relations are bidirectional, few studies have examined how emotional spousal support affects behaviour in the workplace (Perry-Jenkins, Repetti, \& Crouter, 2000). Although it has been previously recommended that the research on the spillover between marital quality and organizational outcomes should be extended to include investigations of mediating processes (Rogers \& May, 2003), empirical research following these recommendations has been scarce. Investigating such mediating processes is important for both the advancement of knowledge in this area and for the practical implications that such understanding could bring. For example, if individuals lack emotional support from their spouse and they are not satisfied with their relationship, they may subsequently experience greater feelings of distress and dissatisfaction with life, which may limit their ability to work with others or perform their job successfully. In effect, the individual's personal well-being may mediate the relation between perceived support and organizational outcomes. 
In the military context, members' reduced well-being might affect their level of personal morale and commitment, as well as their willingness to deploy and separate from their families. Given that military lifestyle represents a major stressor for the entire family, a lack of emotional support and marital dissatisfaction might also be indirectly associated with members' intention to leave the military. When the conflict between the military and the family is high, the solution might be to leave the military in hope of improving one's well-being and recovering the marital relationship and spousal support.

Finally, it has been proposed that, psychological well-being includes both the presence of "positive affect, and the relative absence of psychological distress" (Williams, 2003, p. 474). Considering both positive and negative indicators of psychological well-being allows for a broader understanding of the association between relationship satisfaction and psychological well-being (Kamp Dush, Taylor, \& Kroeger, 2008). The two components of positive affect that have been examined most frequently are life satisfaction and general happiness, whereas depressive symptoms and psychological distress are the most commonly studied aspects of negative affect (Keyes, Shmotkin, \& Ryff, 2002). Within the present study, we focus on life satisfaction as a measure of positive affect, and on psychological distress as a measure of negative affect.

In sum, the purpose of Study 1 was to expand upon previous research by examining the mediating role of members' well-being in the relation between spousal support dimensions and organizational outcomes such as organizational commitment, personal morale, operational readiness and turnover intent (Figure 2). 


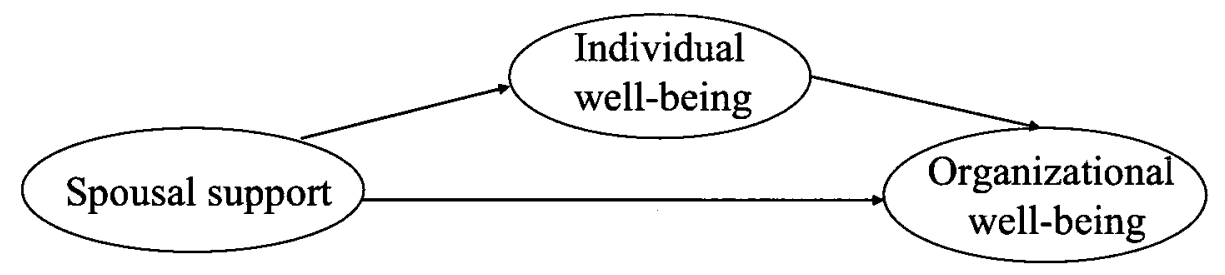

Figure 2. Mediating Effects of Individual Well-being on the Relation between Spousal Support and Organizational Well-being

It was hypothesized that:

1. CF members' marital satisfaction and perceptions of their spouses as supportive, both in general and in relation to their military career, would be associated with greater satisfaction with life and lower psychological distress.

2. CF members' satisfaction with and perceptions of their spouses as supportive, both in general and in relation to their military career, would be associated with positive organizational outcomes, including greater commitment to the organization, personal morale, willingness to deploy, and reduced intention to leave the military.

3. CF members' individual well-being would mediate the effects of perceived spousal support on organizational outcomes. Specifically, members who 
perceived increased spousal support would report higher well-being, which, in turn would be associated with more positive organizational outcomes (as depicted in Figure 2).

\section{Method}

\section{Participants and Procedure}

A large-scale survey of Canadian Forces personnel was undertaken in 2002/03 as part of the Human Dimensions of Deployment Study (HDDS) headed by the research team of the Directorate of Quality of Life (DQOL) in the Canadian Forces. The survey was granted ethical approval by the research ethics committee of the Canadian Forces. A paper-based survey was mailed out to a total of $8817 \mathrm{CF}$ members serving in Canada (non-deployed at the time), randomly selected from a centralized personnel database of CF regular force members. This initial sample size was approximately $15 \%$ of the overall CF regular force population. Responses were received from 4003 members, yielding a response rate of $45.4 \%$. This response rate is typical for employee attitude surveys, not only for the Canadian military, but also for other organizations (Nachmias \& Nachmias, 1987). The analyses conducted in Study 1 are based on the responses of the 2684 participants who reported that they were currently married or in common-law relationships. This group represented $67 \%$ of the entire sample, which corresponds to the proportion of married/common law relationships reported in the Canadian Forces population.

About 90\% (2408) of the participants were men and 10\% (272) were women. The age of the survey participants ranged from 19 to 56 with a mean of 39.85 years $(S D=$ 6.91). Almost $78 \%$ reported English as their first official language and $22 \%$ were 
Francophone. In terms of rank, $30.6 \%$ of the surveyed service members were Junior NonCommissioned Members, Senior Non-Commission Members represented 33.7\% of the sample, Junior Officers were $17.6 \%$, and finally Senior Officers were $18.2 \%$ of the surveyed sample. The percentages within each category on all of these variables correspond well to the percentages of personnel in those categories within the overall Canadian Forces population. It is important to note that the present sample consisted of only married military members, thus it had a somewhat higher proportion of senior ranks than the Canadian Forces population. Approximately $80 \%$ of the participants were married to a civilian spouse, followed by $11 \%$ married to another military member, and $9 \%$ reported to be in common-law relationship $(7.4 \%$ with a civilian and $1.6 \%$ with a military member).

The cover page of the survey provided details necessary to fulfil the requirements for informed consent, including information regarding the purpose of the study ("to examine the human dimensions of military demands in order to enhance the effectiveness of future operations and to respond to the needs of Canadian Forces members and their families"), and assurance that participation was entirely voluntary and that participants were free to skip any question they did not wish to answer. Participants were also guaranteed that their responses would be kept anonymous and strictly confidential, and that results would only be reported in aggregate. On average, the survey required 30 minutes to complete. The questionnaire could be completed in either French or English.

\section{Measures}

Relationship satisfaction. The Quality of Marriage Index (Norton, 1983) was used, which comprises six items asking for overall evaluative judgments about the 
marriage or intimate partnership. Respondents rated the extent to which they agreed with each statement (e.g., "Our marriage/partnership is strong") on a 5-point scale ranging from strongly disagree (1) to strongly agree (5). The inter-item reliability coefficients in previous studies ranged from .92 to .94 (Fincham, Harold, \& Gano-Phillips, 2000). The mean was taken as participants' score of relationship satisfaction, such that higher scores reflected greater satisfaction with their relationship (Cronbach's $\alpha=.97$ ).

Perceived spousal support. A scale was developed to measure participants' perceptions of their spouses' emotional support behaviors. Participants indicated their level of agreement with 10 items (e.g., "Respects my opinions") on a 5-point scale ranging from strongly disagree (1) to strongly agree (5). Ratings on some items were recoded so that high scores indicated strong perceived spousal support. The mean rating across all ten items was used as the overall scale score (Cronbach's $\alpha=.87$ ).

Spousal support for member's military career. To assess the extent to which spouses supported Canadian Forces members' military ambitions (instrumental support), they indicated the extent to which their spouse was supportive in relation to their current service, and in pursuing a long-term career in the Canadian Forces, using a 4-point scale, ranging from not at all supportive (1) to very supportive (4). The mean score across the two items was used as the overall scale score $(r=.73)$.

Psychological distress. The abbreviated version of the General Health Questionnaire (Banks et al., 1980), the GHQ-12, was used to measure psychological distress. This measure asks whether participants have recently experienced events such as 'loss of sleep due to worry' or 'the ability to concentrate on whatever they are doing'. Responses were rated on a 4-point scale ranging from not at all (1) to much more than 
usual (4). This measure has been shown to be a reliable and valid measure of psychological distress for use in occupational studies of this kind (Banks et al., 1980). The inter-item reliability coefficient for the 12 items in previous studies ranged from 0.81 (Boey, Chan, Ko, Goh, \& Lim, 1997) to 0.86 (Limbert, 2004). Ratings on some items were recoded so that high scores indicated greater psychological distress, and the mean rating across all twelve items was used as the overall scale score (Cronbach's $\alpha=.82$ ).

Satisfaction with life. The Satisfaction with Life Scale (SWLS) was used to assess global life satisfaction. This five-item scale was developed by Diener, Emmons, Larsen, and Griffin (1985) to measure life satisfaction as a cognitive-judgment process. The SWLS has shown strong internal consistency and moderate reliability over time (Pavot \& Diener, 1993). The SWLS demonstrates high internal consistency with Cronbach's alphas of .81 and .85 for clinical and community samples (Pavot \& Diener, 1993). The SWLS has been found to be positively associated with other measures of subjective well-being and negatively associated with measures of psychopathology (Diener et al., 1985).

Respondents indicated the extent to which they agreed with each statement (e.g., "In most ways my life is close to ideal") on a 5-point Likert scale ranging from strongly agree (1) to strongly disagree (5). The mean rating across all items was used as the overall scale score (Cronbach's $\alpha=.84)$.

Organizational commitment. The 8-item Soldier Commitment scale (Biehl, vom Hagen, \& Mackewitsch, 2000) was used to assess members' levels of organizational and task-oriented commitment. Agreement with each item (e.g., "I am supporting the CF's mission") was rated on a 5-point scale ranging from strongly disagree (1) to strongly agree (5). Previous research has reported high internal consistency for the full scale 
(Cronbach's $\alpha=.86$ ) (United States Army Medical Research Unit - Europe, 2000). Some items were recoded so that on all items, high scores reflected a high degree of soldier commitment. A final score of commitment was derived by taking the mean of the ratings obtained on all eight items (Cronbach's $\alpha=.81$ ).

Morale. Personal morale was measured using a 4-item scale from the United States Army Medical Research Unit - Europe (2000). Participants were asked to endorse each item (e.g., "Your level of motivation") according to a 5-point scale ranging from very low (1) to very high (5). Castro et al., (2001) reported a Cronbach's $\alpha$ of .90, indicating excellent inter-item reliability. One item was recoded so that on all items, high scores reflected a high degree of personal morale. The mean rating across all four items was used as the overall scale score (Cronbach's $\alpha=.80$ ).

Willingness to deploy. Willingness to deploy was assessed by a single question asking members about their readiness to deploy on international operations or missions. Possible responses ranged from "I would refuse to deploy" (1) to "I am ready and willing to deploy" (4).

Turnover intentions. Turnover intentions were measured with a single question, "Which of the following best describes your current military career intention?" Members were asked about their intention to leave or stay in the military, with response options including 1) definitely stay until retirement; 2) probably stay until retirement; 3) stay until their 20 years were up; 4) stay beyond the present term but not necessarily until retirement; 5) undecided; 6) probably leave upon completion of current terms of service; and 7) definitely get out of the Canadian Forces as soon as possible. This item has been 
used in previous military research to measure career intent (Tremble, Payne, Finch, \& Bullis, 2003; Huffman, Youngcourt, \& Castro, 2003).

\section{Statistical Analysis}

Before conducting tests of the mediation models, correlational analyses between spousal support variables, individual well-being variables and organizational outcomes were conducted. Further, to assess the role of the mediating variables on the relations between predictors and outcomes, a series of multiple mediation models was assessed using the bootstrapping technique. Bootstrapping is a nonparametric procedure wherein a random sample of cases is taken from the total data set, and an estimate of the indirect effect, or point estimate (in this case, the estimate of the magnitude of effectiveness of the mediator) is obtained from that sample. This process is repeated a large number of times (resampling) until confidence intervals for the distribution of the point estimates are generated (Wood, 2005). A significant mediated effect can be concluded if the confidence interval for that effect does not contain zero. Because this method relies on fewer inferential tests than the causal steps approach, it has the advantage of having greater power and lower probability of Type I errors (Preacher \& Hayes, 2008). As per the recommendations of Preacher and Hayes (2008), the program was set up such that 5000 random samples were generated from the original dataset and $95 \%$ confidence intervals for the point estimates (i.e., estimates of the effects in the population that are provided by the sample data) of the indirect effects were generated.

To assess the possibility that members' well-being indicators served as mediators in the process, both psychological distress and satisfaction with life were examined simultaneously. It has been suggested that multiple mediation has several advantages 
over doing a series of simple mediation tests (Preacher \& Hayes, 2008). Specifically, this procedure allows one to test whether a set of mediators has an overall effect on the relationship between an independent and dependent variable in addition to examining the effects of the individual mediators. As well, it permits the comparison of the relative effectiveness of these mediators along with an assessment of the unique effectiveness of a mediator while controlling for the other mediators included in the model (West \& Aiken, 1997). Finally, including multiple mediators in a model reduces the likelihood of parameter bias, which can occur when a number of hypotheses of indirect effects are tested with a series of simple mediating models (Judd \& Kenny, 1981).

\section{Results}

\section{Data Screening}

Prior to analyzing the survey data, screening procedures were employed to identify out-of-range values, estimate plausible means and standard deviations, and estimate other factors such as skewness and kurtosis, nonlinearity, and multicollinearity and singularity.

As the sample was large, the shapes of the distribution were explored for assessing normality through the use of frequency histograms to assess skewness, kurtosis, standard errors and fit with the normal distribution curve. The screening revealed that three variables had values for skewness and kurtosis that did not fall within -1 to +1 range. Nevertheless, no extreme cases of skewness and kurtosis were found (all skewness coefficients were less than absolute value of 2 and all the kurtosis coefficients were less than absolute value of 4). The mean, standard deviation, skewness, and kurtosis for each scale are presented in Table 1. 
Data used in the present study were also screened for multicollinearity and singularity through the exploration of bivariate correlations among the variables. No correlations of values exceeding .70 were found. On each pair, the scatterplots revealed several discrepancy scores, however, in a large sample like this one the leverage of these scores is minimal. Indeed, the Mahalanobis and Cook's statistics (Cook's values ranged between .02 to .05 ) confirmed that that the impact of those discrepant scores was negligible.

Table 1

Descriptive Statistics for the Variables in the Study ${ }^{2}$

\begin{tabular}{lccccc}
\hline Scale & Possible & $M$ & $S D$ & Skewness & Kurtosis \\
& Range & & & & \\
\hline Relationship satisfaction & $1-5$ & 4.28 & 0.84 & -1.40 & 2.05 \\
Perceived spousal support & $1-5$ & 3.90 & 0.60 & -0.40 & 0.19 \\
$\begin{array}{l}\text { Spousal support for member's } \\
\text { military career }\end{array}$ & $1-4$ & 3.35 & 0.82 & -1.10 & 0.21 \\
Psychological distress & $1-4$ & 2.27 & 0.39 & 0.37 & 1.76 \\
Life satisfaction & $1-5$ & 3.54 & 0.76 & -0.40 & -0.03 \\
Organizational commitment & $1-5$ & 3.93 & 0.58 & -0.69 & 0.69 \\
Personal morale & $1-5$ & 3.26 & 0.78 & -0.24 & -0.03 \\
Willingness to deploy & $1-4$ & 3.43 & 0.75 & -1.41 & 1.90 \\
Turnover intent & $1-7$ & 2.97 & 1.72 & 0.65 & -0.55 \\
\hline
\end{tabular}

\footnotetext{
${ }^{2}$ A series of t-tests was conducted to assess differences between women and men on all variables in this study. It was found that women reported higher levels of relationship satisfaction, perceived spousal support, perceived spousal support for member's military career, life satisfaction, and higher turnover intent. However, women were lower on willingness to deploy $(p s<.01)$.
} 


\section{Descriptive Statistics}

As seen in Table 1, in terms of the personal relationship with their spouses, participants scored, on average, well above the midpoint $(p<.01)$ on relationship satisfaction and above the scale midpoint on their perception of spousal support. They also, on average, expressed a positive view of their spouses' support for their military career. On average, participants' scores were just below the midpoint on the 4-point GHQ measure. Similarly, their life satisfaction was slightly above the mid-point on this 5-point scale. In terms of satisfaction with life, a slightly lower percentage of CF members (78\%) reported being 'satisfied' and 'very satisfied' compared to the Canadian general population (90\%) (Statistics Canada, 2007).

Finally, on average respondents reported high willingness to deploy and scored somewhat below the midpoint on their intention to leave the military, as well as on personal morale, but above the midpoint on organizational commitment $(p s<.01)$.

\section{Correlational Analyses}

Before conducting the main analyses, the Pearson product-moment correlations for all the variables in the study were examined (see Table 2). Because the large sample size resulted in substantial power in these analyses, only correlations larger or equal to .20 were regarded as meaningful. As would be expected, high positive correlations were found among the variables assessing perceptions of the spousal relationship, including perceptions of spousal support for the member's career. Also the two measures of personal well-being were highly related to personal morale and organizational commitment, suggesting that participants who demonstrated lower psychological distress and higher satisfaction with life tended to have higher personal morale and stronger 
organizational commitment. However, these indices of personal well-being were largely unrelated to members' willingness to deploy. 
우

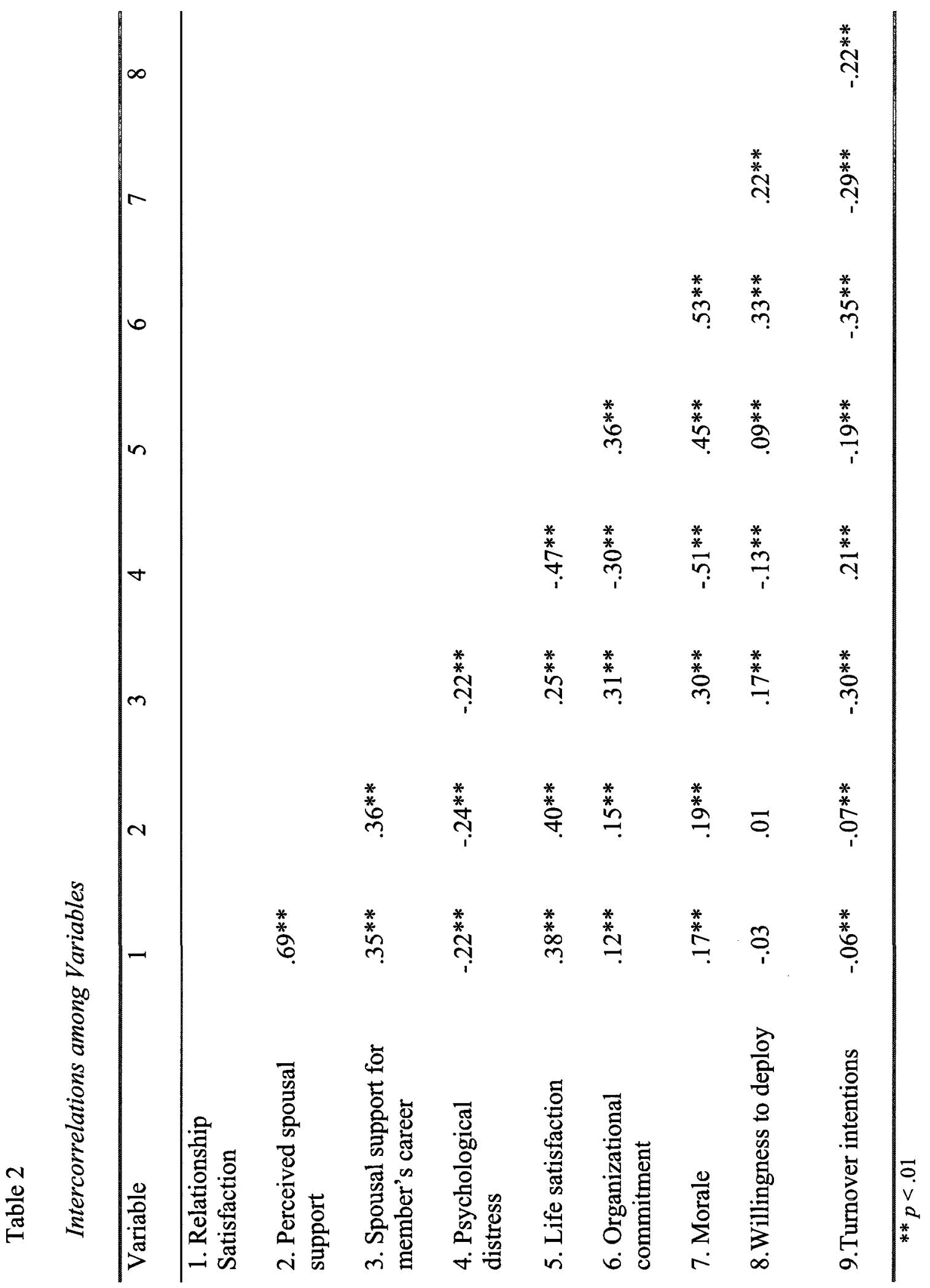


Role of Individual Well-being in Mediating the Relations between Spousal Support for Military Career and Organizational Outcomes

It was expected that spousal support for military career may be associated with altered members' psychological distress and satisfaction with life, which could lead to variations in their organizational commitment, personal morale and turnover intent (Figure 3). Though significant, the correlations between emotional support variables and organizational outcomes were not sufficiently meaningful to break down contributing components by conducting mediation analyses.

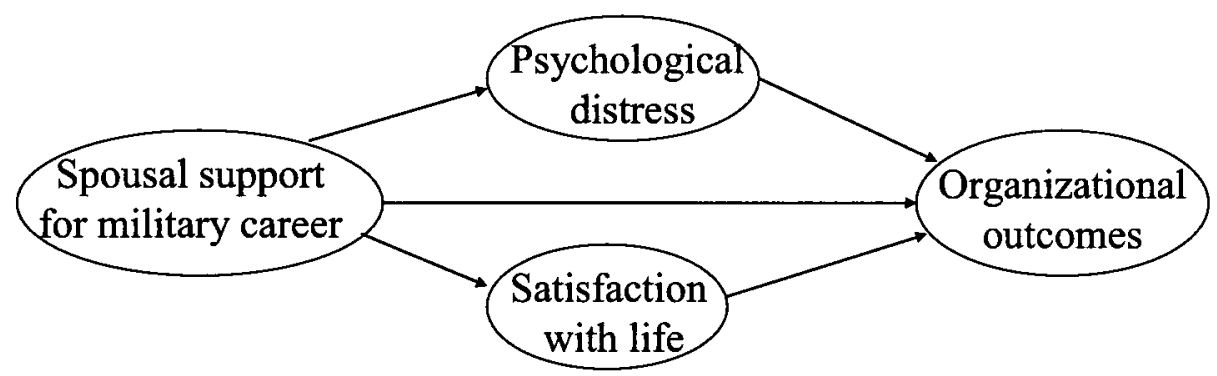

Figure 3. Mediating Effects of Well-being Indicators on the Relation between Spousal Support for Military Career and Organizational Outcomes

Well-being indicators as mediators between spousal support for military career and organizational commitment. Support for member's career was associated with both well-being indicators, as well as organizational commitment. As seen in Table 3, the 
indirect effects of support for member's career on organizational commitment scores remained significant, following inclusion of well-being indicators as potential mediators. However, confidence limits for the total mediation effect did not include zero, indicating a partial mediation model. Examination of the specific indirect effects indicated that wellbeing indicators (i.e., psychological distress and satisfaction with life), were significant unique mediators (shown in Table 3). Thus, higher levels of support for members' career were associated with lower psychological distress and higher satisfaction with life, which in turn were associated with increased organizational commitment. ${ }^{3}$

\footnotetext{
${ }^{3}$ When alternative mediation models were tested, using spousal support variable as a mediator and psychological indicators (i.e., GHQ-12 and SWLS) as independent variables, the relation between psychological distress and organizational commitment was partially mediated by spousal support for members' career. The mediating effect of spousal support for members' career on the relation between SWL scores and organizational commitment was not significant.
} 
Table 3

Direct and Indirect (through Well-being Indicators) Effects of Support for Career on Organizational Commitment: Results of Bootstrap Analysis

Coefficient $\quad S E \quad t \quad p$

Relations between support for career (IV) and well-being indicators (mediators)

Psychological distress

Satisfaction with life

Unique relations between well-being indicators (mediators) and organizational commitment (DV)

$$
\text { Psychological distress }
$$

Satisfaction with life

Direct effects of support for career (IV) on organizational commitment (DV)

Indirect effects (through mediator)

$$
-.11
$$

.01

$-11.35$

.00

.23

.02

12.67

\begin{tabular}{|c|c|c|}
\hline \multirow[b]{2}{*}{ Mediators } & \multicolumn{2}{|c|}{$\begin{array}{c}\text { Bootstrapping } 95 \% \\
\text { CI }\end{array}$} \\
\hline & Lower & Upper \\
\hline Psychological distress & .014 & .030 \\
\hline Satisfaction with life & .033 & .054 \\
\hline TOTAL & .053 & .077 \\
\hline
\end{tabular}

.00 
Well-being indicators as mediators between spousal support for military career and personal morale. As seen in Table 4, the indirect effects of support for member's career on personal morale remained significant, following inclusion of well-being indicators as potential mediators. However, the confidence limit for the total mediation effect did not include zero, indicating a partial mediation model. Examination of the specific indirect effects indicated that well-being indicators (i.e., psychological distress and satisfaction with life), were significant unique mediators (shown in Table 4). Thus, higher levels of support for member's career were associated with lower psychological distress and higher satisfaction with life, which in turn were associated with increased personal morale. ${ }^{4}$

\footnotetext{
${ }^{4}$ When alternative mediation models were tested, using spousal support variable as a mediator and psychological indicators (i.e., GHQ-12 and SWLS) as independent variables, the relation between psychological distress and personal morale was partially mediated by spousal support for members' career. The mediating effect of spousal support for members' career on the relation between SWL scores and personal morale was not significant.
} 
Table 4

Direct and Indirect (through Well-being Indicators) Effects of Support for Career on Personal Morale: Results of Bootstrap Analysis

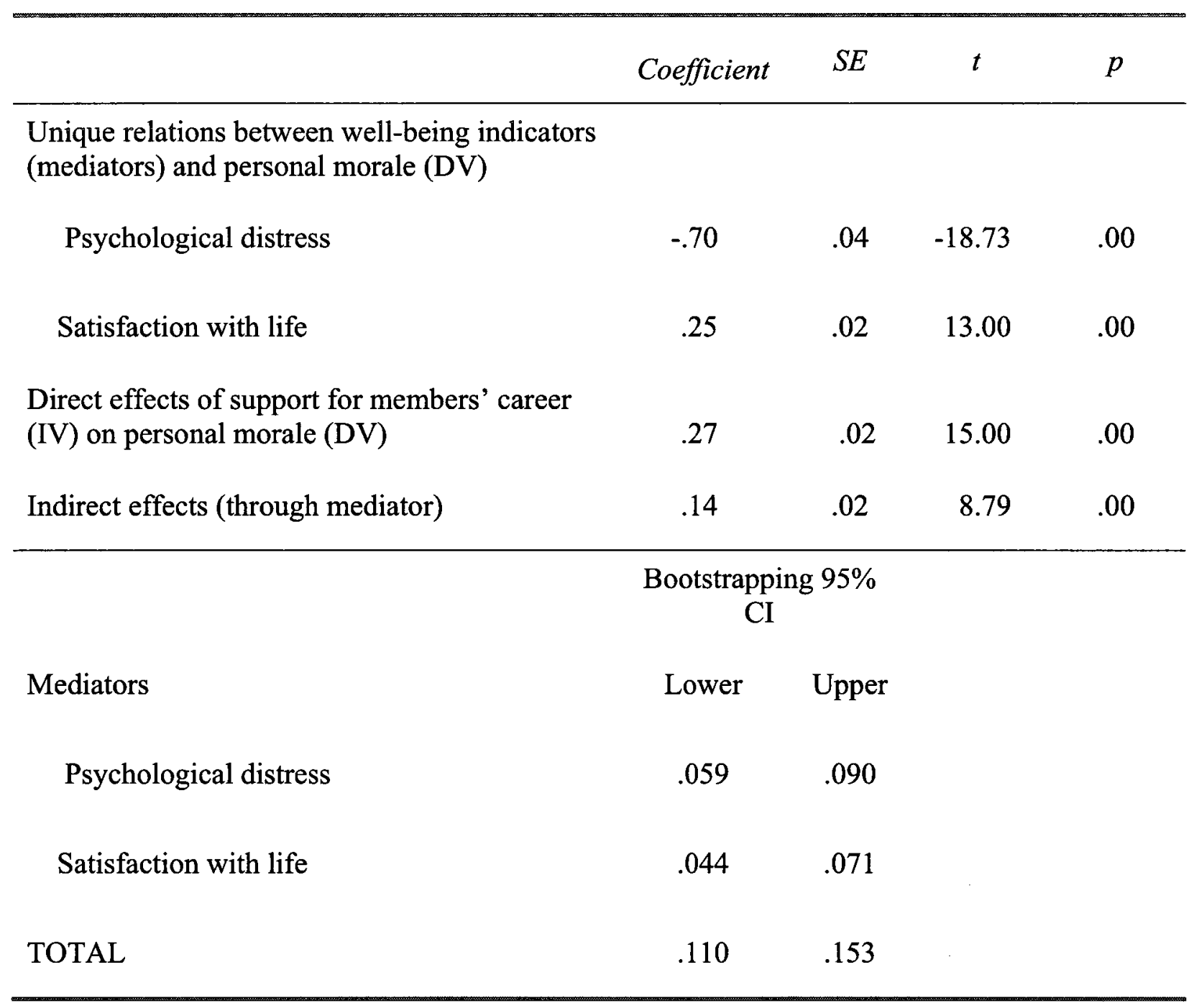

Well-being indicators as mediators between spousal support for career and member turnover intention. Both well-being indicators, psychological distress and satisfaction with life were related to turnover intention. As seen in Table 5, the indirect effects of spousal support for career on turnover intention remained significant, following inclusion of psychological well-being indicators as potential mediators. However, the 
confidence limits for the total mediation effect did not include zero, indicating a partial mediation model. An examination of the specific indirect effects indicated that both psychological distress and satisfaction with life were significant unique mediators, as their $95 \%$ confidence interval did not contain zero. Thus, increased levels of spousal support for career were associated with lower psychological distress and higher satisfaction with life, which in turn were associated with members' lower turnover intention. $^{5}$

\footnotetext{
${ }^{5}$ When alternative mediation models were tested, using spousal support variable as a mediator and psychological indicators (i.e., GHQ-12 and SWLS) as independent variables, the relation between psychological distress and turnover intent was partially mediated by spousal support for members' career. The mediating effect of spousal support for members' career on the relation between SWL scores and turnover intent was not significant.
} 
Table 5

Direct and Indirect (through Well-being Indicators) Effects of Support for Career on

Turnover Intention: Results of Bootstrap Analysis

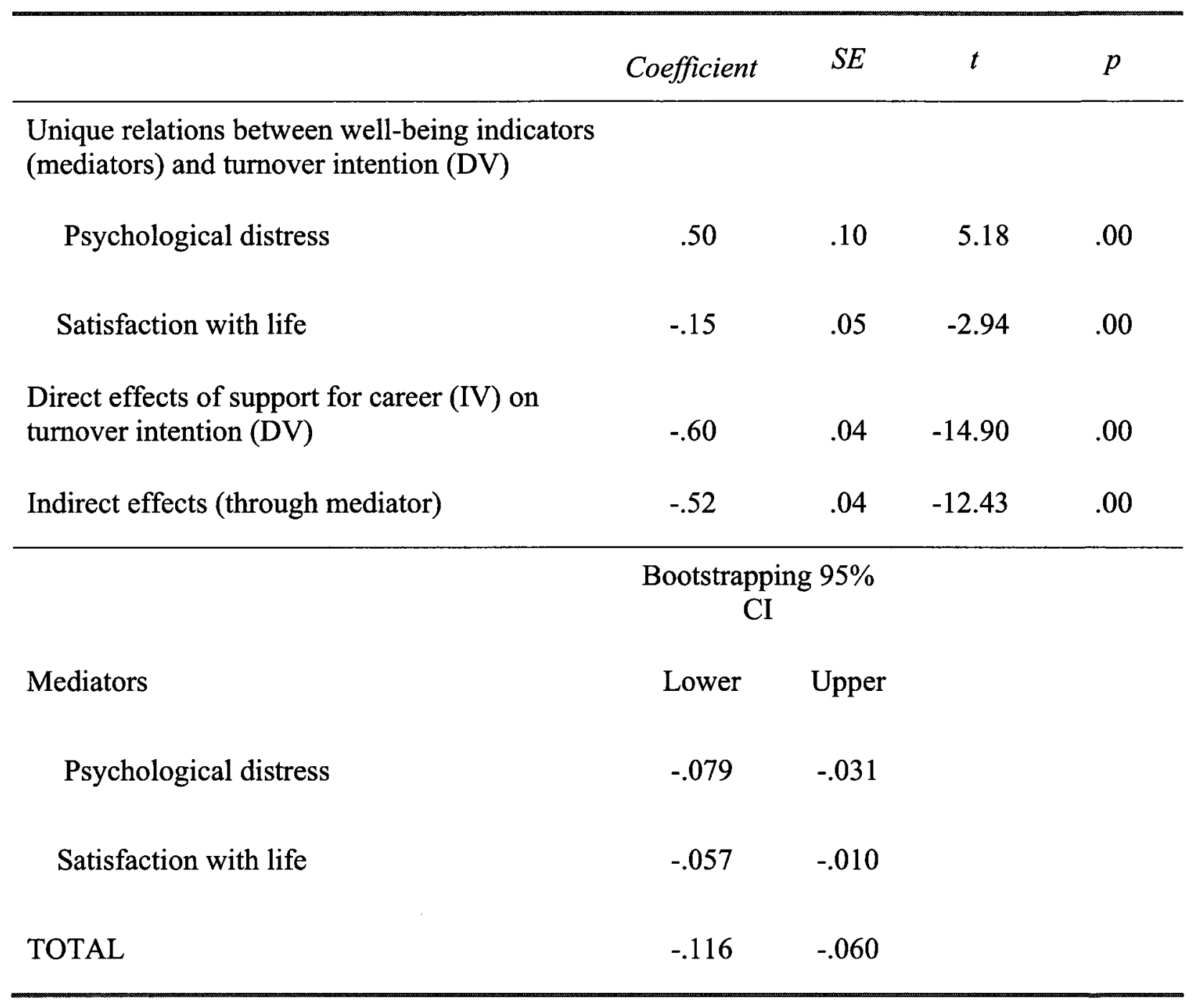

Discussion

Overall, the findings of Study 1 highlighted the influential role that spousal support plays for Canadian military members, not only in terms of members' personal well-being, but also in terms of important organizational outcomes such as organizational commitment, morale and turnover intentions. All of the spousal support variables (i.e., 
satisfaction with relationship, perceived spousal support and spousal support for member's career) were related to members' psychological distress and satisfaction with life. Both psychological distress and satisfaction with life among military members were moderately correlated with their morale and commitment, suggesting that both personal and organizational well-being may be fundamental to the full functioning of military personnel.

Consistent with predictions, emotional spousal support as reflected in the perceived relationship satisfaction and perceived spousal support was associated with increased psychological distress and satisfaction with life. Also, these emotional support variables had a positive, albeit weak, association with members' commitment to the organization and personal morale, and with reduced intention to leave $\mathrm{CF}{ }^{6}$ Interestingly, emotional support variables had no relation with members' willingness to deploy. The specific nature of this construct might account for the lack of this relation. Specifically, having a satisfying and stable relationship and emotional support from the spouses, might trigger mixed feelings in members about separation due to deployment. On the contrary, those members who do not perceive their spouses as supportive might look forward to temporary separation induced by deployment. Given the existence of research showing that deployed members who perceive their spouses as supportive and self-sufficient are better soldiers (Burnam et al., 1992), the association between spousal support and operational readiness should not be dismissed.

Instrumental spousal support, as reflected in the perceived spousal support for members' military career, was associated with lower psychological distress and increased

\footnotetext{
${ }^{6}$ Though significant, these correlations were not sufficiently meaningful to break down contributing components by conducting mediation analyses.
} 
satisfaction with life, as well as with members' commitment to the organization, personal morale, and reduced intention to leave CF. The effect of spousal support for the military career on organizational outcomes was partially mediated by both well-being indicators. This finding suggests that spousal support for the military career had a direct effect on organizational outcomes, which was not accounted for by members' well-being. Given a widespread consensus that juggling the conflicting demands of military and family life raises significant challenges for serving members, it is not surprising that the spousal support for their career had both a direct and an indirect effect on organizational outcomes. As indicated earlier, spouses' support for the military career is in a way an indicator of perceived instrumental support, in that it reflects the willingness of the spouses to carry an extra load caused by military life demands, including deployments. Consistent with previous research (Kelley, Hock, Smith, Bonney, \& Gaffney, 2001), these findings demonstrate the importance of spousal support for a career in the military and for the retention of military personnel. Across numerous studies, service members whose families were supportive of military life were significantly more likely to reenlist when compared with members whose families were less supportive of military life (e.g., Bourg \& Segal, 1999; Bowen, 1989; Kelley et al., 2001; Rosen \& Durand, 2000). Indeed, there is even evidence that the spouse's attitude sometimes has more influence on the member's actual turnover intention than the member's own preference (Bell, Scarville, \& Quigley, 1991).

The contribution of the present study is in illuminating the mechanisms by which the spousal support dimensions impact organizational outcomes. Specifically, members' psychological distress and satisfaction with life mediated the relation between spousal 
support for members' career and organizational outcomes. The previous research proposed a matching hypothesis, which posits that the type of support (e.g. emotional, instrumental) which will be most effective in a particular situation depends on the stressor prevalent in that situation (Cohen \& McKay, 1984). The finding in the present study that support for military career was the strongest predictor of organizational outcomes, directly and indirectly through individual well-being, is consistent with the matching hypothesis by showing that in the context of military life stressors (e.g. frequent separations), spousal willingness to support this lifestyle has the most pervasive influence on the members' organizational outcomes. The overall findings of this study are consistent with the conceptual model of the work-family interface, in which relationships between the work-family interface and work, family, and individual outcomes operate through mediating mechanisms (Voydanoff, 2002).

Overall, given the strength of the relations between the indices of spousal support and the well-being of military members in the Canadian Forces, there is clearly value in ensuring the well-being of military spouses. Previous research has shown partner similarity with respect to general well-being (Galbaud du Fort, Kovess, \& Boivin, 1994) and psychiatric symptomatology (e.g., Dubuis-Stadelmann, Fenton, Ferrero, \& Preisig, 2001; Galbaud du Fort et al., 1994). Between-partners well-being similarity could be due to marital interaction (i.e., mutual influence between partners), as well as due to common life stressors (Whisman, Uebelacker, \& Weinstock, 2004). Both, military members and their spouses experience some of the common stressors of military life such as separations and frequent moves. Furthermore, to maximize members' commitment, morale, willingness to deploy and reduce turnover intention, the CF should explore the 
factors that contribute to spousal willingness to support the military career of their serving spouses.

There were some methodological limitations associated with the present study. The first limitation involved the assessment of some key variables. Even though previous studies have found that one-item measures can be psychometrically comparable to multiple-item measures (Gardner, Cummings, Dunham, \& Pierce, 1998; Wanous \& Hudy, 2001; Wanous, Reichers, \& Hudy, 1997), the results related to willingness to deploy and turnover intention should be interpreted with caution. Specifically, singleitem measures have been criticized because of unknown reliability and concurrent validity. Thus, the measurement unreliability introduced by single items might have attenuated some relationships. Nevertheless, these two items were moderately correlated with other organizational outcomes, thus some validity of these two items is warranted.

Finally, a key limitation of the present investigation was the inability of crosssectional data to distinguish antecedents from consequences, thus preventing this research from teasing out causal effects. Thus, it cannot be stated with certainty that perceived spousal support caused members' higher well-being. It is possible that those participants with more positive well-being were likely to be "good loving spouses" which then would encourage their spouses to reciprocate in terms of support. Indeed, the tests of alternative models supported the possibility that spousal support for members' career might be influenced by members' psychological health.

Study 2

The findings from Study 1 demonstrated a relation between several dimensions of spousal support and serving members' well-being, as well as the role of instrumental 
support in relation to personal morale, commitment to the organization, and intention to stay. Importantly, research on military spouses has indicated that spouses' satisfaction with military life and their support for the members' military careers was associated with their own more positive psychological well-being (Burrell, Adams, Durand, \& Castro, 2006). Therefore, Study 2 evaluated the factors that contributed to the well-being of the military spouses, as well as their willingness to support the military careers of their serving spouses. Furthermore, as noted earlier, the specific characteristics that promote well-being and spousal support might vary as a function of whether the serving member is deployed, or is returning from deployment. Thus, Study 2 also examined the effects of stage of operational deployments on the well-being of spouses and their support for the members' military career.

The greatest single source of stress for military families is family separation created by the deployment of the military member (Burrell et al., 2006; Knox \& Price 1995). Separations often entail a reorganization of family roles and routines as the spouse remaining at home adjusts to the partner's absence. Stressors may include a strain on the marital relationship, childcare concerns, changes in children's well-being, difficulties accessing military services, and practical issues such as those associated with home and car maintenance (Van Vranken, Jellen, Knudson, Marlowe, \& Segal 1984).

Researchers have found that during deployment, common feelings experienced by the spouses left at home included loneliness, worry, sadness, and anxiety (Van Vranken et al., 1984; Wexler \& McGrath, 1991). At this phase, many spouses develop clinical levels of depression (Kelley, 1994), and show symptoms such as irritability, sleep difficulties and loss of appetite (Adler, Bartone, \&Vaitkus, 1995). Of particular concern 
for the spouses of deployed members is the added pressure of single parenting, as many spouses also hold full-time employment of their own (Karney, 2007). Along with the added responsibilities of childcare, the children themselves experience specific challenges during deployment, such as anxiety associated with the absence and safety of their deployed parent (Siebler, 2003). During deployment, children manifest higher levels of depression (Jensen, Martin, \& Watanabe, 1996), experience sadness and tearfulness, possess a need for greater discipline at home (for boys), and have more frequent mental health concerns (Rosen, Teitelbaum, \& Westhuis, 1993). Given the challenges experienced by the children, spouses of deployed members encountering such a stressor could be expected to demonstrate reduced well-being and support for the military career in the absence of resources or skills to effectively cope.

As the deployment ends, the reintegration phase begins. In anticipation of homecoming, both excitement and apprehension increase (Logan, 1987; Pincus et al., 2001; Weins \& Boss, 2006). During the deployment, roles have been redefined, new family systems have developed, and both serving members and their spouses have inevitably changed (Segal, 2006). This phase is typically marked by ambivalence and anxiety (Figley, 1993), as well as disappointment when the fantasy of the reunion does not materialize (Potts, 1988). Common experiences include poor communication, emotional distancing, sexual difficulties and anger (Blount et al., 1992; Jolly, 1987). The children may continue to act out their anxieties associated with parenting absence. Military members who were involved in combat or experienced other traumatic events may introduce the after-effects of these experiences into their family system (Figley, 1993; Gimbel \& Booth, 1994). The reintegration phase can take up to 6 months, as the 
couple and family stabilize their relationships (Pincus et al., 2001). Thus, it could be expected that stressors related to spouses' experiences during the reintegration phase, such as arguing over family roles, conflict (including violence) and lack of communication would further contribute to diminished spousal well-being and reduced support for the military career.

Given the different stressors experienced by spouses as a function of the $\mathrm{CF}$ members' deployment status, Study 2 assessed the well-being of spouses of serving members in these two deployment phases, and compared the well-being of those spouses to that of spouses whose serving spouses had never been deployed or had returned from deployment a while ago ( 7 months or longer). It was expected that spouses of serving members in these two deployment phases would report greater psychological distress and less satisfaction with life than spouses in the "non-deployed" group. Similarly, spouses of non-deployed members might be more willing to support military career than the spouses of deployed and recently returned from deployment members.

There are currently two main perspectives in the literature linking relationship stressors and psychological well-being (Proulx et al., 2007). The stress generation model (Davila, Bradbury, Cohan, \& Tochluk, 1997) posits that individuals with low psychological well-being are more likely to encounter stressful interactions with their spouses and that, in turn, these stressful interactions lead to even greater declines in psychological well-being. The second perspective linking marital quality and psychological well-being proposes that, relationship stressors lead to an increased risk of depression because spouses are among the most important sources of social support, serving as a strong protective factor against depression (Beach, Sandeen, \& O'Leary, 
1990; Brown, Andrews, Harris, Adler, \& Bridge, 1986). Thus, experiencing relationship stressors would lead to lack of spousal social support, which, in turn, would make the individual vulnerable to distress. By applying the transaction theory of stress and coping, the present study might provide an additional perspective to the link between relationship stressors and psychological well-being, particularly during work-related separations and re-unions.

As noted earlier, the transaction theory of stress and coping (Lazarus \& Folkman, 1984 ) is a process model in which intervening variables such as appraisals and coping mediate antecedent stressor and adaptation outcomes. In line with this perspective, spouses encountering severe stressors were expected to appraise their situation as more threatening, and perceive low levels of controllability, and such appraisals would result in a greater likelihood of exhibiting psychological distress and reduced support for members' career. In addition, the strength of the relations between specific stressors experienced and appraisals might vary depending on deployment phase. For example, experiencing parenting stressors during post-deployment might lead to lower appraised threat and more controllability than in deployment phase, given that in post-deployment phase both spouses are available to deal with these stressors. Similarly, relationship stressors might have a stronger impact on increased appraisals of threat and reduced controllability during post-deployment than during deployment. Experiencing these types of stressors might lead to higher appraised threat when both spouses are at home, making it more salient for spouses.

As noted earlier, appraisals may impact upon psychological well-being indirectly, in that appraisals influence the coping strategy used, which, in turn influence 
psychological well-being (Folkman \& Lazarus, 1980). In this regard, spouses who reported increased perceptions of threat and lower appraisals of controllability may be more likely to invoke ineffective coping styles (i.e., less problem-focused coping and more emotional and avoidant coping efforts), which, in turn, would be associated with greater psychological distress and reduced support for members' career. Again, the strength of the relations between appraisals and coping styles might vary depending on deployment phase. For example, appraisals of increased threat during deployment might lead to more avoidant coping than in post-deployment phase.

Despite volumes of research showing a positive relationship between support and well-being, the mechanisms through which support influences psychological health are not well known. One possibility is that support is effective in enhancing well-being because it acts as coping resource (O'Brien \& DeLongis, 1997; Thoits, 1986). As such, perceived social support may influence the use of specific coping strategies, as well as the effectiveness of strategies employed (Carpenter \& Scott, 1992). Perceived spousal support might also affect how spouses apprise the stressors, which in turn would predict their well-being.

In addition, perceived organizational support from the $\mathrm{CF}$ itself, might provide further resources that could facilitate coping, and hence, well-being among spouses. Although a number of military studies found an important role of perceived organizational support for the military members, (e.g. Burnam et al., 1992; Orthner \& Pittman, 1986) only a few found that some indicators of organizational support, such as unit support were related to spousal adaptation (Bowen \& Neenan, 1989; Coolbaugh, \& Rosenthal, 1992; Orthner \& Pittman, 1986; Pittman, 2004). Similarly, there is some 
empirical evidence supporting the link between organizational support and spouses' willingness to support member's military career (Orthner \& Pittman, 1986; Pittman \& Orthner, 1988). None of these studies explored the mechanisms by which organizational support is related to spousal well-being and their willingness to support members' military career. Yet, it might be expected that, like spousal support, perceived organizational support would be related to stress appraisals and coping styles, which, in turn, would be related to spousal well-being and their willingness to support members' military career.

Finally, Study 2 examined whether the mediating role of appraisals and coping in the relation between social support and well-being and willingness to support members' military career varied across the two groups of spouses (during deployment and postdeployment). It was expected that perceived spousal support would be especially effective (i.e., would reduce perceptions of threat and increase appraisals of controllability) during the reintegration phase, as this phase is more likely to entail tensions directly between the spouses. However, perceived organizational support would have stronger relation with the appraisals (i.e., would reduce perception of threat and increase the appraisals of controllability) during the deployment phase because the spouses of military members might be expecting support from the organization to a greater extent than when the military members were at home.

The objectives of the present study were addressed by testing the model presented in Figure 6 below. This study aimed to assess:

1. the effects of parenting and relationship stressors on spousal well-being and their support for the military members' career. It was predicted that experiencing these 
stressors would be detrimental to the spousal well-being and reduce their support for the military members' career.

2. the commonalities and differences among spouses of the three deployment groups (i.e., non-deployed, deployed and post-deployed). It was expected that spouses of non-deployed members would report higher life satisfaction and support for members' military careers and lower psychological distress.

3. the extent to which appraisals of the impact of military life on family mediated the effects of parenting and relationship stressors on well-being and support for the military members' career. It was predicted that spouses who reported experiencing high levels of deployment stressors would report greater perceptions of threat and lower controllability, which, in turn would be associated with lower well-being.

4. the extent to which coping styles mediated the effects of appraisals on well-being. It was predicted that spouses who reported increased perception of threat and lower controllability, would be more likely to endorse ineffective coping styles (i.e., less problem-focused coping and more emotional coping efforts), which, in turn, would be associated with lower well-being and less willingness to support members' career.

5. the influence of social support on stress appraisals. It was predicted that spouses with higher perceived social support would report a reduced perception of threat regarding the impact of military life and higher appraisals of controllability over the stressors it entails. It was also predicted that appraisals would mediate the relation between social support and well-being. 
6. the influence of social support on coping. It was predicted that spouses with higher perceived social support would be more likely to invoke functional coping styles (i.e., more problem-focused coping and less emotional coping efforts). It was also predicted that coping styles would mediate the relation between social support and well-being and willingness to support members' career.

7. the deployment phase would moderate the strength of the relations among the variables in the model.

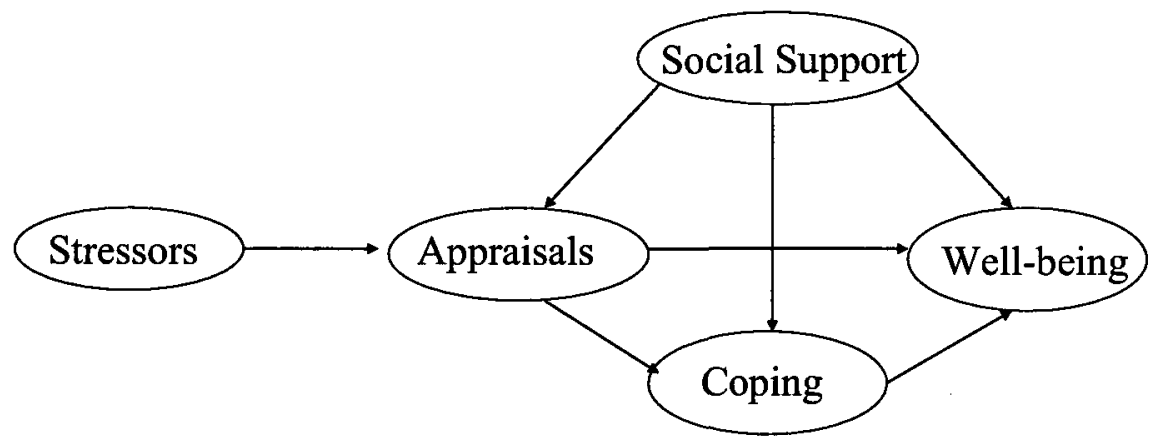

Figure 4. Proposed Model of the Relations between Stress, Social Support, Appraisals, Coping and Well-being 
Method

Participants and Procedure

A large-scale survey of spouses of CF members was undertaken in 2005/06 by the Human Dimensions of Deployment Study (HDDS) project headed by the research team of the Directorate of Quality of Life (DQOL) in CF. The survey was granted ethical approval by the research ethics committee of the Canadian Forces. A paper-based survey was mailed out to a total of 7,039 spouses of CF members randomly selected from a centralized personnel database of CF regular force members. Completed surveys were received from 1,661 spouses, yielding a response rate of $24 \%$. The final sample included 1,644 spouses, as 17 participants reported being divorced or separated and were removed from subsequent analyses.

About $90 \%(1,448)$ of the participants were women and $10 \%(189)$ were men. Participants' ages ranged from 19 to 71 with a mean of 38.63 years $(S D=8.14)$. Almost $74 \%$ reported English as a first official language and $26 \%$ were Francophone. In terms of service in CF, $5.4 \%$ of the surveyed spouses were themselves members of the Regular Force in CF, about $5 \%$ were in the Reserve Force and $20 \%$ were former members of the CF. Approximately $85 \%$ of the participants were married to CF members, followed by $14 \%$ in common-law relationships, and $1 \%$ reported that they were co-habitating. About $64 \%$ (1053) of the participants had children living with them full time, $1.6 \%$ (26) reported having children living with them part time, and additional 5.7\% (93) had both children living with them full time and children with them part time.

Approximately $14 \%$ (218) of the participants reported that their military spouse was deployed at the time of the survey, and 10\% (157) reported that their military spouse 
had returned from a deployment within the previous 7 months. Given the main focus of the present study, namely, to evaluate the relation between deployment stressors and the well-being of military spouses, the majority of the analyses were based on these two groups. We refer to them as the 'deployment' and 'post-deployment' groups. The rest of the participants reported that their military spouse had either never been deployed or had returned from a deployment more than 7 months ago. This group was used to examine the main effects of deployment phase.

The cover page of the survey provided details necessary to fulfil the requirements for informed consent, including information regarding the purpose of the study (i.e. "to help us understand the consequences of military service for you and your loved ones, and will be used to develop new ways of supporting families when military members are away from home") and assurance that participation was entirely voluntary and that participants were free to skip any question they did not wish to answer. Participants were also guaranteed that their responses would be kept anonymous and strictly confidential, and that results would only be reported in aggregate. On average, the survey required 30 minutes to complete. The questionnaires could be completed in either French or English.

\section{Measures}

Parenting stressors. A scale was developed for the purpose of the present study to measure spousal perceptions of children's feelings and experiences common during a deployment. Participants indicated how frequently they observed specific reactions in their child(ren) in terms of 15 items (e.g. "decline in school performance", "acting out", "nightmares") using a 5-item Likert scale ranging from never (1) to always (5). The mean 
rating across the items was used as the overall scale score of parenting stress. Reliability of the scale was high (Cronbach's $\alpha=.93$ ) (all the measures can be seen in Appendix B).

Relationship stressors. A scale comprising 8 items was developed for the present study to measure the frequency of occurrence of various stressful experiences typical after a deployment. (e.g. "My spouse/partner has difficulty compromising", "My spouse/partner is violent after a deployment", "My spouse/partner and I argue about child discipline when he/she returns"). Items were rated on a 5-point Likert scale ranging from never (1) to always (5). The mean rating across the items was used as the overall scale score and the item-total reliability was high (Cronbach's $\alpha=.85$ ).

Appraisals. The Work to Family Conflict scale developed by Netemeyer, Boles, and McMurrian (1996) was adapted as a measure of primary appraisals of the impact of military life on family. This measure assessed the extent to which spouses perceived the demands of the military threatening to their family life. The original scale consisted of five items, such as "My spouse or partner's job produces strain that makes it difficult to fulfill family duties" (see Appendix B for complete description of the items). Three items measured the perceived threat of military life to their family life ("My family life has suffered as a result of my spouse/partner's work commitments") and their career ("My employment or career has suffered as a result of my spouse/partner's service in CF" and "My career progression has suffered as a result of my family obligations."). Participants indicated the extent to which they agreed with the statements using a Likert rating scale ranging from strongly disagree (1) to strongly agree (5). The mean rating across all items was used as the overall scale score (Cronbach's $\alpha=.88$ ). 
In previous studies, secondary appraisal was conceptualised and measured in terms of controllability (Peacock \& Wong, 1990) and perceived control and self-efficacy (Terry, 1994). In line with this, secondary appraisals were assessed in terms of 4 items wherein participants indicated the extent to which they experienced (during a deployment) feelings of 'control', 'capability', 'self-reliance' and 'confidence' on a 5point Likert scale ranging from never (1) to always (5). The mean rating across these four items was used as the scale score (Cronbach's $\alpha=.91$ ).

Coping styles. Coping styles were measured using a 20 -item scale that has been used in various studies conducted by the Walter Reed Army Institute of Research and United States Medical Research Unit (Dolan, Huffman, Adler, \& Castro, 2000). The items reflect a broad spectrum of cognitive/behavioural and socio-emotional strategies that individuals may adopt in response to stressors. Participants indicated the degree to which they used each of the behaviours (e.g. "Look for information about possible choices") as a way of dealing with stressors in general on a 5-point Likert scale ranging from never (1) to always (5). Based on a scree plot derived from a principle components analysis of 20 items, a 4-factor solution was obtained, which explained $48.88 \%$ of the variance. To allow for the possibility of correlations among factors, a factor analysis using an oblique rotation was conducted. Items loading greater than 0.45 indicated that the first factor comprised four items assessing problem-focused coping (e.g. "Look for information about possible choices") (Cronbach's $\alpha=.72$ ). The second factor comprised four items assessing avoidant behaviours (e.g. "Become apathetic or just don't care"(Cronbach's $\alpha=.73$ ). The third factor comprised three items reflecting emotionfocused coping (e.g."Complain to others") (Cronbach's $\alpha=.51$ ). The item "daydreaming" 
loaded on both the avoidant and emotional-coping factors, but it was included in the emotional-coping subscale because daydreaming (or wishful thinking) has been commonly associated with emotional-coping in previous research (Folkman, Lazarus, Gruen, \& DeLongis, 1986). Even though the reliability of this latter factor was quite low, given the importance of this construct in this study, it was decided to retain this subscale but to interpret associated results with caution. The fourth factor comprised three items reflecting religious coping (e.g. "Seek religious guidance") (Cronbach's $\alpha=.90$ ). A score for each of the four categories of coping was obtained by averaging the scores for each set of items. The rest of the items were not included in any of the factors due to their low factor loadings. These factors were comparable to those obtained in other research concerning the development of coping scales, with most identifying the existence of three higher order coping strategy classifications described as problem-focus, emotion and avoidance coping (Endler \& Parker, 1990; Carver et al.,1989; Matheson \& Anisman, 2003).

Perceived organizational support. To assess the extent to which spouses perceived whether "the Canadian Forces recognizes and respects the contribution made by spouses/partners of members during military service in general and deployments in particular", participants responded to this single item using a 4-point scale, ranging from not at all (1) to a great deal (4).

Support for CF members' military career. Similar to Study 1, wherein respondents indicated the extent to which their spouses supported their own military ambitions, in Study 2, the spouses were asked the extent to which they were supportive of the CF members' career. Specifically, they indicated the extent to which they were 
supportive of the members' current service, and pursuing a long-term career in the Canadian Forces, using a 4-point Likert scale, ranging from not at all supportive (1) to very supportive (4). The mean score across the two items was used as the scale score $(\mathrm{r}=$ $.67)$.

The measures of perceived spousal support (Cronbach $\alpha=.88$ ), psychological distress (GHQ-12) (Cronbach's $\alpha=.82$ ), and satisfaction with life (SWLS) (Cronbach $\alpha=$ $.87)$, were described in Study 1.

Statistical Analysis

In order to assess the effects of deployment stage on all conceptual variables, a series of multivariate analyses of variance (MANOVAs) was conducted. These analyses were conducted including all three groups (i.e., deployed, post-deployed and nondeployed) to compare them on social support, coping and well-being, while only deployed and post-deployed groups were compared on deployment stressors and stress appraisals. Significant multivariate effects were followed up by examining the univariate analyses.

As in Study 1, the correlations between the variables were reported. Further, to assess the role of the mediating variables on the relations between predictors and outcomes for the deployed and post-deployed groups, a series of multiple mediation models was assessed using the bootstrapping technique, as described in Study 1. To assess the possibility that coping and appraisals served as mediators in the stress process, multiple mediators were examined simultaneously. Specifically, the two appraisal variables (i.e., threat and controllability), were examined together as a set of potential mediators in the relations between the stressors and spousal well-being and their support 
for members' career, as well as between social support and spousal well-being and their support for members' career. The same approach was used to assess the mediating role of coping in the relation between each of the appraisals and well-being, and the mediating role of appraisals in the relation between each of the forms of social support and wellbeing and support for members' career.

To examine whether the role of mediating variables in the relation between predictors and outcomes varied across the two groups of spouses (during deployment and post-deployment), analyses of moderated mediation effects were conducted using bootstrapping procedure for moderated mediation (Preacher, Rucker, \& Hayes, 2007). There are multiple ways in which the magnitude of an indirect effect may be dependent upon a moderator. We tested three models: 1 . The relation between the independent variable and the mediator varied, depending on the level of moderator (e.g., stressors $\rightarrow$ appraisals depends on deployment stage), but the effect of the mediator on the outcome was constant, (e.g., appraisals $\rightarrow$ well-being); 2 . The path from the independent variable to the mediator (e.g., stressors $\rightarrow$ appraisals) was constant, but the effect of the mediator on the outcome variable depended on the level of moderator, (e.g., appraisals $\rightarrow$ wellbeing depends on deployment stage ); and 3. Both relations were moderated by deployment stage.

Results

\section{Data Screening}

Prior to analyzing the survey data, screening procedures were employed in order to identify out-of-range values, estimate plausible means and standard deviations, and 
estimate other factors such as skewness and kurtosis, nonlinearity, and multicollinearity and singularity.

The screening revealed that four variables had values for skewness or kurtosis that did not fall within -1 to +1 range. Nevertheless, no extreme cases of skewness and kurtosis were found (all skewness coefficients were less than absolute value of 2 and all the kurtosis coefficients were less than absolute value of 4). The mean, standard deviation, skewness, and kurtosis for each scale are presented in Appendix C. Data used in the present study were also screened for multicollinearity and singularity through the exploration of bivariate correlations among the variables. No correlations of values exceeding .60 were found.

\section{Initial Analyses}

\section{Descriptive Statistics}

The descriptive statistics indicate that the majority of spouses of deployed and recently returned from deployment members, experienced relatively few parenting stressors $(M=2.40, S D=0.76)$, as well as relationship stressors $(M=1.91, S D=0.72)$ (both scales ranged from 1 to 5). Reports of these two types of stressors were found to be positively correlated $(r=.49, p<.001)$. The majority of spouses reported positive spousal behaviors $(M=4.07, S D=0.64$ on a 5 -point scale $)$, but not overly positive perceived organizational support $(M=2.33, S D=0.94$; on a 4-point scale). There was a significant, albeit weak relation between these two types of perceived social support $(r=$ $.12, p<.001)$.

On average, spouses scored just above the midpoint on perceived threat $(M=$ $3.10, S D=0.89)$ and reported relatively high levels of controllability and confidence $(M$ 
$=4.11, S D=0.71$ (5-point scale). There was a significant negative relation between these two types of appraisal $(r=-.26, p<.001)$.

As shown in Table 6, on average, spouses reported using each of the coping styles to a moderate degree. Spouses reported using religious coping the least frequently. There were mild to moderate correlations among the factors, as indicated in Table 6 . As expected, emotional coping had the strongest correlation with avoidant coping. Table 6

Descriptive Statistics and Correlations among the Coping Dimensions

\begin{tabular}{lrrrrr}
\hline & $M$ & $S D$ & 1 & 2 & 3 \\
\hline 1. Problem-solving & 3.36 & 0.63 & -- & & \\
2. Emotional coping & 2.45 & 0.73 & -.01 & & \\
3. Avoidant coping & 2.21 & 0.68 & $-.18^{* *}$ & $.43^{* *}$ & \\
4. Religious coping & 1.89 & 0.98 & $.11^{*}$ & $.14^{* *}$ & .06 \\
\hline
\end{tabular}

Note. Possible scores ranged from 1-5.

${ }^{*} p<.05 ;{ }^{* *} p<.01$.

On average, participants' scores were just below the midpoint on the 4-point GHQ measure $(M=2.21, S D=0.39)$. Similarly, their life satisfaction was slightly above the mid-point on this 5-point scale $(M=3.65, S D=0.81)$. The GHQ-12 scores and the SWL scores were negatively correlated $(r=-.47, p<.001)$, indicating that those who reported experiencing greater psychological distress also tended to report lower satisfaction with life. In terms of satisfaction with life, slightly lower percentage of CF 
spouses (74\%) reported being 'satisfied' and 'very satisfied' compared to the Canadian general population (86\%) (Statistics Canada, 2007).

Finally, spouses reported fairly high levels of supportiveness for member's military career $(M=3.74, S D=0.53$; on a 4-point scale). There was a significant, albeit weak relation between spousal willingness to support members' career and their own psychological distress $(r=-.14, p<.001)$ and satisfaction with life $(r=.16, p<.001) .^{7}$

Intercorrelations between appraisal-coping variables. As seen in Table 7, higher threat appraisals were associated with higher emotional and avoidant coping, whereas higher perceived controllability was associated with greater use of problem-focused coping, and reduced endorsement of emotional and avoidant coping styles. Religious coping was not correlated with either appraisal dimension. Given that religious coping was not correlated with any of the stressors and well-being indicators, it was omitted from further analysis.

Table 7

Correlations between Appraisal Dimensions and Coping Styles

\section{Coping}

\begin{tabular}{lcccc}
\hline \multicolumn{1}{c}{ Appraisals } & $\begin{array}{c}\text { Problem- } \\
\text { focused }\end{array}$ & Emotional & Avoidant & Religious \\
\hline Threat & .03 & $.29 * * *$ & $.26^{* * *}$ & .10 \\
Controllability & $.20^{* * *}$ & $-.13^{*}$ & $-.26^{* * *}$ & -.02 \\
\hline
\end{tabular}

${ }^{*} p<.05 ; * * * p<.001$.

\footnotetext{
${ }^{7}$ A series of t-tests was conducted to assess differences between women and men on all variables in this study. It was found that women reported higher levels of problem-solving, emotional and religious coping $(p s<.01)$. Also, women, on average, appraised the impact of military life more threatening $(p<.001)$ and perceived higher spousal support $(p<.05)$.
} 
Comparisons of deployment groups

A one-way MANOVA conducted on perceived spousal and organizational support indicated no significant differences in the perceived support among the three deployment groups, Pillai's $=.007, F(4,2694)=2.20, n s$. Although, there was a significant effect of deployment group on coping styles, Pillai's $=.023, F(8,1838)=2.64$ $p<.01$, the amount of the explained variance was so small to be meaningful.

Table 8

Means and Standard Deviations on Social Support and Coping Styles across Deployment Groups

\begin{tabular}{lccc}
\hline & Deployed & Post-deployed & Non-deployed \\
& $n=216$ & $n=155$ & $n=1133$ \\
\hline Spousal support & 4.08 & 4.05 & 4.06 \\
& $(0.62)$ & $(0.62)$ & $(0.65)$ \\
Organizational & 2.40 & 2.13 & 2.35 \\
support & $(0.92)$ & $(0.97)$ & $(0.94)$ \\
\hline Problem-solving & 3.27 & 3.42 & 3.37 \\
& $(0.64)$ & $(0.67)$ & $(0.63)$ \\
Emotional coping & 2.50 & 2.53 & 2.40 \\
& $(0.72)$ & $(0.76)$ & $(0.70)$ \\
Avoidance coping & 2.30 & 2.14 & 2.19 \\
& $(0.73)$ & $(0.70)$ & $(0.66)$ \\
Religious coping & 1.77 & 1.93 & 1.93 \\
& $(0.96)$ & $(0.94)$ & $(0.99)$ \\
\hline
\end{tabular}

Note. Spousal support scale ranged from 1-5, organizational support scale ranged

from 1-4 and coping style scale ranged from 1-5. 
A one-way MANOVA conducted on psychological distress and satisfaction with life indicated no significant differences in well-being among the three deployment groups, Pillai's $=.006, F(4,3002)=2.30, n s$. As well, there were no significant differences in the support for member's military career among the three deployment groups, $F(2,1500)=1.72$, ns. $^{8}$

${ }^{8}$ In conducting the one-way MANOVA on psychological distress and life satisfaction, Box's M statistic reflecting the homogeneity of covariance matrices assumption was violated. Given the sensitivity of this statistic to unequal sample size of the groups, the approach was taken to reduce the difference in size of the three groups. From the group with largest sample size, "non-deployed" (n=1151), we randomly selected $50 \%$ of the cases to bring this group closer in size to the other two groups, "deployed" $(n=218)$ and "post-deployed" ( $n=157)$. The analyses were re-run and Box's M test for homogeneity of dispersion matrices produced $F(6,2200262)=3.53, \mathrm{p}<.001$, indicated that homogeneity of variance-covariance had been achieved. This analysis indicated a significant effect for deployment stage on spousal well-being (Pillai's $=.013, \mathrm{~F}(4,1868)=3.02, \mathrm{p}<.05)$. However, the amount of the explained variance in well-being variables was less than .04 , the adopted criterion for meaningfulness of effect size. 
Table 9

Means and Standard Deviations on Well-Being Indicators and Support for Military Career across Deployment Groups

\begin{tabular}{lccc}
\hline & $\begin{array}{c}\text { Deployed } \\
(n=216)\end{array}$ & $\begin{array}{c}\text { Post-deployed } \\
(n=155)\end{array}$ & $\begin{array}{c}\text { Non-deployed } \\
(n=1133)\end{array}$ \\
\hline $\begin{array}{l}\text { Psychological distress } \\
\text { (Range 1-4) }\end{array}$ & 2.28 & 2.23 & 2.2 \\
& $(0.43)$ & $(0.46)$ & $(0.36)$ \\
Satisfaction with life & 3.60 & 3.61 & 3.69 \\
(Range 1-5) & $(0.78)$ & $(0.89)$ & $(0.78)$ \\
Support for member's & 3.72 & 3.67 & 3.75 \\
military career (Range 1-4) & $(0.53)$ & $(0.64)$ & $(0.51)$ \\
\hline
\end{tabular}

Group differences between deployed and post-deployed

To assess whether the two deployment groups (CF member currently deployed vs. returned from deployment less than 7 months ago) were significantly different on reported stressors, a one-way MANOVA was conducted on parenting and relationship stressors, and once again, indicated no significant differences, Pillai's $=.001, F(2,224)=$ $1.07, n s$. Likewise, there were no significant differences between the deployment and post-deployment groups in their appraisals (threat, controllability) of the relation between military and family life, Pillai's $=.016, F(2,369)=2.98, n s$. 
Table 10

Means and Standard Deviations on Deployment Stressors and Appraisal Dimensions across Deployment Groups

\begin{tabular}{lcc}
\hline & $\begin{array}{c}\text { Deployed } \\
n=216\end{array}$ & $\begin{array}{c}\text { Post-deployed } \\
n=155\end{array}$ \\
\hline Parenting stressors & 2.42 & 2.39 \\
& $(0.72)$ & $(0.78)$ \\
Relationship stressors & 2.03 & 1.99 \\
& $(0.78)$ & $(0.68)$ \\
\hline Threat & 3.06 & 3.20 \\
& $(0.83)$ & $(0.94)$ \\
Controllability & 4.06 & 4.17 \\
& $(0.70)$ & $(0.71)$ \\
\hline
\end{tabular}

Note. All scales ranged from 1-5.

\section{Mediated Analyses}

Prior to conducting mediation analysis, the relations (direct effects) between each predictor and outcome variables were assessed to evaluate whether they were sufficiently meaningful to break down contributing components by conducting mediation analyses. Only correlations larger or equal to .20 were regarded as meaningful (the correlation table can be seen in Appendix C). 
Role of Appraisals in Mediating the Relations between Stressors and Well-Being/Support for members' career

It was expected that parenting and relationship stressors may be associated with altered appraisals of the relation between military and family life, which could lead to variations in psychological distress, satisfaction with life and support for members' career (Figure 5).

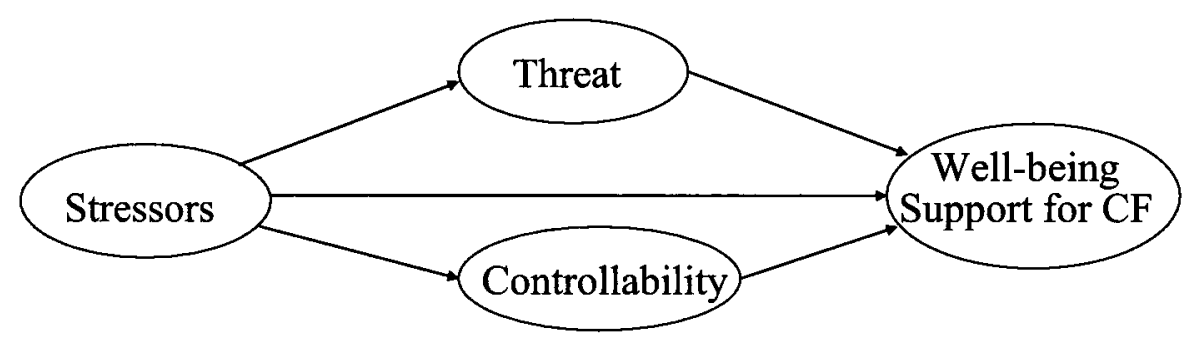

Figure 5. Mediating Effects of Appraisals on the Relation between Stressors and Wellbeing and Support for Military's Career

Appraisals as mediators between stressors and GHQ scores. As seen in Table 11, parenting stressors were associated with perceived threat and controllability, both of which were associated with GHQ scores. The indirect effect of parenting stressors on GHQ scores was not significant following inclusion of appraisals as potential mediators, and given that the confidence limit for the total mediation effect did not include zero, it 
appears that appraisals fully mediated the relation between parenting stressors and GHQ scores. Moreover, both perceived threat and controllability were unique mediators, as their $95 \%$ confidence interval did not contain zero (shown in Table 11). Thus, increased levels of parenting stressors were associated with increased perceived threat and lower controllability, which in turn were associated with greater psychological distress.

Table 11

Direct and Indirect (through Appraisals) Effects of Parenting Stressors on Psychological Distress: Results of Bootstrap Analysis

Coefficient $S E \quad t \quad p$

Relations between parenting stressors (IV) and appraisals (mediators)

Threat .36

.07

$5.23 \quad .00$

Controllability $-.30$

.06

Unique relations between appraisals (mediators) and GHQ (DV)

Threat .13

.03

$4.13 \quad .00$

Controllability

$-.14$

$\begin{array}{lll}.04 & -3.98 & .00\end{array}$

Direct effects of parenting stressors (IV) on GHQ (DV)

$\begin{array}{llll}.18 & .04 & 5.05 & .00\end{array}$

Indirect Effects (through mediators)

.09

.04

2.50 .05

\section{Bootstrapping 95\%}

Mediators

Lower Upper

Threat

.024

.075

Controllability

.019

.075

TOTAL

.056 
Similar to parenting stressors, relationship stressors were associated with both appraisal dimensions (Table 12). The indirect effects of relationship stressors on GHQ scores remained significant following inclusion of appraisals as potential mediators. However, confidence limits for the total mediation effect did not include zero, indicating a partial mediation by both perceived threat and controllability. Thus, increased levels of relationship stressors were associated with the appraisals of greater threat, and reduced controllability, which in turn were associated with greater psychological distress. 
Table 12

Direct and Indirect (through Appraisals) Effects of Relationship Stressors on

Psychological Distress: Results of Bootstrap Analysis

Coefficient $S E \quad t \quad p$

Relations between relationship stressors (IV)

and appraisals (mediators)

Threat

$\begin{array}{llll}.44 & .06 & 6.92 \quad .90\end{array}$

Controllability

$-.27$

$.05 \quad-5.00$

.00

Unique relations between appraisals

(mediators) and GHQ (DV)

Threat

$.03 \quad 4.47$

.00

Controllability

$-.12$

$\begin{array}{ll}.03 & -3.90\end{array}$

.00

Direct effects of relationship stressors (IV) on

GHQ (DV)

.22

.03

6.77

.00

Indirect effects (through mediator)

.13

.03

4.02

.00

\begin{tabular}{lcc}
\hline & Bootstrapping $95 \%$ \\
Mediators & CI & \\
Threat & & Upper \\
Controllability & .030 & .081 \\
TOTAL & .014 & .062 \\
& .055 & .126 \\
\hline
\end{tabular}

Appraisals as mediators between stressors and SWL scores. As seen in Table 13, the indirect effect of parenting stressors on SWL scores was not significant with 
appraisals included in the equation. Based on the confidence limits, it appears that both appraisal dimensions were implicated in fully mediating the relation between parenting stressors and satisfaction with life. As with GHQ, increased levels of parenting stressors were associated with the appraisals of greater threat and lower controllability, which in turn were associated with lower satisfaction with life.

Table 13

Direct and Indirect (through Appraisals) Effects of Parenting Stressors on Satisfaction with Life: Results of Bootstrap Analysis

Coefficient $S E \quad t \quad p$

Unique relations between appraisals

(mediators) and SWL (DV)

Threat

$-.29$

$.06 \quad-4.68$

.00

Controllability

.22

.07

3.10

.00

Direct effects of parenting stressors (IV) on

SWL (DV)

Indirect effects (through mediators)
$-.27$

$-.10$
.07

.07

$-1.42$
.00

.16

\section{Bootstrapping $95 \% \mathrm{CI}$}

Mediators

Lower Upper

Threat

$-.178$

$-.050$

Controllability

$-.122$

$-.028$

TOTAL 
As seen in Table 14, the indirect effects of relationship stressors on SWL scores remained significant following inclusion of appraisals as potential mediators. However, examination of the confidence limits suggest that both, perceived threat and controllability were significant unique mediators. Thus, increased levels of relationship stressors were associated with the appraisals of greater threat and reduced controllability, which partially mediated the relation with lower satisfaction with life.

Table 14

Direct and Indirect (through Appraisals) Effects of Relationship Stressors on Satisfaction with Life: Results of Bootstrap Analysis

Coefficient $\quad S E \quad p$

Unique relations between appraisals

(mediators) and SWL (DV)

Threat

$-.18$

.05

$-3.68$

.00

Controllability

.16

.06

2.63

.01

Direct effects of relationship stressors (IV)

$-.45$

.06

$-7.63$

.00

on SWL (DV)

Indirect effects (through mediator)

$-.33$

.06

$-5.27$

.00

\section{Bootstrapping 95\% CI}

Mediators

Lower Upper

Threat

$-.139$

$-.037$

Controllability

$-.086 \quad-.009$

TOTAL

$-.191$

$-.071$ 
Appraisals as mediators between stressors and support for members' career. As seen in Table 15, the indirect effect of parenting stressors on support scores was not significant following inclusion of appraisals as potential mediators and given that the confidence limit for the total mediation effect did not include zero, it appears that appraisals fully mediated the relation between parenting stressors and support for members' career. Moreover, only perceived threat was a unique mediator, as its $95 \%$ confidence interval did not contain zero.

Table 15

Direct and Indirect (through Appraisals) Effects of Parenting Stressors on Support for Members' Career: Results of Bootstrap Analysis

Coefficient $S E \quad t \quad p$

Unique relations between appraisals

(mediators) and support (DV)

Threat $-.16$

.05

$-3.37$

.00

Controllability .11

.05

1.97

Direct effects of parenting stressors (IV) on support (DV)

$-.15$

.06

.05

$-1.09$

\section{Bootstrapping 95\% CI}

Mediators

Threat

Controllability

TOTAL
Lower Upper

$\begin{array}{ll}-.111 & -.023\end{array}$

$-.074 \quad .002$

$\begin{array}{ll}-.146 & -.047\end{array}$ 
As seen in Table 16, the indirect effects of relationship stressors on support scores was not significant with appraisals included in the equation. Based on the confidence limits, it appears that both appraisal dimensions were implicated in fully mediating the relation between relationship stressors and support for members' career. Thus, increased levels of relationship stressors were associated with the appraisals of greater threat and lower controllability, which in turn were associated with decreased support for members' military career.

Table 16

Direct and Indirect (through Appraisals) Effects of Relationship Stressors on Support for Members' Career: Results of Bootstrap Analysis

Coefficient $\quad S E \quad p$

\begin{tabular}{|c|c|c|c|c|}
\hline \multicolumn{5}{|l|}{$\begin{array}{l}\text { Unique relations between appraisals } \\
\text { (mediators) and support (DV) }\end{array}$} \\
\hline Threat & -.12 & .04 & -3.13 & .00 \\
\hline Controllability & .11 & .05 & 2.42 & .02 \\
\hline $\begin{array}{l}\text { Direct effects of relationship stressors (IV) } \\
\text { on support (DV) }\end{array}$ & -.16 & .04 & -3.57 & .00 \\
\hline \multirow[t]{2}{*}{ Indirect effects (through mediator) } & -.08 & .05 & -1.64 & .10 \\
\hline & \multicolumn{3}{|c|}{ Bootstrapping $95 \% \mathrm{CI}$} & \\
\hline Mediators & Lower & Upper & & \\
\hline Threat & -.099 & -.019 & & \\
\hline Controllability & -.065 & -.005 & & \\
\hline TOTAL & -.133 & -.005 & & \\
\hline
\end{tabular}


Summary of mediating relations: Role of appraisals in mediating the relation between stressors and well-being/support for career (Figure 6). Appraisals of threat and controllability fully mediated the relation between parenting stressors and well-being indicators (i.e., GHQ and SWL scores), and partially mediated the relation between relationship stressors and well-being indicators. The relation between parenting stressors and support for members' career was fully mediated by appraisal of threat only, while both appraisals (i.e., threat and controllability) fully mediated the relation between relationship stressors and support for military's career. ${ }^{9}$

${ }^{9}$ When alternative mediation models were tested, using well-being indicators and support for members' career as mediators and appraisals as dependent variables, the relation between the stressors and appraisals was partially mediated by GHQ scores. The mediating effect of SWL scores on the relation between stressors and appraisals was not significant. Support for members' career appeared to partially mediate the relation between relationship (but not parenting) stressors and both appraisals. 


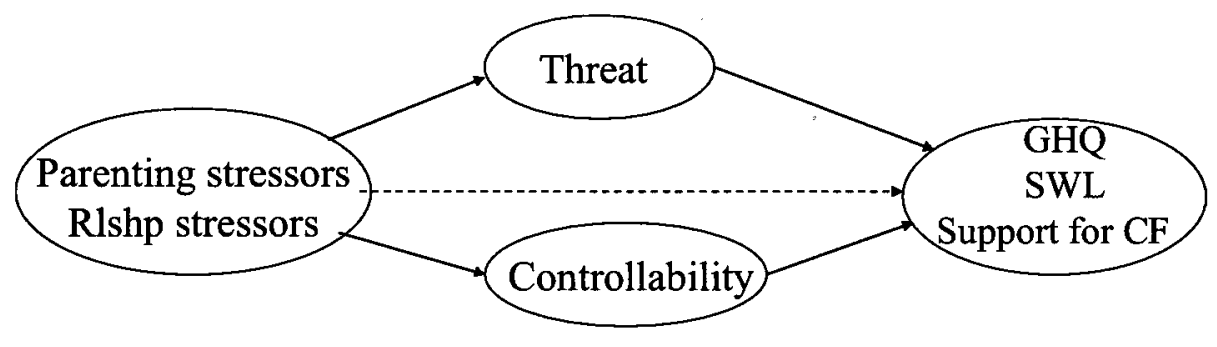

Figure 6. Path Diagram depicting the Mediating Effects of Appraisals on the Relation between Stressors and Well-being and Support for CF

Moderated mediation. To examine whether the mediating role of appraisals varied across the two groups of spouses (during deployment and post-deployment), analyses of moderated mediation effects were conducted using bootstrapping procedure for moderated mediation (Preacher et al., 2007). A series of moderated mediation analyses was conducted for each independent variable (i.e. parenting stressors and relationship stressors), for each mediator (i.e. two appraisal dimensions) and for each dependent variable (i.e. GHQ, SWL, support for members' career). These analyses revealed no significant interaction effects for any of the models predicting well-being indicators, suggesting that the role of appraisals in mediating the relation between the stressors (i.e. parenting stressors and relationship stressors) and well-being indicators (i.e., GHQ and SWL), did not differ across these two deployment groups. 
However, the indirect effect of both parenting stressors and relationship stressors on support for members' career through appraisal of threat did appear to be moderated by deployment phase (Table 17 and 18 respectively). Specifically, the relation between appraised threat and the support for members' career varied, depending on deployment stage, while the effect of parenting/relationship stressors on the appraised threat was constant (i.e. model 3). Given the interaction, the indirect effect was followed-up by estimating conditional indirect effects at each level of deployment phase ${ }^{10}$. As seen in Tables 17 and 18, appraised threat predicted reduced support for members' career among post-deployment participants, but was not related to support for members' career among the participants whose spouses were currently deployed.

${ }^{10}$ This procedure outputs a $\mathrm{z}$ score which is the ratio of the conditional effect to the estimated standard error to test for mediation at various levels of moderation. 
Table 17

Moderating effect of Deployment Phase on the Relation between Parenting Stressors and Support for Career (through Threat appraisal)

\begin{tabular}{|c|c|c|c|c|}
\hline & Coefficient & $S E$ & $t$ & $p$ \\
\hline Parenting stressors - Support for career & -.105 & .05 & -1.98 & .05 \\
\hline Threat - Support for career & -.065 & .06 & -1.08 & .28 \\
\hline Deployment phase - Support for career & .543 & .29 & 1.85 & .07 \\
\hline Threat X Deployment phase & -.197 & .09 & -2.25 & .03 \\
\hline Conditional indirect effect & Indirect effect & $S E$ & $Z$ & $p$ \\
\hline Deployed (coded as 0 ) & -.02 & .02 & -1.04 & .30 \\
\hline Post-deployed (coded as 1 ) & -.10 & .03 & -3.10 & .00 \\
\hline
\end{tabular}


Table 18

Moderating effect of Deployment Phase on the Relation between Relationship Stressors and Support for Career (through Threat appraisal)

Coefficient $\quad S E \quad t \quad p$

Relationship stressors - Support for career

$-.088$

.06

$-1.48$

.14

Threat - Support for career

$-.050$

.07

$-0.73$

.46

Deployment phase - Support for career

.665

.31

2.12

.04

Threat X Deployment phase

$-.226$

.09

$-2.41$

.02

Conditional indirect effect

Indirect effect

$S E$

Z

Z

$P$

Deployed (coded as 0)

$-.02$

.03

$-0.71$

.48

Post-deployed (coded as 1)

$-.11$

.03

$-3.17$

.00

Role of Coping in Mediating the Relation between Appraisals and Well-being ${ }^{11}$

It was expected that the two appraisal dimensions, i.e., threat and controllability may be associated with altered coping styles, which could lead to variations in psychological distress and satisfaction with life (Figure 7).

\footnotetext{
${ }^{11}$ The correlations between appraisals, coping and support for members' career were not sufficiently meaningful to break down contributing components by conducting mediation analyses.
} 


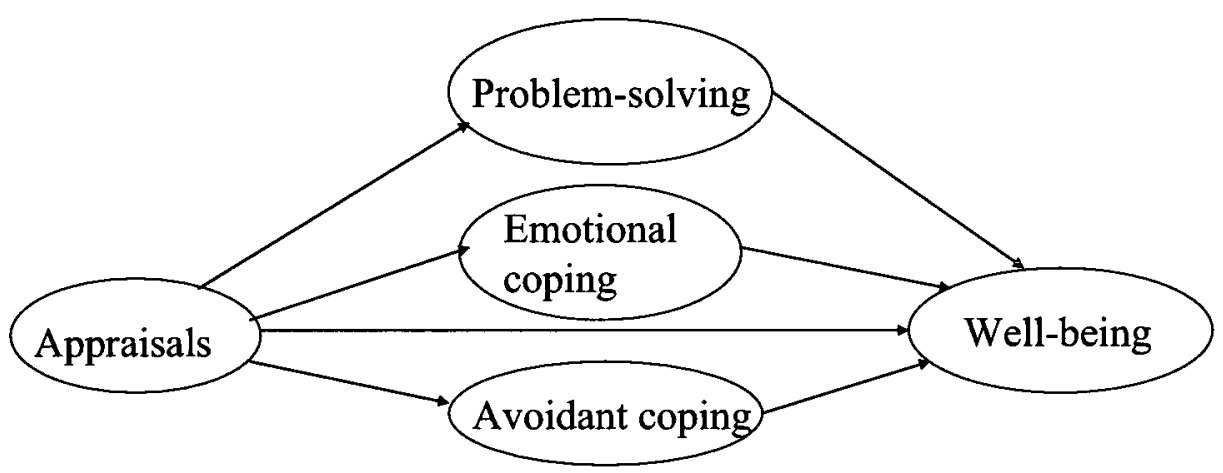

Figure 7. Mediating Effects of Coping on the Relation between Stress Appraisals and Well-being

Coping styles as mediators between appraisals and GHQ scores. As seen in Table 19, appraisal of threat was related to emotional and avoidant coping, but not to problemsolving coping. As well, all coping styles were related to GHQ scores. The indirect effects of threat appraisal on GHQ scores remained significant following inclusion of coping styles as potential mediators. However, confidence limit for the total mediation effect did not include zero, supporting the presence of partial mediation. In this regard, emotional coping and avoidant coping both uniquely mediated the effects of threat. Thus, increased perceptions of threat were associated with higher emotional and avoidant coping, which in turn were associated with greater psychological distress. 
Table 19

Direct and Indirect (through Coping) Effects of Appraisal of Threat on Psychological

Distress: Results of Bootstrap Analysis

Coefficient $S E$

$t$

$p$

Relations between threat (IV) and coping (mediators)

Problem solving

.02

.04

0.53

.59

Emotional coping

.25

.04

5.88

.00

Avoidant coping

.22

.04

5.24

.00

Unique relations between coping (mediators) and GHQ (DV)

Problem solving $-.09$

.03

$-2.95$

Emotional coping

.07

.03

2.32

.02

Avoidant coping

.09

.03

2.74

.01

Direct effects of threat (IV) on GHQ (DV)

.19

.02

7.85

.00

Indirect effects (through mediators)

.15

.02

6.27

.00

Bootstrapping $95 \%$

CI

Mediators

Lower Upper

Problem solving

$-.013$

.005

Emotional coping

.004

.036

Avoidant coping

.006

.038

TOTAL

.015

.059 
As seen in Table 20, appraisals of controllability were associated with all coping styles. The indirect effects of controllability appraisals on GHQ remained significant following inclusion of coping styles as potential mediators. However, examination of the confidence limits suggest that emotional and avoidant coping styles were significant unique mediators. Thus, increased perception of controllability was associated with reduced emotional and avoidant coping, which in turn were associated with lower psychological distress. 
Table 20

Direct and Indirect (through Coping) Effects of Appraisal of Controllability on Psychological Distress: Results of Bootstrap Analysis

\section{Coefficient}

$S E$

$t$

$p$

\begin{tabular}{|c|c|c|c|c|}
\hline \multicolumn{5}{|l|}{$\begin{array}{l}\text { Relations between controllability (IV) and } \\
\text { coping (mediators) }\end{array}$} \\
\hline Problem solving & .18 & .05 & 3.83 & .00 \\
\hline Emotional coping & -.13 & .05 & -2.46 & .01 \\
\hline Avoidant coping & -.25 & .05 & -4.85 & .00 \\
\hline \multicolumn{5}{|l|}{$\begin{array}{l}\text { Unique relations between coping (mediators) } \\
\text { and GHQ (DV) }\end{array}$} \\
\hline Problem solving & -.06 & .03 & -1.71 & .09 \\
\hline Emotional coping & .11 & .03 & 3.41 & .00 \\
\hline Avoidant coping & .10 & .03 & 2.88 & .00 \\
\hline $\begin{array}{l}\text { Direct effects of controllability (IV) on GHQ } \\
\text { (DV) }\end{array}$ & -.19 & .03 & -6.16 & .00 \\
\hline \multirow[t]{2}{*}{ Indirect effects (through mediator) } & -.14 & .03 & -4.60 & .00 \\
\hline & \multicolumn{2}{|c|}{$\begin{array}{l}\text { Bootstrapping } 95 \% \\
\text { CI }\end{array}$} & & \\
\hline Mediators & Lower & Upper & & \\
\hline Problem solving & -.030 & .001 & & \\
\hline Emotional coping & -.034 & -.004 & & \\
\hline Avoidant coping & -.046 & -.009 & & \\
\hline TOTAL & -.077 & -.026 & & \\
\hline
\end{tabular}


Coping styles as mediators between appraisals and SWL. As seen in Table 21, the indirect effects of threat appraisals on SWL scores remained significant following inclusion of coping styles as potential mediators. However, confidence limit for the total mediation effect did not include zero, indicating a partial mediation. In this regard, avoidant coping only uniquely mediated the effect of threat. Thus, increased perception of threat was associated with higher avoidant coping, which in turn was associated with lower satisfaction with life. 
Table 21

Direct and Indirect (through Coping) Effects of Appraisal of Threat on Satisfaction with Life: Results of Bootstrap Analysis

Coefficient $\quad S E \quad t \quad p$

\begin{tabular}{|c|c|c|c|c|}
\hline \multicolumn{5}{|l|}{ Unique relations between coping (mediators) } \\
\hline Problem solving & .17 & .06 & 2.88 & .00 \\
\hline Emotional coping & -.09 & .06 & -1.50 & .13 \\
\hline Avoidant coping & -.24 & .06 & -3.87 & .00 \\
\hline Direct effects of threat (IV) on SWL (DV) & -.32 & .05 & -6.97 & .00 \\
\hline Indirect effects (through mediator) & -.25 & .05 & -5.39 & .00 \\
\hline
\end{tabular}

\section{Bootstrapping 95\%}

CI

Mediators

Lower Upper

Problem solving

$-.010 \quad .024$

Emotional coping

$-.057 \quad .006$

Avoidant coping

$-.090 \quad-.021$

TOTAL

$-.116$

$-.028$

As seen in Table 22, the indirect effects of controllability appraisals on SWL scores remained significant following inclusion of coping styles as potential mediators. However, confidence limits for the total mediation effect did not include zero, indicating a partial mediation. In this regard, only avoidant strategies uniquely mediated the effect 
of controllability. Thus, increased perceptions of controllability was associated with reduced avoidance coping, which in turn was associated with higher satisfaction with life. Table 22

Direct and Indirect (through Coping) Effects of Appraisal of Controllability on Satisfaction with Life: Results of Bootstrap Analysis

Coefficient $\quad S E \quad p$

Unique relations between coping (mediators)

and SWL (DV)

Problem solving 12

.06

1.89

.06

Emotional coping

$-.1$

.06

$-2.46$

.01

Avoidant coping

$-.26$

.06

$-4.05$

.00

Direct effects of controllability (IV) on SWL

.30

.06

5.13

.00

(DV)

Indirect effects (through mediator)

.20

.06

3.38

.00

\section{Bootstrapping 95\%}

CI

Mediators

Lower Upper

Problem solving

.000

.052

Emotional coping

.000

.053

Avoidant coping

.029

.113

TOTAL

.062 
Summary of mediating relations: Role of coping in mediating the relation between appraisals and well-being/support for career (Figure 8). Overall, emotional and avoidant coping consistently partially mediated the relations between two appraisal dimensions (i.e., threat and controllability) and psychological distress. Avoidant coping (but not emotional coping) was also a consistent partial mediator of the relation of both appraisal dimensions and satisfaction with life. None of the coping styles mediated the relation between two appraisals and support for members' career. ${ }^{12}$

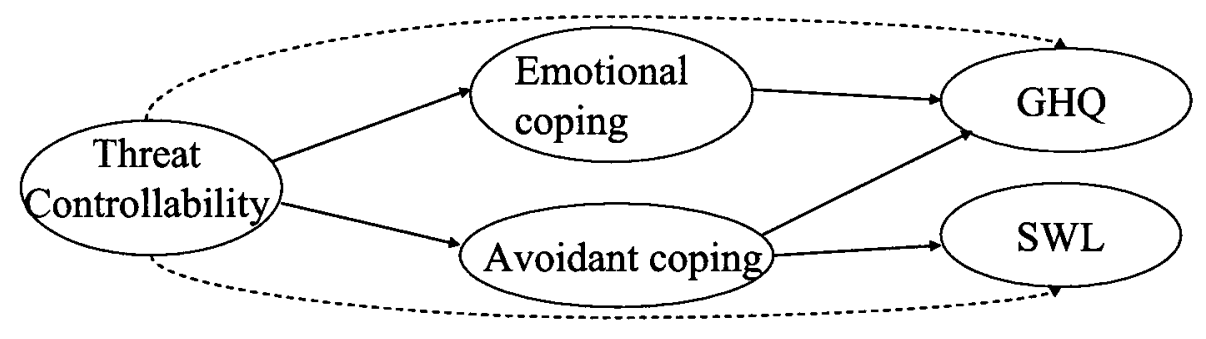

Figure 8. Path Diagram depicting the Mediating Effects of Coping on the Relation between Appraisals and Well-being Indicators

12 When alternative mediation models were tested, using coping styles as independent variable and appraisals as mediators, the relation of emotional coping and well-being indicators (i.e., GHQ and SWL) was partially mediated by each appraisal. Similarly, the relation of avoidant coping and well-being indicators was partially mediated by each appraisal, while the relation of problem solving and GHQ scores (but not SWL) was partially mediated by controllability (but not appraisal of threat). Only appraisal of threat (but not controllability) fully mediated the relation between emotional and avoidant coping and support for members' career. 
Moderated mediation. To examine whether the mediating role of coping styles varied across the two groups of spouses (during deployment and post-deployment), a series of moderated mediation analyses was conducted for each independent variable (i.e. threat and controllability), for each mediator (i.e. problem solving, emotional and avoidant coping) and for each dependent variable (i.e. GHQ and SWLS). These analyses revealed no significant interaction effects for any of the models, indicating that the role of coping styles in mediating the relation between the two appraisal dimensions and wellbeing indicators (i.e., GHQ and SWLS) did not differ across these two deployment groups.

Role of Appraisals in Mediating the Relations between Social Support and Well-being and Support for Members' Career

It was expected that social support may be associated with altered appraisals, which could lead to variations in psychological distress, satisfaction with life and support for members' career (Figure 9). 


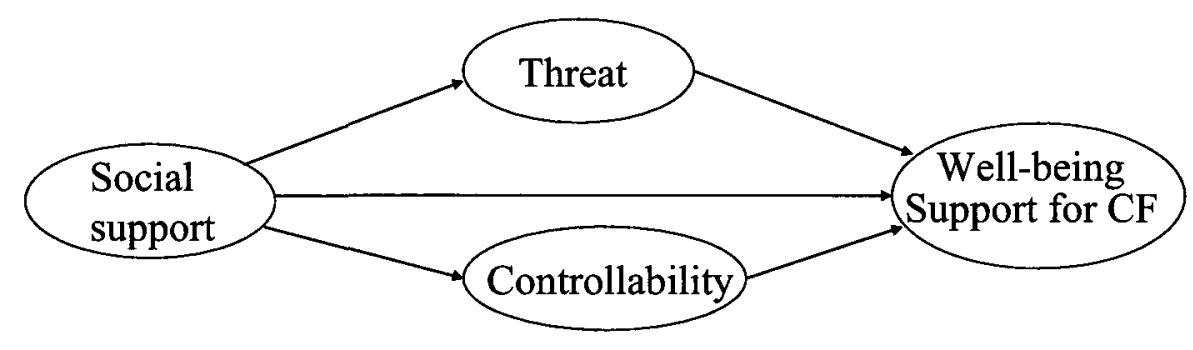

Figure 9. Mediating Effects of Appraisals on the Relation between Social Support and Well-being

Appraisals as mediators between spousal support and GHQ scores $^{13}$. As seen in Table 23, perceived spousal support was associated with perceived threat and controllability, both of which were associated with GHQ score. The indirect effects of spousal support on GHQ scores remained significant, following inclusion of appraisals as potential mediators. However, confidence limit for the total mediation effect did not include zero, indicating a partial mediation by both perceived threat and controllability. Thus, increased levels of perceived spousal support were associated with appraisals of reduced threat and greater controllability, which in turn were associated with lower psychological distress.

\footnotetext{
${ }^{13}$ Though significant, the correlation between organizational support and GHQ was not sufficiently meaningful to break down contributing components by conducting mediation analyses.
} 
Table 23

Direct and Indirect (through Appraisals) Effects of Spousal Support on Psychological Distress: Results of Bootstrap Analysis

Coefficient $S E \quad t \quad p$

\begin{tabular}{|c|c|c|c|c|}
\hline \multicolumn{5}{|l|}{$\begin{array}{l}\text { Relations between spousal support (IV) and } \\
\text { appraisals (mediators) }\end{array}$} \\
\hline Threat & -.32 & .07 & -4.41 & .00 \\
\hline Controllability & .24 & .06 & 4.06 & .00 \\
\hline \multicolumn{5}{|l|}{$\begin{array}{l}\text { Unique relations between appraisals } \\
\text { (mediators) and GHQ (DV) }\end{array}$} \\
\hline Threat & .14 & .02 & 5.83 & .00 \\
\hline Controllability & -.12 & .03 & -3.99 & .00 \\
\hline Direct effects of spousal support (IV) on & -.22 & .04 & -6.33 & .00 \\
\hline \multicolumn{5}{|l|}{ GHQ (DV) } \\
\hline \multirow[t]{2}{*}{ Indirect effects (through mediator) } & -.15 & .03 & -4.42 & .00 \\
\hline & \multicolumn{4}{|c|}{ Bootstrapping 95\% CI } \\
\hline Mediators & Lower & Upper & & \\
\hline Threat & -.075 & -.023 & & \\
\hline Controllability & -.056 & -.012 & & \\
\hline TOTAL & -.114 & -.044 & & \\
\hline
\end{tabular}


Appraisals as mediators between social support and SWL scores. As seen in Table 24, the indirect effects of spousal support on SWL scores remained significant, following inclusion of appraisals as potential mediators. However, examination of the confidence limits suggest that both perceived threat and controllability were significant unique mediators. Thus, increased levels of perceived spousal support were associated with the appraisals of reduced threat and greater controllability, which partially mediated the relation with higher satisfaction with life.

Table 24

Direct and Indirect (through Appraisals) Effects of Spousal Support on Satisfaction with Life: Results of Bootstrap Analysis

Coefficient $S E \quad t \quad p$

Unique relations between appraisals

(mediators) and SWL (DV)

Threat

$-.21$

.04

$-4.88$

.00

Controllability

.14

.05

2.64

.01

Direct effects of spousal support (IV) on SWL (DV)

Indirect effects (through mediator)

.61

.06

9.72

.00

.50

.06

8.15

.00

\section{Bootstrapping $95 \% \mathrm{CI}$}

Mediators

Lower Upper

Threat

.033

.122

Controllability

.009

.072

TOTAL

.060

.163 
As seen in Table 25, the indirect effect of organizational support on SWL scores was not significant with appraisals included in the equation. Based on the confidence limits, it appears that both appraisal dimensions were implicated in fully mediating the relation between perceived organizational support and satisfaction with life. Thus, increased levels of perceived organizational support were associated with appraisals of lower threat and greater controllability, which in turn were associated with higher satisfaction with life. 
Table 25

Direct and Indirect (through Appraisals) Effects of Organizational Support on Satisfaction with Life: Results of Bootstrap Analysis

\begin{tabular}{|c|c|c|c|c|}
\hline & Coefficient & $\overline{S E}$ & $t$ & $p$ \\
\hline \multicolumn{5}{|l|}{ Relationship between org support (IV) and } \\
\hline \multicolumn{5}{|l|}{ appraisals (mediators) } \\
\hline Threat & -.33 & .05 & -7.00 & .00 \\
\hline Controllability & .10 & .04 & 2.56 & .01 \\
\hline \multicolumn{5}{|l|}{ Unique relations between appraisals (mediators) } \\
\hline \multicolumn{5}{|l|}{ and SWL (DV) } \\
\hline Threat & -.25 & .05 & -4.90 & .00 \\
\hline Controllability & .21 & .06 & 3.47 & .00 \\
\hline Direct effects of org support (IV) on SWL (DV) & .19 & .05 & 4.19 & .00 \\
\hline \multirow[t]{2}{*}{ Indirect effects (through mediator) } & .09 & .05 & 1.94 & .05 \\
\hline & \multicolumn{2}{|c|}{$\begin{array}{c}\text { Bootstrapping } 95 \% \\
\text { CI }\end{array}$} & & \\
\hline Mediators & Lower & Upper & & \\
\hline Threat & .043 & .129 & & \\
\hline Controllability & .006 & .046 & & \\
\hline TOTAL & .059 & .153 & & \\
\hline
\end{tabular}


Appraisals as mediators between spousal support and support for members' career $^{14}$. As seen in Table 26, the indirect effects of spousal support on support for members' career remained significant, following inclusion of appraisals as potential mediators. However, confidence limits for the total mediation effect did not include zero, indicating a partial mediation by both perceived threat and controllability. Thus, increased levels of perceived spousal support were associated with reduced appraisals of threat and greater controllability, which in turn were associated with greater support for members' career.

\footnotetext{
${ }^{14}$ Though significant, the correlation between organizational support and support for members' career was
} not sufficiently meaningful to break down contributing components by conducting mediation analyses. 
Table 26

Direct and Indirect (through Appraisals) Effects of Spousal Support on Support for Members' Career: Results of Bootstrap Analysis

Coefficient $\quad S E \quad t \quad p$

Unique relations between appraisals

(mediators) and support for career (DV)

Threat

Controllability

Direct effects of spousal support (IV) on support for career (DV)

Indirect effects (through mediator)
$-.12$

.09

.20

.14
.03

.04

.05

4.27

$-3.58$

2.07

Bootstrapping $95 \% \mathrm{CI}$

Mediators Lower Upper

Threat

Controllability

TOTAL
.016

.003

.002 $\begin{array}{ll}.05 & 2.97\end{array}$

.00
.00

.00

.04 
satisfaction with life. ${ }^{15}$

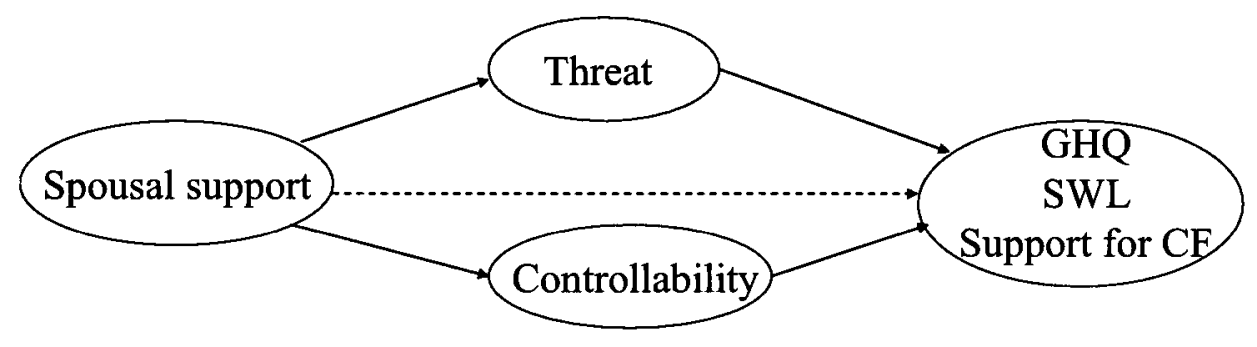

Figure 10. Path Diagram depicting the Mediating Effects of Appraisals on the Relation between Spousal Support and Well-being indicators and Support for CF

\footnotetext{
${ }^{15}$ When alternative mediation models were tested, using appraisals as independent variables and social support as mediators, the relation between two appraisals and satisfaction with life was partially mediated by both spousal support and organizational support. However, only spousal support partially mediated the relation of controllability and psychological distress. Similarly, only spousal support was a partial mediator between each of the appraisals and support for members' career.
} 


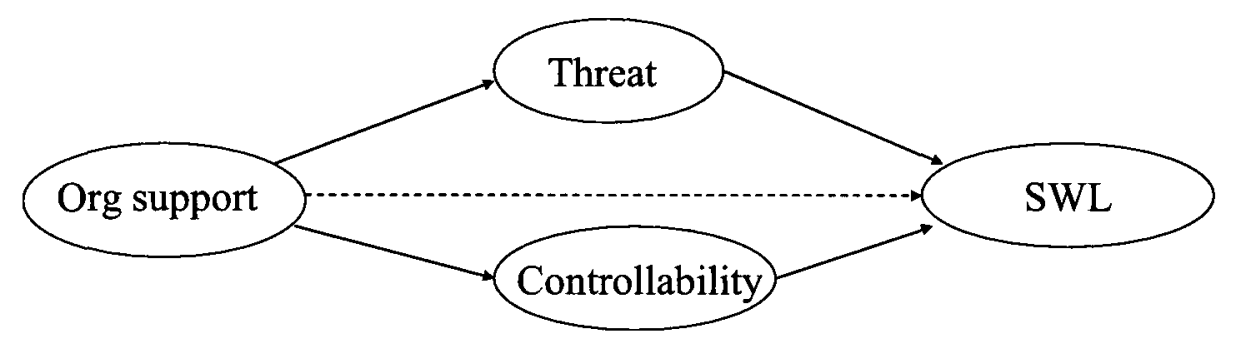

Figure 11. Path Diagram depicting the Mediating Effects of Appraisals on the Relation between Organizational Support and Satisfaction with life

Moderated mediation. To examine whether the mediating role of appraisals varied across the two groups of spouses (during deployment and post-deployment), analyses of moderated mediation effects were conducted. As before, a series of moderated mediation analyses was conducted for each independent variable (i.e. spousal support and organizational support), for each mediator (i.e. two appraisal dimensions) and for each dependent variable (i.e. GHQ, SWL and support for members' career). These analyses revealed no significant interaction effects for any of the models predicting well-being indicators, suggesting that the role of appraisals in mediating the relation between spousal support and well-being indicators (i.e., GHQ and SWL) did not differ across these two deployment groups.

However, the indirect effect of spousal support on support for members' career through appraisal of threat did appear to be moderated by deployment phase (Table 27). 
Specifically, the relation between appraised threat and the support for members' career varied, depending on deployment stage, but the effect of spousal support on the appraised threat was constant (i.e. model 3). Given the interaction, the indirect effect was followedup by estimating conditional indirect effects at each level of deployment phase ${ }^{16}$. As seen in Table 27, appraised threat predicted reduced support for members' career among postdeployment participants, but was not related to support for members' career among the participants whose spouses were currently deployed.

Table 27

Moderating Effect of Deployment Phase on the Relation between Spousal Support and Support for Career (through Threat Appraisal)

Coefficient $\quad S E \quad t \quad p$

Spousal support - Support for career

.170

.05

3.52

.00

Threat - Support for career

$-.058$

.05

$-1.23$

.22

Deployment phase - Support for career

.489

.22

2.27

.02

Threat X Deployment phase

$-.165$

.07

$-2.48$

.01

Conditional indirect effect

Deployed (coded as 0)

Post-deployed (coded as 1)
Indirect effect

.02

.07
.02

.03

$p$

. 
Role of Coping in Mediating the Relations between Social Support and Well-being and Support for Members' Career

It was expected that perceived social support may be associated with altered coping styles, which could lead to variations in psychological distress, satisfaction with life and support for members' career (Figure 12).

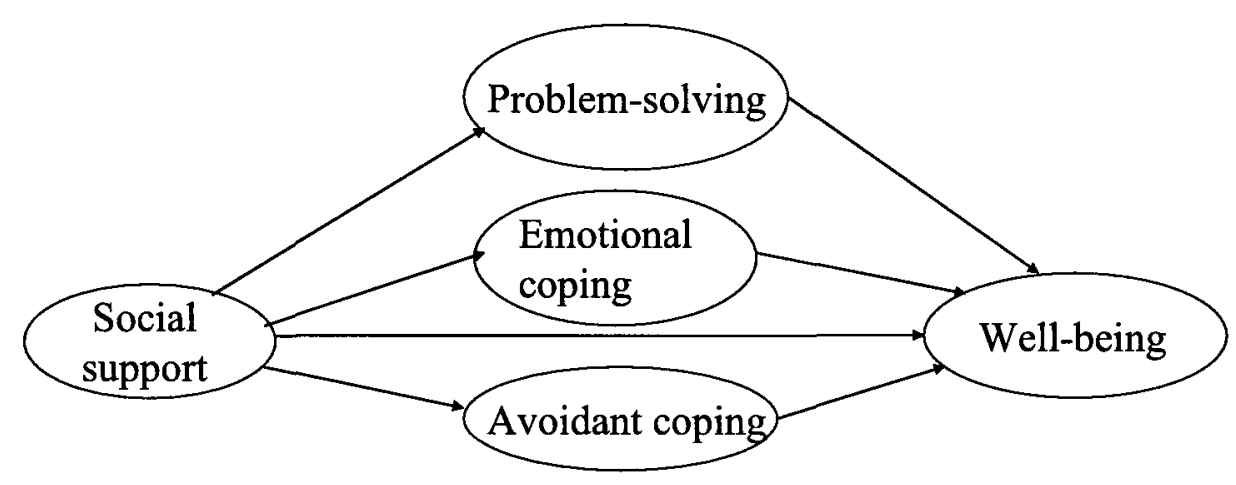

Figure 12. Mediating Effects of Coping on the Relation between Social Support and Well-being

Coping styles as mediators between spousal support and GHQ scores ${ }^{17}$. As seen in Table 28, perceived spousal support was associated with all three coping styles. Furthermore, emotional and avoidant coping were associated with GHQ score. The indirect effects of spousal support on GHQ scores remained significant, following inclusion of coping styles as potential mediators. However, confidence limit for the total

\footnotetext{
${ }^{17}$ Though significant, the correlation between organizational support and GHQ was not sufficiently meaningful to break down contributing components by conducting mediation analyses.
} 
mediation effect did not include zero, indicating a partial mediation model. Examination of the specific indirect effects indicated that emotional and avoidant coping were significant unique mediators (Table 28). Thus, increased levels of perceived spousal support were associated with reduced emotional and avoidance coping, which in turn were associated with lower psychological distress. 
Table 28

Direct and Indirect (through Coping) Effects of Spousal Support on Psychological

Distress: Results of Bootstrap Analysis

Coefficient $\quad S E \quad t \quad p$

Relations between spousal support (IV) and coping (mediators)

Problem solving .21

.05

3.91

.00

Emotional coping

$-.27$

.06

$-4.44$

.00

Avoidant coping

$-.35$

$.06-6.01$

.00

Unique relations between coping (mediators) and GHQ (DV)

Problem solving

Emotional coping

Avoidant coping

Direct effects of spousal support (IV) on GHQ (DV)

Indirect effects (through mediator)
$-.06$

.10

.10

$-.22$

$-.15$
.03

$-1.80$

.03

.03

2.88

.00

$3.06 \quad .00$

Bootstrapping 95\% CI

Mediators

Lower Upper

Problem solving

$-.036$

.000

Emotional coping

$-.050 \quad-.010$

Avoidant coping

$-.064 \quad-.012$

TOTAL
$-6.29$

.00

$.04 \quad-4.12$

.00 
Coping styles as mediators between social support and SWL scores. As seen in Table 29, only avoidant coping was associated with SWL score. The indirect effects of spousal support on SWL scores remained significant, following inclusion of coping styles as potential mediators. However, confidence limit for the total mediation effect did not include zero, indicating a partial mediation model. Examination of the specific indirect effects indicated that only avoidant coping was a unique mediator. Thus, increased levels of perceived spousal support were associated with the reduced avoidant coping, which in turn was associated with higher satisfaction with life. 
Table 29

Direct and Indirect (through Appraisals) Effects of Spousal Support on Satisfaction with Life: Results of Bootstrap Analysis

\begin{tabular}{|c|c|c|c|c|}
\hline \multicolumn{5}{|l|}{ Unique relations between coping (mediators) } \\
\hline \multicolumn{5}{|l|}{ and SWL (DV) } \\
\hline Problem solving & .08 & .06 & 1.31 & .19 \\
\hline Emotional coping & -.10 & .06 & -1.74 & .08 \\
\hline Avoidant coping & -.20 & .06 & -3.40 & .00 \\
\hline Direct effects of spousal support (IV) on & .62 & .06 & 9.80 & .00 \\
\hline \multicolumn{5}{|l|}{ SWL (DV) } \\
\hline \multirow[t]{2}{*}{ Indirect effects (through mediator) } & .50 & .07 & 7.67 & .00 \\
\hline & \multicolumn{4}{|c|}{ Bootstrapping 95\% CI } \\
\hline Mediators & Lower & Upper & & \\
\hline Problem solving & -.007 & .047 & & \\
\hline Emotional coping & -.002 & .072 & & \\
\hline Avoidant coping & .028 & .129 & & \\
\hline TOTAL & .062 & .176 & & \\
\hline
\end{tabular}

As seen in Table 30, the indirect effects of organizational support on SWL scores remained significant, following inclusion of coping styles as potential mediators. However, confidence limits for the total mediation effect did not include zero, indicating a partial mediation model. Examination of the specific indirect effects indicated that emotional and avoidant coping were unique mediators. Thus, increased levels of 
perceived organizational support was associated with the reduced emotional and avoidant coping, which in turn were associated with higher satisfaction with life.

Table 30

Direct and Indirect (through Coping) Effects of Organizational Support on Satisfaction with Life: Results of Bootstrap Analysis

Coefficient $\quad S E \quad p$

\begin{tabular}{|c|c|c|c|c|}
\hline \multicolumn{5}{|l|}{$\begin{array}{l}\text { Relationship between org support (IV) and } \\
\text { coping (mediators) }\end{array}$} \\
\hline Problem solving & .00 & .04 & -0.05 & .96 \\
\hline Emotional coping & -.14 & .04 & -3.29 & .00 \\
\hline Avoidant coping & -.09 & .04 & -2.26 & .02 \\
\hline \multicolumn{5}{|l|}{ Unique relations between coping (mediators) } \\
\hline \multicolumn{5}{|l|}{ and SWL (DV) } \\
\hline Problem solving & .13 & .06 & 2.02 & .04 \\
\hline Emotional coping & -.15 & .06 & -2.43 & .02 \\
\hline Avoidant coping & -.27 & .06 & -4.20 & .00 \\
\hline Direct effects of org support (IV) on SWL & .19 & .05 & 4.18 & .00 \\
\hline \multicolumn{5}{|l|}{$(\mathrm{DV})$} \\
\hline Indirect Effects (through mediator) & .15 & .04 & 3.35 & .00 \\
\hline
\end{tabular}

Bootstrapping $95 \% \mathrm{CI}$

Mediators

Lower Upper

Problem solving

$-.013 \quad .011$

Emotional coping

$.004 \quad .050$

Avoidant coping

.004

.055

TOTAL

.011

.086 
Summary of mediating relations: Role of coping in mediating the relation between social support and well-being (Figures 13 and 14). Overall, avoidant coping consistently mediated the relations between spousal support and well-being (i.e., psychological distress and satisfaction with life). Similarly, emotional coping was a unique mediator of spousal support and psychological distress (but not SWL). Both, emotional and avoidant coping mediated the effects of organizational support on SWL. Problem solving was not a significant mediator in any of the models. None of the coping styles mediated the relation between social support variables and support for members' career. ${ }^{18}$

18 When alternative mediation models were tested, using coping styles as the independent variable and support variables as mediators, the relation of problem-solving and well-being variables was fully mediated by spousal support. The relation of emotional coping/avoidant coping and well-being variables was partially mediated by perceived spousal support while organizational support played a partial mediating role only in relation between emotional coping/avoidant coping and satisfaction with life (but not psychological distress). The relation between emotional/avoidant coping and support for career was fully mediated by spousal and organizational support, while social support variables did not mediate the relation between problem solving and support for members' career. 


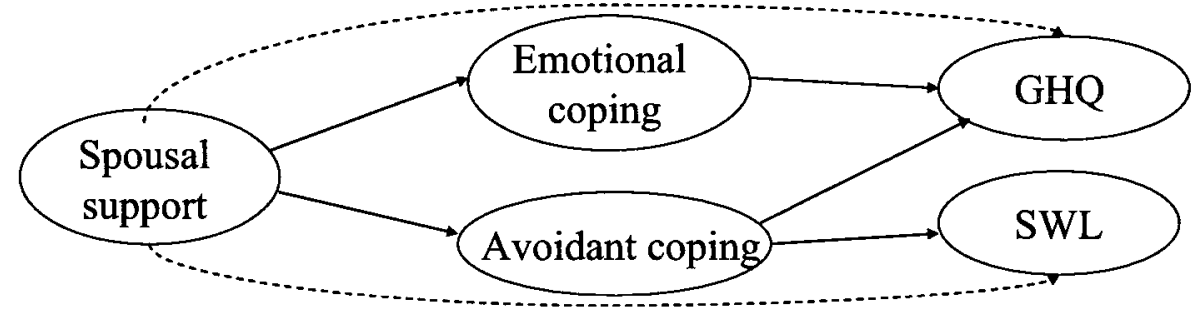

Figure 13. Path Diagram depicting the Mediating Effects of Coping on the Relation between Spousal Support and Well-being Indicators

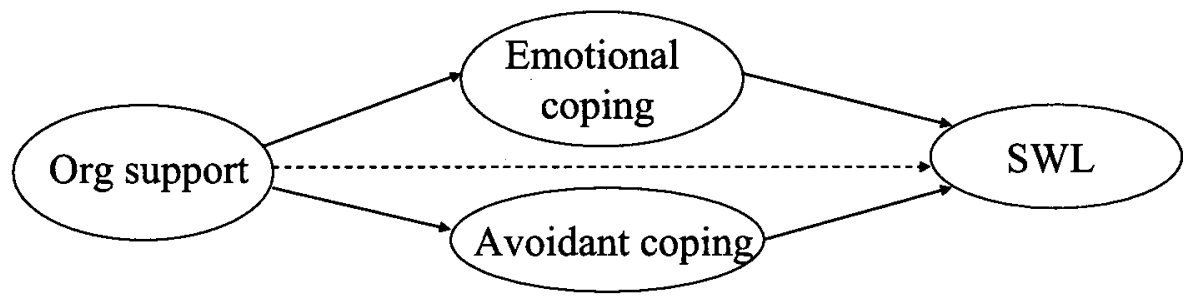

Figure 14. Path Diagram depicting the Mediating Effects of Coping on the Relation between Organizational Support and Satisfaction with life 
Moderated mediation. To examine whether the mediating role of coping styles varied across the two groups of spouses (during deployment and post-deployment), analyses of moderated mediation effects were conducted. Series of moderated mediation analyses were conducted for each independent variable (i.e. spousal support and organizational support), for each mediator (i.e. problem solving, emotional and avoidant coping) and for each dependent variable (i.e. GHQ, SWL and support for members' career). These analyses revealed no significant interaction effects for any of the models, indicating that the role of coping styles in mediating the relation between the social support measures and well-being indicators (i.e., GHQ, SWL and support for members' career) did not differ across these two deployment groups.

\section{Discussion}

The findings from Study 1 demonstrated that spousal support provided a vital resource for service members' well-being, readiness, performance and ability to carry out the military mission. Therefore, it is important to understand what factors contribute to the well-being of the military spouses, as it has been found that exposure to a person's psychological distress may cause burden and even depressive symptoms in significant others (Benazon \& Coyne, 2000; Joiner \& Katz, 1999). In particular, it is crucial to understand how spouses can maintain their well-being and support the military career of serving members during and after military deployments. The present study suggested that social support from the member and from the CF may alter spouses' appraisals of the stressors associated with a military lifestyle, and enhance well-being.

While the impact of military life on families has been a focus of the work-family interface studies (Adams et al., 2005), only recently there has been explicit reference to 
the extensive research concerning models of stress and coping (Hammer, Cullen, Marchand, \& Dezsofi, 2006). Military spouses face a number of unique stressors as they attempt to meet the demands placed upon them by the military institution. Therefore, the present study aimed to bridge the perspectives of the work-family interface and the stress and coping research. Furthermore, by including relational outcomes when dealing with interpersonal stressors, this study adds to the theoretical and explanatory value of stress and coping theories.

Deployment Stressors, Appraisals and Spousal Well-being

Service members' deployment status has been construed as constituting a special source of stress for spouses (Figley, 1993). Yet, in the present study, there was little difference in the well-being, or the appraisals, coping styles, or support resources of spouses of deployed members compared to those whose partners had not been deployed within the past 7 months. A possible explanation for this finding could be that military lifestyle demands (such as frequent relocations, separations and long hours) might have a pervasive effect on the well-being of all spouses, including those of non-deployed members, so that deployment itself does not in fact represent a powerful stressor. Overall, there is some indication that military spouses report more mental health issues than the general population (Pierce \& Luchsinger, 1986), which was confirmed by the findings of this study, wherein a somewhat higher proportion of the spouses reported lower satisfaction with life, compared to the population at large.

Another explanation for why deployment did not play a role in spousal well-being could be due to the length of deployment. The majority of the studies that found deployment to be a distress factor come from the U.S. where the length of deployment is 
at least twice that typically enacted in Canada. Indeed, it has previously been suggested that shorter deployments are associated with modest, temporarily behavioural and emotional symptoms in family members, while lengthy separations can result in more persistent negative effects (Jensen, Martin, \& Watanable, 1996).

Furthermore, a possible reason why the two deployment groups did not differ in the stress process predicting their well-being may have to do with the nature of the deployment. Previous research has found that deployment and post-deployment are phases through which the spouses experience all range of stressors and emotions (Adler et al., 1995). Timing is very important in terms of the stressors that are experienced and the reactions to these stressors. Some authors have suggested that there are actually five emotional stages within these two deployment phases (Pincus et al., 2001). For example, the spouses of members who have just returned from a deployment were probably experiencing a "honeymoon" period (lasting a few weeks) and were very different from the spouses who have past the "honeymoon" period and were re-negotiating their roles and re-establishing emotional connection (Pavlicin, 2003). Unfortunately, the sample size and methodology of the present study could not afford to examine the differences across five emotional stages.

However, the results of this study do point to moderate relations between parenting and relationship stressors experienced by the spouses during deployment and re-integration phases and their well-being. As expected, among spouses whose partners were currently deployed or had been recently deployed, both parenting stressors and relationship stressors were associated with greater psychological distress and lower satisfaction with life. This finding is in line with previous research that has shown that 
interpersonal stressors have a particularly deleterious effect on physical and psychological well-being (Baumeister \& Leary, 1995; Bolger, DeLongis, Kessler, \& Schilling, 1989). The poorer psychological health of spouses may undermine their capacity to provide social support to CF members, but in addition, greater stressors directly undermined spouses' instrumental support for members' careers.

Multiple studies have found parenting stressors to be among the most significant predictors of reduced quality of life and well-being among military spouses (Everson, 2005; Medway, David, Cafferty, \& Chappell, 1995). Yet, parenting stressors faced by military spouses during deployment (dealing with these stressors as a single parent) or during re-integration (military parent is frequently only physically present, but emotionally absent) implies specific circumstances which might amplify the experience of parenting stressors. Much like the findings of the present study, general parenting stressors have been found to affect the physical and psychological health of parents (Abidin, 1992; Crnic \& Greenberg, 1990), and dealing with these stressors in the absence of a second parent constitutes special challenges for parents. It has been found that single parents report higher levels of parenting stressors than married parents (Copeland \& Harbaugh, 2005). Single parenting assumes not only increased workload and responsibilities of parenting, but also lack of social and emotional support during the time of stress. These factors would contribute to appraising the military lifestyle demands as more threatening and uncontrollable. Indeed, in the present study, spousal appraisals of the impact of the military lifestyle on their family and career appeared to be key to understanding the impact of parenting stressors on spousal well-being. Specifically, employing positive appraisals (lower threat and higher perceived control) of military 
lifestyle may provide a psychological respite, allowing the parent to replenish the energy and psychological resources that have been depleted by parenting stressors. If so, finding ways to reduce the threatening aspects of military lifestyle demands and increase overall perceived control and confidence, could attenuate the impact of both parenting and relationship stressors on spousal well-being.

Similar to the process of dealing with parenting stressors, spouses experiencing increased levels of relationship stressors also perceived the military lifestyle demands as threatening and less controllable. This in turn fostered higher psychological distress and lower satisfaction with life, as well as lower support for serving members' military career.

While the effect of parenting stressors on the well-being indicators was fully explained by the extent to which spouses perceived the military lifestyle demands as threatening and controllable, the effects of relationship stressors were partially mediated. It may be that the impact of relationship stressors is more complex than that of parenting stressors and may involve a number of third variables or nonlinear processes. Future research might examine other third variables besides appraisals that might serve as mediators between relationship stressors and psychological well-being. Alternatively, it is possible that such variations in the extent of mediation could be an artifact of the direct effect being somewhat weaker for parenting stressors compared to the direct effect of relationship stressors, so removing any variance resulted in full mediation.

Although the transactional model emphasizes the situational specificity of the appraisal process (i.e., appraisal of the specific stressors), the present study demonstrates that primary and secondary appraisals of the more generic situation in which the stressors 
are situated, are constructs of central importance for understanding the impact of stressors, in this case, during deployment and re-integration phases on spousal wellbeing. It has been suggested that for coping and appraisal processes to mediate the effect of stressors on adaptational outcomes, they had to be at least moderately stable across diverse stressful situations. This stability might be due to the influence of personality characteristics and/or derived from the person being in the same kinds of environmental conditions (Folkman et al., 1986). Assessing the appraisal process with a more generic but still contextual approach, which goes above appraising specific aspects of single stressors, might have added necessary stability to these constructs. Theoretically, identifying the stable aspects of stressful person-environment transactions and the appraisals that occur within this context might increase our ability to explain longer-term adaptational outcomes. At the higher level of abstraction, the links between appraisal, coping, and outcomes such as psychological well-being may become clearer (Folkman et al., 1986).

It needs to be cautioned that the cross-sectional design of this study does not allow the evaluation of causal inferences. The tests of alternative models supported the possibility that psychological distress (but not life satisfaction) accounted for the relation between both parenting and relationship stressors and appraisals. Satisfaction with life did not play intervening role, thus it seems that this construct is more appropriate as an outcome. The possible reason for different results, depending on the well-being measure, could be attributable to the nature of the constructs under investigation. Feeling increased psychological distress, such as troubles sleeping, concentrating and feeling depressed, is certainly an outcome of stressors, but also influences how we perceive our ability to cope 
with stressors and the level of threat they present. Satisfaction with life, on the other hand, as a judgment, may be more a summative result of our experiences and appraisals, and it might not necessary impede our ability to perceive ourselves as capable to deal with demands.

Similarly, the alternative model showed that the support for CF members' military career accounted for the relation between relationship stressors (but not parenting stressors) and stress appraisals. Indeed, it does not seem unreasonable that relationship challenges, such as arguing with spouses about issues like finances, spousal roles and children, might lead to a decreased level of overall support for their military spouses, including support for their military career, along with more negative appraisals of the demands of military life-style. Overall, these alternative models point to the process of appraisal-well-being as a dynamic one in which psychological well-being and appraisals are reciprocal and dynamic. For this reason, future longitudinal research would allow one to explore those issues.

\section{Appraisals and Coping}

In the transactional model of stress and coping (Lazarus \& Folkman 1984), appraisal processes regarding a stressful situation are considered important antecedents to coping processes. In the present study, military spouses of both deployed and postdeployed members reported using problem-solving strategies more frequently than either emotional or avoidance coping, implying greater efforts to alter the sources of their stress than contending with the emotional repercussions.

In line with previous research (Lazarus \& Folkman 1984; Carver et al. 1989; Matheson \& Anisman 2003; Ysseldyk et al., 2009), appraisals and coping styles were 
predictive of psychological distress and satisfaction with life, as well as with willingness to support members' career. Most notably, the use of avoidant and emotional coping styles in the present study was related to an increased psychological distress and lowered satisfaction with life, as well as lowered spousal willingness to support serving members' career. Although, not as strongly as emotional and avoidant coping, the use of a problemsolving coping style was related to psychological distress, satisfaction with life, as well as the extent to which they support members' military career.

Also consistent with previous research (Amiot, Terry, Jimmieson, \& Callan 2006; Conway \& Terry, 1992; Folkman and Lazarus, 1980; Folkman et al., 1986), increased perceptions of controllability were related to greater endorsement of problem-solving strategies and decreased use of emotional and avoidant coping. While perceived threat was associated with higher emotional and avoidant coping, it had no relation with the use of problem-solving strategies. These findings are consistent with previous research, (Mikulincer, \& Florian, 1995; Portello \& Long, 2001) showing that appraising a situation as threatening will not motivate the use of problem solving strategies.

The use of problem solving strategies did not mediate the relation between appraisals of controllability and the well-being indicators. However, as anticipated, emotional and avoidant coping partially mediated the relations between appraisals (i.e., threat and controllability) and psychological distress. While both emotional and avoidant coping played a role in mediating appraisals and psychological distress, only avoidant coping was a mediator between appraisals and life satisfaction. It is possible that emotional coping and psychological distress constructs are closer in temporal proximity. The increased use of emotional coping might trigger immediate outcomes, such as feeling 
sad, depressed, irritated or annoyed ("during the past week"), whereas judgments of the conditions of life encompass a reflection on life overall, and hence represents a more stable construct (Pavot \& Diener, 2008).

Once again, however, it needs to be noted that these data were correlational. Indeed, the alternative models in which appraisals were defined as emanating from particular styles of coping, and thereby mediated the relations between coping and wellbeing were supported. In this sense, various coping styles may be, in part, dispositional and could serve as schemas that guide the appraisals of stressors. As it has been suggested in previous research, it is likely that bidirectional relations exist among the variables so that, not only does appraisal influence coping, but coping may also influence the person's (re)appraisal of what is threatening and whether one has an ability to cope with the stressors (Folkman et al., 1986).

None of the coping styles accounted for the relation between appraisals and support for CF members' careers. However, the test of alternative models supported the possibility that emotional and avoidant coping styles evoked greater appraisals of the demands of military life as threatening and uncontrollable, which in turn prompted lower support for members' career. Moreover, appraisals of threat interacted with deployment phase, to predict ${ }^{19}$ spousal support for members' careers among spouses of post-deployed members, but not among spouses of deployed members. It seems that appraising militarily lifestyle demands as threatening while members are deployed might not motivate them to decrease their willingness to support members' military career. A possible reason is that although they might appraise the demands as threatening, they

\footnotetext{
${ }^{19}$ This interaction was significant for each model in which appraised threat was a mediator, including parenting stressors, relationship stressors, spousal support and organizational support as independent variables.
} 
might feel disloyal to their spouses if they refuse support for their military career, at the time when members are away from home.

The present study may have also been limited to some extent by the measure of coping styles that was used. This scale has only a few items for each coping dimension and might not capture the numerous ways that individuals use to deal with stressors. The measure was selected due to its previous usage with military samples. However, future studies could explore using a more in depth and multidimensional coping measure. Future studies could also benefit from including an emotional approach measure of coping styles, such as expression and processing of emotions. It has been suggested that in certain circumstances an emotional approach, a more adaptive form of emotional coping that involves the use of emotions to actively deal with stressors, may be associated with lower anxiety and depressive symptoms, and with greater life satisfaction (Stanton, Danoff-Burg, Cameron, \& Ellis, 1994; Stanton et al., 2000).

\section{Social Support, Appraisals and Well-being}

Consistent with previous research (Taylor, 2007), higher levels of perceived social support were related to both lower distress and increased satisfaction with life. Of all predictors of satisfaction with life (i.e., stressors, appraisals, coping styles, social support), perceived spousal support was the strongest. Although spousal support has been found to be a powerful and consistent predictor of well-being in other studies (e.g., Pakenham, Chiu, Bursnall, \& Cannon 2007), finding spousal support the strongest predictor of satisfaction with life in the present study might be especially relevant, due to the demands of military lifestyle and the isolation from other sources of support resulting from frequent relocations. 
Social networks have been regarded as an environmental antecedent variable that is followed by mediating processes such as appraisals (Lazarus \& Folkman, 1984). Indeed, the appraisal of the demands of military lifestyle and perceived controllability in dealing with these demands accounted for the relation between perceived spousal support and well-being indicators, as well as support for members' military career (partial mediation). The findings in this study are consistent with previous research that found that perceived social support predicted overall positive appraisal of the future, which in turn predicted depressive symptomatology and satisfaction with life (Karademas, 2006). It would seem that being loved, respected and supported by a significant other decreased the spousal appraisal of the threatening aspects of the military demands and helped them feel capable of dealing with them and controlling them, which ultimately impacted positively spouses' well-being and satisfaction with life, and increased their willingness to support members' career.

Spouses who perceived that the military recognized and respected their contribution (organizational support) appeared to be more likely to appraise military lifestyle demands as less threatening and more controllable. These appraisals in turn fully accounted for the relation between perceived organizational support and satisfaction with life. Not surprisingly, however, compared to organizational support, spousal support had much stronger relation with spousal well-being and their willingness to support members' career. Thus, spousal willingness to support members' career is more dependent on how supportive their military spouses are in return, than on how much the Canadian Forces recognize and respect their contribution. 
Once again, however, it is very possible that stress appraisals can influence one's ability to recognize and acknowledge supportive behaviours of their spouses, as well as those of the organization. Indeed, tests of alternative models assessing the possibility that stress appraisals influenced perceptions of spousal and organizational support were significant. Thus, as with the appraisal coping process more generally, support perceptions may be part of a dynamic system of relations, that cannot be teased apart at a single measurement time.

\section{Social Support and Coping}

It has been proposed that social support as a coping resource contributes to proactive coping (Greenglass, 2002; Schwarzer \& Taubert, 2002; Taylor, 2007), while unsupportive interactions contribute to denial and disengagement coping, which in turn is associated with distress (Song \& Ingram, 2002). Consistent with this research, in the present study, social support (i.e., spousal support and organizational support) was negatively associated with emotional and avoidant coping, while spousal support was positively related to the use of problem solving strategies.

Emotional and avoidant coping partially mediated the relation between spousal support and well-being. Consistent with previous research (e.g., Morris, O'Brien, DeLongis, \& Campbell, 1995), these findings suggest that when support from significant others is lacking, or when one is dissatisfied with the support that $\mathrm{s} / \mathrm{he}$ is provided, individuals may be more likely to engage in maladaptive or counterproductive modes of coping that have negative repercussions for their own well-being. Even when sources of stress originate outside the context of a marital relationship, much of the individual's 
coping with that stress may be undertaken with the support of, and in collaboration with a significant other (DeLongis \& Holtzman, 2005).

The relation between perceived organizational support and spousal satisfaction with life was partially mediated by reduced emotional and avoidant coping. It appears that not feeling recognized and respected for their contributions triggered the spouses to use more emotional and avoidant coping, while it had no effect on the use of problemsolving strategies. This latter finding may be a methodological artifact, in that the measure of organizational support focused on participants' perceptions of recognition and respect from the $\mathrm{CF}$, but did not tap onto their willingness to seek social support or the extent to which it was a source of valuable information or tangible support. These latter dimensions were the aspects of social support that have been found to promote the use of problem-solving strategies (Carpenter \& Scott, 1992).

None of the coping styles accounted for the relations between social support and support for members' career. Although both spousal support and organizational support were associated with spousal willingness to support members' military career, they are evidently motivated by factors other than coping processes. Given the reciprocity proposition (Liang, Krause, \& Bennett, 2001), the link between perceived spousal support (from CF members), perceived organizational support and spousal willingness to support members' military career might be more direct. Indeed, the empirical evidence has shown that when partners realized that their spouses invested considerable coping effort and sought support, partners contributed additional support (Schwarzer \& Weiner, 1991). Likewise, those CF spouses who perceived their military spouse engaging in positive support behaviours, (e.g., respecting their opinions) and those who perceive that 
CF recognizes and values their contribution were more likely to support military members' CF career. They might feel moral obligation and psychological contract that they owe the members and the organization.

Once again, given the correlational nature of the data, alternative causal models were tested and supported. The notion that support and coping may operate in a reciprocal fashion has been suggested previously by DeLongis and Holtzman (2005). They suggested that if potential support providers do not receive cues indicating the need to provide support, they might fail to provide the much-needed support (2005). In the context of the present study, the use of adaptive coping by the spouses (e.g., looking for new information and attempting to change what is causing stress) might be influencing perceptions that the military members are more supportive, which in turn positively influenced spousal well-being. Conversely, the use of negative, hostile coping styles may elicit unsatisfactory support (or more negative perceptions of that support), which may in turn elicit further maladaptive coping responses (Holtzman, Newth, \& DeLongis, 2004). It is interesting that problem-solving strategies did not account for the relation between spousal support and well-being, but that the alternative model was supported. Thus, the specific contextual factors in which coping styles are used must be taken into consideration when determining their efficacy.

\section{General Discussion}

The aim of the present research was to assess the impact that the demands of a military lifestyle have on military families, and the crossover effects of spousal support on CF members. A growing body of research shows the links between family life and organizational outcomes (Smith-Major et al., 2002), work-family conflict and both 
individual (Frone, 2000, Frone et al., 1992; Thomas \& Ganster, 1995) and organizational outcomes (Adams et al., 1996; Jex, 1998). The main criticism of the work-family interface studies is the insufficient attention given to the mechanisms that may explain these relationships (Voydanoff, 2002).

Consistent with previous research (Bourg \& Segal, 1999; Etheridge, 1989; Lakhani, 1995; Orthner, 1990; Orthner \& Pittman, 1986; Rosen et al., 1989; Seboda \& Szoc, 1984; Segal \& Harris, 1993; White et al., 1999; Wilcove et al., 2003), aspects of spousal support (particularly instrumental support) appeared to be related to various military organizational outcomes (Study 1). Extending the past research findings, this study examined the mechanisms by which the spousal support dimensions influenced organizational outcomes. Specifically, members' psychological distress and satisfaction with life accounted for the relation between spousal support for members' career and organizational outcomes.

Given the importance of spouses' support for the CF members' career on both psychological and organizational outcomes, Study 2 evaluated the factors that contributed to the well-being of the military spouses, as well as the factors that influenced their willingness to support the military career of their serving spouses. Some of the stressors to which the military spouses are exposed during the deployment and re-integration phases might be similar to those experienced by many families in which a spouse is in an occupation that requires separations and reunions. Indeed, given the global economy trends, this lifestyle might be more prevalent today. However, given the threats to the very lives of spouses who are on military deployments, which itself can serve as a 
persistent and traumatic stressor for spouses (Kubany et al., 2000), the experience of military spouses may be unique.

How spouses appraised the demands of a military lifestyle (i.e., threatening and/or controllable) accounted for the relation between parenting and relationship stressors experienced during deployment and re-integration, and their well-being, as well as their willingness to support members' military career. Similar to other stress and coping studies (Carver et al., 1989; Lazarus, 1999; Matheson \& Anisman, 2003; Ysseldyl et al., 2009), this study validated the proposition that appraisals and coping processes work together in predicting spousal well-being. Overall, seeing the demands of the military life as threatening and uncontrollable triggered the use of maladaptive coping styles, which further fostered higher psychological distress and lower satisfaction with life. As previously proposed, only when the demands were appraised controllable, was one more likely to use problem solving strategies. However, the coping processes did not account for the relation between appraisals and support for members' career, suggesting that coping, although related to support for members' career, was not the mechanism by which appraisals of military lifestyle affected spousal willingness to support members' career. This finding sheds light on the limited effect of coping on an outcome that has not traditionally been explored in the stress and coping literature, namely, spousal support for the serving member's career, but is nevertheless important motivating mechanism for the spousal well-being. Therefore, future studies should explore other factors that might influence spousal willingness to support members' military career. Given the trends toward globalization, such factors might also be explored for civilian occupations requiring separations and re-unions. 
Past research on the social support - well-being relation was extended in the present study by evaluating the mechanisms by which the social support experiences of the spouses of CF members, in particular perceived spousal support and perceived organizational support, influenced their well-being and willingness to support members' military careers. While both coping and appraisal processes accounted for the relation between both types of support and well-being, only appraisal processes accounted for the relation between spousal support and willingness to support members' career. While these findings highlight the relations between social support, appraisals and coping with the well-being of the spouses, they further demonstrate that the impact of social support on spousal willingness to support members' career was not determined by their coping styles. The latter finding has implications for both the military families and the military organization and should be taken into account when developing family and organizational interventions.

Family - military interface. As was noted earlier, there is a large number of families in the military. Over $60 \%$ of the CF military members are married, and family members outnumber single soldiers by a ratio of three to two (HRMS, 2009). This means that most military members live at the intersection of the military and family institutions. Together, military and family obligations can exceed the service member's ability to adequately meet expectations; they create conflict between the demands of both, and ultimately force the service member to choose. As illustrated in this thesis, the military organization, the spouses, and the behavior of the CF members themselves, all play critical parts in determining whether and to what degree the conflict occurs and how it is resolved. The findings of the present study are in line with research that demonstrates a 
synergy between the military organization, the member, and the family that can positively affect retention and commitment to the unit, the mission, and the military organization (White et al., 1999; Wilcove et al., 2003).

The findings of Study 2 pointed to perceived organizational support as a significant contributor to alleviating work-family stressors and improving spousal wellbeing and support for members' career. Perceived organizational support is, no doubt, influenced by the leadership of the organization. Thus, it could be implied that leadership training related to work and family issues that is provided at the unit and organizational level in the military, may stimulate organizational support to serving members and their families, which in turn would increase spouses' perceived support from the military organization. In addition, the efforts to keep deployed members in contact with their families would work both ways by boosting the morale of the service members while reassuring spouses of their continued support.

A member's ability to view his/her unit and family as complimentary rather than competitive strengthens the belief that he/she is an effective military member and a good family member (Kirkland \& Katz, 1989). The organization should develop the expert knowledge necessary to care for families, accommodate their needs, and understand how it can improve their members' and their families' satisfaction with military life. Furthermore, as this study emphasizes the need to bring marital health to the forefront, a psycho-educational component could be incorporated into the regularly scheduled training days so as to enhance the general awareness of marital health. As well, personnel policy makers might review the existing policies regarding the personnel access to marital strength initiatives. 
Spousal adaptation. In order to have maximum impact in supporting military families, it is necessary to identify the sources of stressors for military spouses, as well as the processes that are involved in dealing with them. Unfortunately, as a number of researchers have noted (e.g., Bowen \& Orthner, 1989; Karney \& Crown, 2007), such an understanding is currently lacking. Yet, there is a widespread consensus that juggling the conflicting demands of military and family life raises significant challenges for military spouses.

This thesis has identified several classes of factors that underlie the coping patterns of families struggling with the demands of military lifestyle. In general, coping resources and strategies associated with the regulation of distress were related to the promotion of life satisfaction of military spouses. Although it was suggested that coping styles would emanate from particular appraisals, it appears that appraisals and coping appear to work in conjunction with one another in a reciprocal manner. Such bidirectionality was also evident when considering the role of support perceptions in appraisals and coping and how these factors influenced well-being. This dynamic pattern of relations has implications for promoting well-being among military spouses and facilitating their adaptation to the military lifestyle. Understanding one's coping styles provides important information about how he/she may react when facing problems, specifically whether he/she tends to approach or avoid problems, lacks confidence in his/her problem solving, or feels emotionally in control. For example, spouse's avoidant strategies may be leading to more perceived threat, and less controllability and ability to deal with the situation. In such cases, coping skills training could be an efficient intervention strategy. These findings contribute to our understanding of what factors 
compel spouses to feel empowered enough to deal with the deployment stressors as opposed to engaging in withdrawal.

Just as support from spouses enhanced the well-being of CF members, CF members' support for their spouses played a very important role for the psychological distress and satisfaction with life of the spouses, thus reciprocity is seen as a determinant of the support provision (Liang et al., 2001). Given that spouses and service members were likely to be experiencing many of the same stressors of deployment, the reciprocity findings are in line with the proposals that empathic understanding is the condition under which social support as a coping mechanism should be most effective (Thoits, 1986). Furthermore, there is empirical evidence that the stress and strain that a partner experiences, affect the individual's well-being and vice versa (e.g., Hammer, Allen, \& Grigsby, 1997; Westman \& Etzion, 1995; Westamn \& Vinokur, 1998). Thus, organizational efforts to reduce the stress and strain of military members should also target their spouses. The interventions for military couples should target building spousal support and helping military couples strengthen their relationships.

Although not specifically addressed in the present study, it could be expected that the quality of the relationship and spousal support might be especially important for the members while they are deployed. Some evidence has been found that suggests the importance of communication during separation (Wood et al., 1995) and of the links between perceived spousal support and personal morale of the members during deployment (Rosen et al., 1989). In this regard, the present study provided strong evidence for a reciprocal relationship, such as the importance of perceived spousal support from deployed members for the spouses left at home (Study 2). 
Clearly a gap in the present investigation was the absence of couple-level data. For example, the couple-level data would provide insight into interpersonal relationships and patterns of family life that the usual focus on personal capacities and support system characteristics that make up much of the existing literature in the area of coping with stress, is not able to provide. Examining the crossover effects of stress and strain using the couple as the unit of analysis may increase our understanding of the complexities of multiple roles in different domains. Therefore, future studies should attempt to examine couple-level data.

In evaluating the relations between spouses' deployment stressors and their wellbeing, it may be useful to consider individual difference variables that evolve from earlier life experiences, such as previous traumatic stress experiences. Previous stressor encounters may make an individual more vulnerable to psychopathology upon subsequent stressor encounters. Finally, there may be limitations to the generalizability of the present study, as the majority of the spouses were women (90\%). Although this is consistent with the military spouses' population, the generalizability of the findings is limited to this population.

\section{Theoretical and Methodological Contributions}

The major contribution of this research stems from its integrative perspective, namely, the simultaneous inclusion and exploration of several levels of variables (personal, interpersonal, and organizational). The findings of this study contribute to the research area that recognizes that work and family are in fact interconnected domains. Specifically, the findings advance work-family studies by assessing the mechanisms by which different dimensions of spousal support may influence key organizational 
outcomes, such as personal morale, organizational commitment, intention to stay and operational readiness. This research points to novel and fruitful directions for future work-family research, as it suggests that it is worth devoting more attention to the role that cognitive appraisal processes play in people's experiences of work-family role combination.

Furthermore, the findings on organizational outcomes might be beneficial to occupational stress researchers and job stress models. What all job stress models have in common is their focus on the organizational work environment. Given the findings of this study, it may be helpful to expand the job stress models beyond the study of job-specific stressors, to include the influence of the family life domain on organizational outcomes. In addition to testing coping-appraisal processes in predicting psychological distress, Study 2 included life satisfaction and support for members' military career as the outcomes of this process. While for the most of the tested models these processes operated similarly, there were some differences that are worth pointing out. As described earlier, key differences were identified in the mediating role of coping in the relation between appraisals or social support and support for members' career. Appraising military lifestyle demands as threatening and uncontrollable, or perceiving a lack of reciprocated support from the CF member or from the military, fostered lower support for members' career independently of the individuals' coping styles. Thus, the spousal capacity to cope with a situation did not alter their support for the CF member's career. Based on the findings of this study, coping processes seem more relevant for individual well-being than for spousal willingness to support members' career. Spousal willingness 
to support members' career might instead be motivated by other factors (e.g., quality of the relationship), which would be worthwhile to examine in future research.

Coping researchers identified methodological issues associated with laboratory studies and suggested that "...because constraints of the laboratory limit researchers' ability to simulate the meaning or duration of serious real-life stressors, we strongly encourage pursuing research under real-life circumstances, with all their complexity" (Folkman \& Moskowitz, 2000, p. 117). In the present study real life stressful events that participants actually experienced were explored, thus contributing to an understanding of the role of appraisals and coping in serious real-life stressful events experienced by serving members and their spouses. Therefore, the findings of the present study validate the laboratory findings and bring further understanding to the limits of coping processes in their role in relational outcomes.

The unique demands of military service (e.g., operational deployments, risk of injury or death, frequent separations and posting) combined with isolation from traditional sources of support such as extended families, close friends and stable community relationships, impinge on every aspect of the lives of serving members and their spouses. These realities are associated with personal and interpersonal stress for military families. Although direct relations between the work-family interface and work, family and individual outcomes have been documented in past research (Frone, 2000; Frone et al., 1992; Thomas \& Ganster, 1995), insufficient attention has been given to the mechanisms that may explain these relationships. The findings of Study 1 pointed to the influential role that spousal support, especially instrumental support, played for both $\mathrm{CF}$ members' well-being, and organizational outcomes. 
Furthermore, research in the work-life area has typically concerned individuals' assessment of work-life conflict created by their own work commitments (i.e., inter-role conflict). Study 2 went beyond this by examining the perceptions of spouses and their appraisals of threatening aspects of military life. It indicated that spousal appraisals of the impact of the military lifestyle on their family and career appeared to be the key to mediating the impact of deployment related stressors (e.g., children's distress) on spousal well-being. Although it was suggested that coping styles would emanate from particular appraisals, it appears that appraisals and coping worked in conjunction with one another in a reciprocal manner. Such bidirectionality was also evident when considering the role of support perceptions in appraisals and coping, and how these factors influenced wellbeing. As discussed earlier, this dynamic pattern of relations has implications for promoting well-being among military spouses and facilitating their adaptation to the military lifestyle. The unique nature of military life sometimes requires the family members to subjugate their own needs and desires in order to meet the military demands, which makes military families unique and deserving of respect and best support possible. 


\section{References}

Abidin, R. R. (1992). The determinants of parenting behavior. Journal of Clinical Child \& Adolescent Psychology, 21, 407-412.

Adams, G. A., Durand, D. B., Burrell, L., Teitelbaum, J. M., Pehrson, K. L., \& Hawkins, J. P. (2005). Direct and indirect effects of operations tempo on outcomes for soldiers and spouses. Military Psychology, 17, 229-246.

Adams, G. A., King, L. A., \& King, D. W. (1996). Relationships of job and family involvement, family social support, and work-family conflict with job and life satisfaction. Journal of Applied Psychology, 81, 411-420.

Adlaf, E. M., Ialomiteanu, A., \& Rehm, J. (2008). CAMH Monitor eReport: Addiction \& mental health indicators among Ontario adults, 1977-2005 (CAMH Research Document Series No. 24). Toronto: Centre for Addiction and Mental Health. Retrieved August 28, 2006, from http://www.camh.net/research/population_life_course.html

Adler, A. B., Bartone, P. T., \& Vaitkus, M. A. (1995). Family stress and adaptation during a US Army Europe peacekeeping deployment (WRAIR/TR-95-0007). Washington, DC: Walter Reed Army Institute of Research.

Adler, A. B., Vaitkus, M. A., \& Martin, J. A. (1996). Combat exposure and posttraumatic stress symptomotology among U.S. soldiers deployed to the Gulf War. Military Psychology, 8, 1-14.

Allen, N. J. (2003). Organizational commitment in the military: A discussion of theory and practice. Military Psychology, 15, 237-253.

Allen, T. D. (2001). Family-supportive work environments: The role of organizational 
perceptions. Journal of Vocational Behavior, 58, 414-435.

Allen, T. D., Herst, D. E., Bruck, C. S., \& Sutton, M. (2000). Consequences associated with work-to-family conflict: A review and agenda for future research. Journal of Occupational Health Psychology, 5, 278-308.

Amiot, C. E., Terry, D. J. Jimmieson, N. L., \& Callan, V. J. (2006). A longitudinal investigation of coping processes during a merger: Implications for job satisfaction and organizational identification. Journal of Management, 32, 552574.

Antonovsky, A. (1974). Conceptual and methodological problems in the study of resistance resources and stressful life events. In B.S. Dohrenwend and B.P. Dohrenwend (Eds.), Stressful Life Events: Their Nature and Effects (pp. 245-58). New York: Wiley.

Arseltine, R. H., \& Kessler, R. C. (1993). Marital disruption and depression in a community sample. Journal of Health and Social Behaviour, 34, 237-251.

Banks, M. H., Clegg, C. W., Jackson, P. R., Kemp, N. J., Stafford, E. M., \& Wall, T. D. (1980). The use of the General Health Questionnaire as an indicator of mental health in occupational studies. Journal of Occupational Psychology, 53, 187-194.

Barrera, M. Jr. (1986). Distinctions between social support concepts, measures, and models. American Journal of Community Psychology, 14, 413-445.

Baumeister, R. F., \& Leary, M. R. (1995). The need to belong: Desire for interpersonal attachments as a fundamental human motivation. Psychological Bulletin, 117, $497-529$. 
Beach, S. R. H., Fincham, F. D., Katz, J., \& Bradbury, T. N. (1996). Social support in marriage: A cognitive perspective. In G. R. Pierce, B. R. Sarason, \& I. G. Sarason (Eds), Handbook of social support and the family (pp. 43-65). New York: Plenum Press.

Beach, S. R. H., Martin, J. K., Blum, T. C., \& Roman, P. M. (1993). Effects of marital and co-worker relationships on negative affect: testing the central role of marriage. American Journal of Family Therapy, 21, 313-323.

Beach, S. R. H., \& O’Leary, K. D. (1993). Marital discord and dysphoria: For whom does the marital relationship predict depressive symptomatology? Journal of Social and Personal Relationships, 10, 405-420.

Beach, S. R. H., Sandeen, E. E., \& O'Leary, K. D. (1990). Depression in marriage: A Model for etiology and treatment. New York: Guilford Press.

Bell, D. B., Scarville, J., \& Quigley, B. (1991). The Army Family Research Program: Origin, purpose, and accomplishments. (ARI Research Note 91-44). Alexandria, VA: US Army Research Institute for the Behavioral and Social Sciences.

Benazon, N. R., \& Coyne, J. C. (2000). Living with a depressed spouse. Journal of Family Psychology, 14, 71-79.

Beutell, N. J., \& Greenhaus, J. H. (1983). Integration of home and non-home roles: Women's conflict and coping behavior. Journal of Applied Psychology, 68, 4348.

Biehl, H., vom Hagen, U., \& Mackewitsch, R. (2000). Die Motivation von soldaten im 
Auslandseinsatz: Ein problemaufris in forschungspraktischer perspektive. In G.

Kuemmel, \& Pruefert, A. (Eds.), Military Sociology. The Richness of a Discipline (pp. 345-378). Baden- Baden.

Black, W. G. (1993). Military-induced family separation: A stress reduction intervention. Social Work, 38, 273-280.

Blount, B. W., Curry, A., \& Lubin, G. I. (1992). Family separations in the military. Military Medicine, 157, 76-80.

Boey, K. W., Chan, K. B., Ko, Y. C., Goh, L. G., \& Lim, G. C. (1997). Work stress and psychological well-being among the nursing profession in Singapore. Singapore Medical Journal, 38, 256-260.

Bolger, N., DeLongis, A., Kessler, R. C., \& Schilling, E. A. (1989). Effects of daily stress on negative mood. Journal of Personality and Social Psychology, 57, 808-818.

Bourg, C., \& Segal, M. W. (1999). The impact of family supportive policies and practices on organizational commitment to the army. Armed Forces \& Society, $25,633-652$.

Bowen, G. L. (1989). Satisfaction with family life in the military. Armed Forces and Society, 15, 571-592.

Bowen, G. L., \& Neenan, P. A. (1989). Organizational attitude toward families and satisfaction with the military as a way of life: Perceptions of civilian spouses of U.S. Army members. Family Perspective, 23, 3-13.

Bowen, G. L., \& Orthner, D. K. (1989). The organization family: Work and family linkages in the U.S. military. New York: Praeger.

Brown, G. W., Andrews, T. H., Adler, Z., \& Bridge, L. (1986). Social support, self- 
esteem and depression. Psychological Medicine, 16, 813-831.

Burke, R. J. (1988). Some antecedents and consequences of work-family conflict. Journal of Social Behavior and Personality, 3, 287-302.

Burnam, M. A., Meridith, L. S., Sherbourne, C. D., Valdez, R. B., \& Vernez, G. (1992). Army families and soldier readiness. Santa Monica, CA: RAND.

Burrell, L. M., Adams, G. A., Durand, D. B., \& Castro, C. A. (2006). The impact of military lifestyle demands on well-being, army, and family outcomes. Armed Forces \& Society, 33, 43-58.

Burrell, L. M., Durand, D. B., \& Fortado, J. (2003). Military community integration and its effect on well-being and retention. Armed Forces \& Society, 30, 7-24.

Carpenter, B. N., \& Scott, S. M. (1992). Interpersonal aspects of coping. In B. N. Carpenter (Ed.), Personal coping: Theory, research, and application (pp. 93109). Westport, CT: Praeger Publishers.

Carver, C. S., Scheier, M. F., \& Weintraub, J. K. (1989). Assessing coping styles: A theoretically based approach. Journal of Personality and Social Psychology, 56, 267-283.

Castro, C. A., Bienvenu, R. V., Huffman, A. H., \& Adler, A. B. (2001). Soldier dimensions and operational readiness in U.S. Army Forces deployed to Kosovo. Frederick, MD: U.S. Army Medical Research \& Materiel Command.

Chang, E. C., \& Strunk, D. R. (1999). Dysphoria: Relations to appraisals, coping, and adjustment. Journal of Counseling Psychology, 46, 99-108.

Cohan, C. L., \& Bradbury, T. N. (1997). Negative life events, marital interaction, and the longitudinal course of newlywed marriage. Journal of Personality and Social 
Psychology, 73, 114-128.

Cohen, S., \& McKay, G. (1984). Social support, stress, and the buffering hypothesis: A theoretical analysis. In A. Baum, S. E. Taylor, and J. E. Singer (Eds.), Handbook of psychology and health: Vol. 4. Social psychological aspects of health (pp.253268). Hillsdale, NJ: Lawrence Erlbaum Associates, Publishers.

Cohen, S., \& Wills, T. A. (1985). Stress, social support, and the buffering hypothesis. Psychological Bulletin, 98, 310-357.

Coolbaugh, K. W., \& Rosenthal, A. (1992). Family separations in the Army (ARI Technical Report No. 964). Alexandria, VA: U.S. Army Research Institute for the Behavioral and Social Sciences.

Conway, V. J., \& Terry, D. J. (1992). Appraised controllability as a moderator of the effectiveness of different coping strategies: A test of the goodness of fit hypothesis. Australian Journal of Psychology, 44, 1-7.

Copeland, D., \& Harbaugh, B. L. (2005). Differences in parenting stress between married and single first time mothers at six to eight weeks after birth. Comprehensive Pediatric Nursing, 28, 139-152.

Coyne, J. C., \& DeLongis, A. (1986). Going beyond social support: The role of social relationships in adaptation. Journal of Consulting and Clinical Psychology, 54, 454-460.

Crnic, K. A., \& Greeneberg, M. T. (1990). Minor parenting stress with young children. Child Development, 61, 1628-1637.

Davila, J., Bradbury, T. N., Cohan, C. L., \& Tochluk, S. (1997). Marital functioning and 
depressive symptoms: Evidence for a stress generation model. Journal of Personality and Social Psychology, 73, 849-861.

Day, A., \& Chamberlain, T. (2006). Committing to your work, spouse, and children: Implications for work family conflict. Journal of Vocational Behavior, $68,116-$ 130.

Dehle, C., Larsen, D., \& Landers, J. E. (2001). Social support in marriage. American Journal of Family Therapy, 29, 307-324.

DeLongis, A., \& Holtzman, S. (2005). Coping in context: the role of stress, social support, and personality in coping. Journal of Personality, 73, 1633-1656.

Desivilya, H. S., \& Gal, R. (1996). Coping with stress in families of servicemen: Searching for win-win solutions to conflict between the family and the military organization. Family Process, 35, 211-225.

Diener, E., Emmons, R. A., Larsen, R. J., \& Griffin, S. (1985). The satisfaction with life scale. Journal of Personality Assessment, 49, 71-75.

Dirkzwager, A. J. E., Bramsen, I., Ader, H., \& van der Ploeg, H. M. (2005). Secondary traumatization in partners and parents of Dutch peacekeeping soldiers. Journal of Family Psychology, 19, 217-226.

Dirkzwager, A. J. E., Bramsen, I., \& van der Ploeg, H. M. (2003). Social support, coping, life events, and posttraumatic stress symptoms among former peacekeepers: A prospective study. Personality and Individual Differences, 34, $1545-1559$.

Dolan, A. B., Huffman, A. H., Adler, A. B., \& Castro, C. A. (2000). USAREUR/7A OPTEMPO and PERSTEMPO Study - In-Progress Report 5 (USAMRU-E 
Technical Brief \# 01-01). Heidelberg, Germany: U.S. Army Medical Research Unit-Europe.

Drummet, A. R., Coleman, M., \& Cable, S. (2003). Military families under stress: Implications for family life education. Family Relations, 52, 279-287.

Dubuis-Stadelmann, E., Fenton, B. T., Ferrero, F., \& Preisig, M. (2001). Spouse similarity for temperament, personality, and psychiatric symptomatology. Personality and Individual Differences, 30, 1095-1112.

Dunkel-Schetter, C., \& Bennett, T. L. (1990). Differentiating the cognitive and behavioral aspects of social support. In B. R. Sarason, I. G. Sarason, \& G. R. Pierce (Eds.), Social support: An interactional view (pp. 267 - 296). New York: Wiley.

Dunkel-Schetter, C., Feinstein, L. G., Taylor, S. E., \& Falke, R. L. (1992). Patterns of coping with cancer. Health Psychology, 11, 79-87.

Eagle, B. W., Miles, E. W., \& Icenogle, M. L. (1997). Interrole conflicts and the permeability of work and family domains: Are there gender differences? The Journal of Vocational Behavior, 50, 168-184.

Eisenberger, R., Fasolo, P. M., \& Davis-LaMastro, V. (1990). Effects of perceived organizational support on employee diligence, innovation, and commitment. Journal of Applied Psychology, 53, 51-59.

Eisenberger, R., Huntington, R., Hutchison, S., \& Sowa, D. (1986). Perceived organizational support. Journal of Applied Psychology, 71, 500-507. Elal, G., \& Krespi M. (1999). Life events, social support and depression in 
haemodialysis patients. Journal of community and Applied Social Psychology, 9, 23-33.

Ender, M. G. (2006). Voices from the backseat: Demands of growing up in military families. In Castro, C.A., Adler, A.B. \& Britt, C. (Eds.), Military life: The psychology of serving in peace and combat. Vol. 3: The military family (pp. 138166). Westport, CT: Praeger Security International.

Endler, N. S., \& Parker, J. D. A. (1990). The multidimensional assessment of coping: A critical evaluation. Journal of Personality and Social Psychology, 58, 844-854.

Etheridge, R. M. (1989). Family factors affecting retention: A Review of the Literature Alexandria, VA: U.S. Army Research Institute for the Behavioral and Social Sciences. Research Report 1511.

Everson, R. B. (2005). Quality of life among army spouses: Parenting and family stress during deployment to Operation Iraqi Freedom. Unpublished masters thesis, Florida State University, Florida, United States of America.

Figley, C. R. (1993). Coping with stressors on the home front. Journal of Social Issues, $49,51-71$.

Fincham, F. D., Harold, G., \& Gano-Phillips, S. (2000). The longitudinal relation between attributions and marital satisfaction: Direction of effects and role of efficacy expectations. Journal of Family Psychology, 14, 267-285.

Folkman, S., \& Lazarus, R. S. (1980). An analysis of coping in a middle aged community sample. Journal of Health and Social Behavior, 21, 219-239.

Folkman, S., \& Lazarus, R. S. (1985). If it changes it must be a process: Study of emotion 
and coping during three stages of a college examination. Journal of Personality and Social Psychology, 48, 150-170.

Folkman, S., \& Lazarus, R. S. (1991). Coping and emotion. In A. Monat \& R. S. Lazarus (Eds.), Stress and coping: An anthology (3rd ed., pp. 207-227). New York: Columbia University Press.

Folkman, S., Lazarus, R. S., Gruen, R. J., \& DeLongis, A. (1986). Appraisal, coping, health status, and psychological symptoms. Journal of Personality and Social Psychology, 30, 571-579.

Folkman, S., \& Moskowitz, J. (2000). Positive affect and the other side of coping. American Psychologist, 55, 647-654.

Frankel, H., Snowden, L. R., \& Nelson, L. S. (1992). Wives' adjustment to military deployment: An empirical evaluation of a family stress model. International Journal of Sociology of the Family, 22, 93-117.

Fricker, R. D. Jr. (2002). The effects of perstempo on officer retention in the US military. Santa Monica, CA: RAND.

Frone, M. R. (2000). Work-Family conflict and employee psychiatric disorders: The national comorbidity survey. Journal of Applied Psychology, 85, 888-895.

Frone, M. R., Russell, M., \& Barnes, G. M. (1996). Work-family conflict, gender, and health-related outcomes: A study of employed parents in two community samples. Journal of Occupational Health Psychology, 1, 57-69.

Frone, M. R., Russell, M., \& Cooper, M. L. (1992). Antecedents and outcomes of workfamily conflict: Testing a model of work-family interface. Journal of Applied Psychology, 77, 65-78. 
Gade, P. A., Tiggle, R. B., \& Schumm, W. R. (2003). The measurement and consequences of military organizational commitment in soldiers and spouses. Military Psychology, 15, 191-207.

Gal, R. (1986). Unit morale: From a theoretical puzzle to an empirical illustration - An Israeli Example. Journal of Applied Social Psychology, 16, 549-564.

Galbaud du Fort, G., Kovess, V., \& Boivin, J. F. (1994). Spouse similarity for psychological distress and well-being: A population study. Psychological Medicine, 24, 431-447.

Ganster, D. E, Fusilier, M. R, \& Mayes, B. T. (1986). Role of social support in the experience of stress at work. Journal of Applied Psychology, 71, 102-110.

Gardner, D. G., Cummings, L. L., Dunham, R. B., \& Pierce, J. L. (1998). Single-item versus multiple-item measurement scales: An empirical comparison. Educational and Psychological Measurement, 58, 898-915.

Gimbel, C., \& Booth, A. (1994). Why does military combat experience adversely affect marital relations? Journal of Marriage and the Family, 56, 691-703.

Greenglass, E. R. (2002). Proactive coping. In E. Frydenberg (Ed.), Beyond coping: Meeting goals, vision, and challenges (pp. 37-62). London: Oxford University Press.

Grieger, T. A., Cozza, S. J., Ursano, R. J., Hoge, C., Martinez, P. E., Engel, C. C., \& Wain, H. J. (2006). Posttraumatic stress disorder and depression in battle-injured soldiers. American Journal of Psychiatry, 163, 1777-1783.

Haber, M. G., Cohen J. L., Lucas, T., \& Baltes, B. B. (2007). The relationship between 
self-reported received and perceived social support: A meta-analytic review. American Journal of Community Psychology, 39, 133-144.

Halverson, R. R., Bliese, P. D., Moore, R. E., \& Castro, C. A. (1995). Psychological well-being and physical health of soldiers deployed for Operation Uphold Democracy: A summary of human dimensions research in Haiti. Washington, DC: Defense Technical Information Center. DTIC ADA298125.

Hammer, L. B., Allen, E., \& Grigsby, T. D. (1997). Work-family conflict in dual-earner couples: Within-individual and crossover effects of work and family. Journal of Vocational Behavior, 50, 185-203.

Hammer, L. B., Cullen, J. C., Marchand, G. C., \& Dezsofi, J. A. (2006). Reducing the negative impact of work-family conflict on military personnel: Individual coping strategies and multilevel interventions. In C. A. Castro, A. B. Adler, \& T. W. Britt (Eds.), Military life: The psychology of serving in peace and combat. Vol. 3: The military family (pp. 220-242). Westport, CT: Praeger Security International.

Hoge, C. W., Castro, C. A., Messer, S. C., McGurk, D., Cotting, D. I., \& Koffman, R.L. (2004). Combat duty in Iraq and Afghanistan, mental health problems, and barriers to care. New England Journal of Medicine, 351, 13-22.

Holahan, C. J., \& Moos, R. H. (1987). Personal and contextual determinants of coping strategies. Journal of Personality and Social Psychology, 52, 946-955.

Holtzman, S., Newth, S., \& DeLongis, A. (2004). The role of social support in coping with daily pain among patients with rheumatoid arthritis. Journal of Health Psychology, 9, 677-695. 
Hosek, J. R., \& Totten, M. (1998). Does perstempo hurt reenlistment? The effect of long or hostile perstempo on reenlistment. Santa Monica, CA: RAND

Hosek, J. R., \& Totten, M. (2002). Serving away from home: How deployments influence reenlistment. Santa Monica, CA: RAND.

House, J. S. (1981).Work stress and social support. Reading, MA: Addison - Wesley.

House, J. S., Landis, K. R., \& Umberson, D. (1988). Social relationships and health. Science, 241, 540-545.

Huffman, A. H., Youngcourt, S. S., \& Castro C. A. (2003). The importance of a family friendly work environment for increasing employee performance and retention. IMTA 2003 Proceedings. Retrieved August $28^{\text {th }} 2009$, from www.internationalmta.org/2003/2003Proceedings/03IMTAproceedings.pdf Human Resource Managament System (HRMS). (2009). Statistical reports. Retrieved August $20^{\text {th }}, 2009$, from http://dhrim04.desc.mil.ca/engraph/statistical_e.asp?cat=1

Hunter, E. J. (1982). Families under the flag: A review of military family literature. New York City, NY: Praeger.

Jensen, P. S., Martin, D., \& Watanabe, H. K. (1996). Children's response to parenting separation during Operation Desert Storm. Journal of American Academy of Child and Adolescent Psychiatry, 35, 433-41.

Jex, S. M. (1998). Stress and job performance: Theory, research, and implications for managerial practice. Thousand Oaks, CA: Sage.

Johnson, S. L., \& Jacob, T. (1997). Marital interactions of depressed men and women. Journal of Consulting and Clinical Psychology, 65, 15-23. 
Joiner, T. E., \& Katz, J. (1999). Contagion of depressive symptoms and mood: Metaanalytic review and explanations from cognitive, behavioral, and interpersonal viewpoints. Clinical Psychology: Science and Practice, 6, 149-164.

Jolly, R. A. (1987). Military man, family man: Crown property? London, UK: Brassey's Defence Publishers.

Judd, C. M., \& Kenny, D. A. (1981). Process analysis: Estimating mediation in treatment evaluations. Evaluation Review, 5, 602-619.

Julien, D., Chartrand, E., Simard, M-C., Bouthillier, D., \& Begin, J. (2003). Conflict, social support, and relationship quality: An observational study of heterosexual, gay male, and lesbian couples' communication. Journal of Family Psychology, $17,419-428$.

Kamp Dush, C. M., Taylor, M. G., \& Kroeger, R. A. (2008). Marital happiness and psychological well-being across the life course. Family Relations, 57, 211-226.

Kanter, R. M. (1977). Work and family in the United States: A critical review and agenda for research and policy. New York: Russell Sage Foundation.

Karademas, E. C. (2006). Self-efficacy, social support and well-being: The mediating role of optimism. Personality and Individual Differences, 40, 1281-1290.

Karney, B. R., \& Crown, J. S. (2007). Families under stress: An assessment of data, theory, and research on marriage and divorce in the military. Santa Monica, CA: RAND Corporation. Retrieved August 20th, 2009, from http://www.rand.org/pubs/monographs/MG599/.

Katz, S. (2002). When the child's illness is life threatening: Impact on the parents. Pediatric Nursing, 28, 453-463. 
Kaul, M., \& Lakey, B. (2003). Where is the support in perceived support? The role of generic relationship satisfaction and enacted support in perceived support's relation to low distress. Journal of Social and Clinical Psychology, 22, 59-78.

Kelley, M. I. (1994). Military-induced separation in relation to maternal adjustment and children's behaviors. Military Psychology, 6, 163-176.

Kelley, M. L., Hock, E., Smith, K. M., Bonney, J. F., \& Gaffney, M. A. (2001). Internalizing and externalizing behavior of children with enlisted Navy mothers experiencing military induced separation. Journal of the American Academy of Child and Adolescent Psychiatry, 40, 464-71.

Keyes, C. L. M., Shmotkin, D., \& Ryff, C. D. (2002). Optimizing well-being: The empirical encounter of two traditions. Journal of Personality and Social Psychology, 82, 1007-1022.

Kirkland, F. R., \& Katz, P. (1989). Combat readiness and the Army family. Military Review, 49, 63-74.

Knox, J., \& Price, D. H. (1995). The changing American military family: Opportunities for social work. Social Service Review, 69, 479-497.

Kobasa, S. C., Maddi, S. R., \& Kahn, S. (1982). Hardiness and health: a prospective study. Journal of Personality and Social Psychology, 42, 168-177.

Kossek, E. E., \& Ozeki, C. (1998). Work-family conflict, policies, and the job life satisfaction relationship: A review and directions for future organizational behavior-human resources research. Journal of Applied Psychology, 83, 139-149.

Kubany, E. S., Haynes, S. N., Leisen, M. B., Owens, J.A., Kaplan, A. S., Watson, S. B. \& Burns, K. (2000). Development and preliminary validation of a brief broad- 
spectrum measure of trauma exposure: the traumatic life events questionnaire. Psychological Assessment, 12, 210-224.

Lakey, B., \& Cohen, S. (2000). Social support theory and measurement. In S. Cohen, L. G. Underwood, \& B. H. Gottlieb (Eds.), Social support measurement and intervention: A guide for health and social scientists (pp. 29-52). London, UK: Oxford University Press.

Lakhani, H. (1995). Reenlistment intentions of citizen soldiers in the U.S. Army. Armed Forces \& Society, 22, 117-130.

Lazarus, R. S. (1981). The stress and coping paradigm. In C. Eisdorfer, D. Cohen, A. Kleinman \& P. Maxim (Eds.), Models for clinical psychopathology, (pp. 177214). New York: Spectrum.

Lazarus, R. S. (1993). Coping theory and research: Past, present and future. Psychosomatic Medicine, 55, 234-247.

Lazarus, R. S. (1999). Stress and emotion. A new synthesis. New York: Springer.

Lazarus, R. S. (2000). Toward better research on stress and coping. American Psychologist, 55, 665-673.

Lazarus, R. S., \& DeLongis, A. (1983). Psychological stress and coping in aging. American Psychologist, 38, 245-254.

Lazarus, R. S., \& Folkman, S. (1984). Stress, appraisal and coping. New York: Springer.

Leavy, R. L. (1983). Social support and psychological disorder: A review. Journal of Community Psychology, 11, 3-21.

Liang, J., Krause, N. M., \& Bennett, J. M. (2001). Social exchange and well-being: Is 
giving better than receiving? Psychology and Aging, 16, 511-523.

Limbert, C. (2004). Psychological well-Being and job satisfaction amongst military personnel on unaccompanied tours: The impact of perceived social support and coping strategies. Military Psychology, 16, 37-51.

Logan, K.V. (1987). The emotional cycle of deployment. U. S. Naval Institute Proceedings, 113, 43-47.

MacDermid, S. M., Olson, T. M., \& Weiss, H. (2002). Supporting military families throughout deployment, Military Family Research Institute. Retrieved January 22, 2007 , from http://www.cfs.purdue.edu/mfri/pages/research/MFRI_Brief_Deployment_Suppor t.pdf

Martin, T. N., \& O'Laughlin, M. S. (1984). Predictors of organizational commitment: The study of part-time army reservists. Journal of Vocational Behavior, 25, 270283.

Martin, J. A., Vaitkus, M. A., Johnson, M. D, Mikolajek, L. M., \& Ray, D. L. (1996). Deployment from Europe: The family perspective. In R. J. Ursano \& A. E. Norwood (Eds.), Emotional aftermath of the Persian Gulf War: Veterans, families, communities, and nations (pp. 227-250). Washington, DC: American Psychiatric Press.

Matheson, K., \& Anisman, H. (2003). Systems of coping associated with dysphoria, anxiety and depressive illness: A multivariate profile perspective. Stress, 6, 223234.

Matheson, K., Skomorovsky, A., Fiocco, A., \& Anisman, H. (2007). The limits of 
'adaptive' coping: Well-being and mood reactions to stressors among women in abusive dating relationships. Stress, 10, 75-91.

McCreary, D. R., Thompson, M. M., \& Pastò, L. (2003). The impact of family concerns on the predeployment well-being of Canadian Forces personnel. Canadian Journal of Police and Security Services, 1, 33-40.

McCubbin, H. I. (1998). African-American military families: Military families in foreign environments. In H. I. McCubbin, E. A. Thompson, A. I. Thompson, \& J. A. Futrell (Eds.), Resiliency in African-American families (pp. 67-97). Thousand Oaks, CA: Sage.

McCubbin, H. I., \& Dahl, B. B. (1976). Prolonged family separation in the military: A longitudinal study. In H. McCubbin, B. B. Dahl, \& E. Hunter (Eds.), Families in the Military System (pp. 112-145). Beverly Hills, CA: Sage.

Medway, F., David, K., Cafferty, T., \& Chappell, K. (1995). Family disruption and adult attachment correlates of spouse and child reaction to separation and reunion during operation Desert Storm. Journal of Social and Clinical Psychology, 14, 97118.

Mikulincer, M., \& Florian, V. (1995). Appraisal of and coping with a real-life stressful situation: The contribution of attachment styles. Society for Personality and Social Psychology, 21, 404-414.

Morris, J., O'Brien, T. B., DeLongis, A., \& Campbell, J. D. (1995). Coping and social support in step-families. Paper presented at the annual meeting of the American Psychological Association, New York. 
Mowday, R. T, Porter, L., \& Steers, R. M. (1982). Employee-organization linkages:

The psychology of commitment, absenteeism, and turnover. New York: Academic Press.

Murphy, P. J., Farley, K. M. J., Dobreva-Martinova, T., \& Gingras, C. (1997). Stress in peace support operations: Recent Canadian experiences. Paper presented to the NATO Research \& Technology Organization Aerospace Medical Panel Symposium on Aeromedical Support Issues in Contingency Operations, Rotterdam, Netherlands.

Nachmias, D., \& Nachmias, C. (1987). Research methods in the social sciences $\left(3^{\text {rd }}\right.$ ed.). New York: St. Martin's.

Netemeyer, R. G., Boles, J. S., \& McMurrian, R. (1996). Development and validation of work-family conflict and family-work conflict scales. Journal of Applied Psychology, 81, 400-410.

Nice, D. S. (1981). A longitudinal analysis of Navy family separation. Navy Personnel Research and Development Center, San Diego, CA.

Norton, R. (1983). Measuring marital quality. Journal of Marriage and the Family, 45, $141-151$.

O'Brien, T. B., \& DeLongis, A. (1997). Coping with chronic stress: An interpersonal perspective. In B. H. Gottlieb (Ed.), Coping with chronic stress (pp. 161-190). New York: Plenum Publishing Corporation.

Oliver, L. W. (1991). The relationship of family factors to readiness: What we know, what we need to know and what we can tell policy makers. Alexandria, VA: U.S. Army Research Institute. 
Orthner, D. K. (1990). Family Impacts on the Retention of Military Personnel. Paper presented at the Military Family Research Review Conference, Washington, D.C.

Orthner, D. K., \& Pittman, J. (1986). Family contributions to work commitments. Journal of Marriage and the Family 48, 573-581.

Pakenham, K. I., Chiu, J., Bursnall, S., \& Cannon, T. (2007). Relations between social support, appraisal and coping and both positive and negative outcomes in young careers. Journal of Health Psychology, 12, 89-102.

Parasuraman, S., Purohit, Y. S., \& Godshalk, V. M. (1996). Work and family variables, entrepreneurial career success and psychological well-being. Journal of Vocational Behavior, 48, 275-300.

Parry, G., \& Shapiro, D. A. (1986). Social support and life events in working class women: Stress buffering or independent effects? Archives of General Psychiatry, $43,315-323$.

Pavlicin, K. (2003). Surviving deployment: A guide for military families. Saint Paul, MN: Elva Resa.

Pavot, W., \& Diener, E. (1993). Review of the Satisfaction with Life Scale. Psychological Assessment, 5, 164-172.

Pavot, W., \& Diener, E. (2008). The Satisfaction with Life Scale and the emerging construct of life satisfaction. Journal of Positive Psychology: Dedicated to furthering research and promoting good practice, 3, 137-152.

Peacock, E. J., \& Wong, P. T. P. (1990). Measuring life stress: The stress appraisal measure (SAM): A multidimensional approach to cognitive appraisal. Stress Medicine, 6, 227-236. 
Perry-Jenkins, M., Repetti, R., \& Crouter, A. C. (2000). Work and family in the 1990s. Journal of Marriage and the Family, 62, $27-63$.

Pierce M. M., \& Luchsinger M. L. (1986). Psychological distress among air force wives. In: Proceedings of the 10th Symposium on Psychology in the Department of Defense (pp 643-648). Colorado Springs, Col: US Air Force Academy.

Pincus, S. H., House, R., Christensen, J., \& Adler, L. E. (2001). The emotional cycle of deployment: A military family perspective. Army Medical Department Journal, 6, $15-23$.

Pittman, J. F., Kerpelman, J. L., \& McFadyen, J. M. (2004). Internal and external adaptation in army families: Lessons from Operations Desert Shield and Desert Storm. Family Relations, 53, 249-260.

Pittman, J. F., \& Orthner, D. K. (1988). Predictors of spouse support for the work communities. Journal of Marriage and the Family, 50, 335-348.

Pleck, J. H. (1997). Paternal involvement: Levels, sources, and consequences. In M. E. Lamb (Ed.) The role of the father in child development (pp. 66-103). New York: John Wiley \& Sons.

Pliske, R. M. (1988). Families and readiness: An examination of the 1985 Department of Defense survey of enlisted personnel. Alexandria, VA: U.S. Army Research Institute for the Behavioral and Social Sciences.

Poortman, A. (2005). How work affects divorce: The mediating role of financial and time pressures. Journal of Family Issues, 26, 168-195.

Portello, J. Y., \& Long, B. C. (2001). Appraisals and coping with workplace 
interpersonal stress: A model for women managers. Journal of Counseling Psychology, 48, 144-156.

Potts, P. (1988). Home sweet home? Air Force Times, 61-67.

Preacher, K. J., \& Hayes, A. F. (2008). Asymptotic and resampling strategies for assessing and comparing indirect effects in multiple mediator models. Behavior Research Methods, 40, 879-891.

Preacher, K. J., Rucker, D. D., \& Hayes, A. F. (2007). Addressing moderated mediation hypotheses: Theory, methods, and prescriptions. Multivariate Behavioral Research, 42, 185-227.

Presser, H. B. (2000). Non-standard work schedules and marital instability. Journal of Marriage and the Family, 62, 93-110.

Proulx, C. M., Helms, H. M., \& Buehler, C. (2007). Marital quality and personal wellbeing: A meta-analysis. Journal of Marriage and Family, 69, 576-593.

Rogers, S. J., \& May, D. C. (2003). Spillover between marital quality and job satisfaction: Long-term patterns and gender differences. Journal of Marriage and Family, 65, 482-495.

Rohall, D. E., Segal, M. W., \& Segal, D. R. (1999). Examining the importance of organizational supports on family adjustment to army life in a period of increasing separation. Journal of Political and Military Sociology, 27, 49-65.

Roseman, I. J. (1991). Appraisal determinants of discrete emotions. Cognition and Emotion, 5, 161-200.

Rosen, L. N., \& Durand, D. B. (1995). The family factor and retention among married soldiers deployed in Operation Desert Storm. Military Psychology, 7, 221-234. 
Rosen, L. N., \& Durand, D.B. (2000). Coping with the unique demands of military family life. In J. A. Martin, L. N. Rosen, \& L. R. Sparacino (Eds.), The Military Family: A Practice Guide for Human Service Providers (pp. 55-72). Westport, CT: Praeger Publishers.

Rosen, L. N., \& Martin, L. (1996). Childhood antecedents of psychological adaptation to military life, Military Medicine, 161, 665-668.

Rosen, L. N., Moghadam, L. Z., \& Vaitkus, M. A. (1989). The military family's influence on soldiers' personal morale: A path analytic model. Military Psychology, 1, 201-213.

Rosen, L. N., Teitelbaum, J. M., \& Westhuis, D. J. (1993). Children's reaction to the Desert Storm Deployment: Initial findings from a survey of Army families. Military Medicine, 158, 465-469.

Sarason, I. G., Sarason, B. R., \& Pierce, G. R. (1990). Anxiety, cognitive interference, and performance: Communication, cognition and anxiety. Journal of Social Behavior and Personality, 5, 1-18.

Schumm, W. R., Bell, D. B., Ender, M. G., \& Rice, R. E. (2004). Expectations, use, and evaluation of communication media among deployed peacekeepers. Armed Forces \& Society, 30, 649-662.

Schwarzer, R., \& Taubert, S. (2002). Tenacious goal pursuits and striving toward personal growth: Proactive coping. In E. Frydenberg (Ed.), Beyond coping: Meeting goals, vision, and challenges (pp. 19-35). London: Oxford University Press.

Schwarzer, R., \& Weiner, B. (1991). Stigma controllability and coping as predictors of 
emotions and social support. Journal of Social and Personal Relationships, 8 , 133-140.

Seboda, B. L., \& Szoc, R. (1984). Family factors critical to the retention of Naval personnel: The link between retention intention and retention behavior. Columbia, Md: Technicality Westinghouse Public Applied Systems.

Segal, M. W. (1986). The military and the family as greedy institutions. The Armed Forces \& Society, 1, 9-38.

Segal, M. W. (1989). The nature of work and family linkages: A theoretical perspective. In G. L. Bowen, \& D. K. Orthner (Eds ), The organization family: Work and family linkages in the US military (pp. 3-36). New York: Praeger.

Segal, M. W. (2006). Military family research. In A. D. Mangelsdorff (Ed.), Psychology in the service of national security. Washington, DC: American Psychological Association.

Segal, M. W., \& Harris, J. J. (1993). What we know about Army families. Alexandria VA: U.S. Army Research Institute for the Behavioral and Social Sciences.

Sharpe, J., \& English, A. (2006). Observations on the association between operational readiness and personal readiness in the Canadian Forces. Defence R\&D Canada - Toronto.

Shore, L. M., \& Tetrick, L. E. (1991).A construct validity study of the survey of perceived organizational support. Journal of Applied Psychology, 76, 637-643.

Siebler, P. (2003). Supporting Australian Defence Force peacekeepers and their families: The case of East Timor. Directorate of Strategic Personnel Planning and Research. Retrieved August 20th, 2009, from 
http://www.defence.gov.au/dpe/dpe_site/publications/SupportingADFpeacekeepe rs.pdf

Smith, C. A., \& Lazarus, R. S. (1993). Appraisal components, core relational themes, and the emotions. Cognition and Emotion, 7, 233-269.

Smith-Major, V. L., Klein, K. J., \& Ehrhart, M. G. (2002). Work time, work interference with family, and psychological distress. Journal of Applied Psychology, 87, 427436.

Solomon, Z., Margalit, C., Waysman, M., \& Bleich, A. (1991). In the shadow of the Gulf War: Psychological distress, social support and coping among Israeli soldiers in a high risk area. Israeli Journal of Medical Science, 27, 687-695.

Solomon, Z., \& Mikulincer, M. (1990). Life events and combat-related posttraumatic stress disorder: The intervening role of locus of control and social support. Military Psychology, 2, 241-256.

Song, Y. S., \& Ingram, K. M. (2002). Unsupportive social interactions, availability of social support, and coping: Their relationship to mood disturbance among African Americans living with HIV. Journal of Social and Personal Relationships, 19, 6785.

Stafford, E. M., \& Grady, B. A. (2003). Military family support. Pediatric Annals, 32, $110-115$.

Stamper, C. L., \& Johlke, M. C. (2003). The impact of perceived organizational support on the relationship between boundary spanner role stress and work outcomes. Journal of Management, 29, 569-588.

Stanley, J., Segal, M. W., \& Laughton, C. J. (1990). Grass roots family action and 
military policy responses. Marriage and Family Review, 15, 207-223.

Stanton, A. L., Danoff-Burg, S., Cameron, C. L., Bishop, M. Collins, C. A., Kirk, S. B, Sworowski, L. A., \& Twillman, R. (2000). Emotionally expressive coping predicts psychological and physical adjustment to breast cancer. Journal of Consulting and Clinical Psychology, 68, 875-882.

Stanton, A. L., Danoff-Burg, S., Cameron, C. L., \& Ellis, A. P. (1994). Coping through emotional approach: Problems of conceptualization and confounding. Journal of Personality and Social Psychology, 66, 350-362.

Statistics Canada. (2007). Canadian community health survey. Table 105-0501 - Health indicator profile, annual estimates, by age group and sex, Canada, provinces, territories, health regions (2007 boundaries) and peer groups, occasional. CANSIM (database). Retrieved August 20th, 2009, from $\mathrm{http} / / /$ cansim2.statcan.gc.ca/cgi-win/cnsmcgi.exe?Lang=E\&CNSM-Fi=CII/CII_1eng.htm.

Sticha, P. J., Sadacca, R., DiFazio, A. S., \& Knerr, C. M. (1999). Personnel tempo: Definition, measurement, and effects on retention, readiness, and quality of life. Alexandria, Virginia: US Army Research Institute for the Behavioral and Social Sciences. ARI Contractor Report 99- 04.

Suchet, M., \& Barling, J. (1986). Employed mothers: Interrole conflict, spouse support and marital functioning. Journal of Occupational Behaviour, 7, 167-178.

Sudom, K., \& Dursun, S. (2006). The Relationship Study: Qualitative Findings. DRDC Centre for Operational Research and Analysis. Ottawa, Canada: Defence Research \& Development Canada. 
Tak, Y. R., \& McCubbin, M. (2002). Family stress, perceived social support and coping following the diagnosis of a child's congenital heart disease. Journal of Advanced Nursing, 39, 190-198.

Taylor, S. E. (2007). Social support. In H. S. Friedman and R. C. Silver (Eds.), Foundations of Health Psychology (pp. 145-171). New York, NY: Oxford University Press.

Tamres, L. K., Janicki, D., \& Helgeson, V. S. (2002). Sex differences in coping behavior: A meta-analytic review and an examination of relative coping. Personality and Social Psychology Review, 6, 2-30.

Teitelbaum, J. M. (1992). ODS and post-ODS divorce and child behavioral problems. Paper Presented at the Office of the Secretary of Defense Family Research in-Progress Review, the Pentagon, Washington, DC.

Terry, D. J. (1992). Stress, coping and coping resources as correlates of adaptation in myocardial infarction patients. British Journal of Clinical Psychology, 31, 215225.

Terry, D. J. (1994). Determinants of coping: The role of stable and situational factors. Journal of Personality and Social Psychology, 66, 895-910.

Terry, D. J., Callan, V. J., \& Sartori, G. (1996). Employee adjustment to an organizational merger: Stress, coping and intergroup differences. Stress Medicine, $12,105-122$.

Terry, D. J., Tonge, L., \& Callan, V. J. (1995). Employee adjustment to stress: The role of coping resources, situational factors and coping responses. Anxiety, Stress and Coping, 8, 1-24. 
Thoits, P. A. (1986). Social support as coping assistance. Journal of Consulting and Clinical Psychology, 54, 416-423.

Thomas, L. T., \& Ganster, D. C. (1995). Impact of family supportive work variables on work-family conflict and strain: A control perspective. Journal of Applied Psychology, 80, 6-15.

Tower, R. B., \& Kasl, S. V. (1995). Depressive symptoms across older spouses and the moderating effect of marital closeness. Psychology and Aging, 10, 625-638.

Tremble, T. R., Payne, S. C., Finch, J. F., \& Bullis, R. C. (2003). Opening organizational archives to research: Analog measures of organizational commitment. Military Psychology, 15, 167- 190.

Tucker, J. S., Sinclair, R. R., \& Thomas, J. L. (2005). The multilevel effects of occupational stressors on soldier's well-being, organizational attachment, and readiness. Journal of Occupational Health Psychology, 10, 276-299.

US Army Medical Research Unit-Europe. (2000). Consensus work group: Common survey measures. Based on the proceedings of the work group discussions held on 27-28 November 2000, in Heidelberg, Germany.

Valentiner, D. P., Holahan, C. J., \& Moos, R. H. (1994). Social support, appraisals of event controllability, and coping: An integrative model. Journal of Personality and Social Psychology, 66, 1094-1102.

Van Breda, A. D. (1999). Developing resilience to routine separations: An occupational social work intervention. Families in Society, 80, 597-605.

Van Breda, A. D. (2001). Resilience Theory: A literature review. South African Military Health Service, Military Psychological Institute, Social Work 
Research \& Development.

Van Vranken, E. W., Jellen, L. K., Knudson, K. H. M., Marlowe, D. H., \& Segal, M. W. (1984). The impact of deployment separation on Army families. Washington, DC: Department of Military Psychiatry, Walter Reed Army Institute of Research.

Vernez, G., \& Zellman, G. (1987). Families and mission: A review of the effects of family factors on Army attrition, retention, and readiness. Santa Monica, CA: RAND Corporation.

Villeneuve, M., Dobreva-Martinova, T., Little, G., \& Izzo, N. R. (2000). Military unit effectiveness and readiness: A theoretical framework. Paper presented at the Human in Command Conference, Breda, the Netherlands.

Vitaliano, P. P., DeWolfe, D. J., Mainro, R. D., Russo, J., \& Katon, W. (1990). Appraised changeability of a stressor as a modifier of the relationship between coping and depression: A test of the hypothesis of fit. Journal of Personality and Social Psychology, 59, 582-592.

Voydanoff, P. (2002). Linkages between the work-family interface and work, family, and individual outcomes. Journal of Family Issues, 23, 138-164.

Wanous, J. P., \& Hudy, M. J. (2001). Single-item reliability: A replication and extension. Organizational Research Methods, 4, 361-375.

Wanous, J. P., Reichers, A. E., \& Hudy, M. J. (1997). Overall job satisfaction: How good are single-item measures? Journal of Applied Psychology, 82, 247-252.

Weins, T. W., \& Boss, P. (2006). Maintaining family resiliency before, during and after 
military separation. In C.A. Castro, A. B. Adler, \& C. A. Britt (Eds.), Military life: The psychology of serving in peace and combat. Vol. 3: The military family (pp. 13-38). Westport, CT: Praeger Security International.

West, S. G., \& Aiken, L. S. (1997). Towards understanding individual effects in multiple component prevention programs: Design and analysis strategies. In K. Bryant, M. Windle, \& S. West (Eds.), The science of prevention: Methodological advances from alcohol and substance abuse research (pp. 167-209). Washington, DC: American Psychological Association.

Westhius, D. J. (1999). Working with military families during deployments. In J. Daley (Ed.), Social work practice in the military (pp. 217-233). New York: Hawthorne.

Westman, M., \& Etzion, D. (1995). Crossover of stress, strain and resources from one spouse to another. Journal of Organizational Behavior, 16, 169-181.

Westman, M., \& Vinokur, A. D. (1998). Unraveling the Relationship of Distress Levels Within Couples: Common Stressors, Empathic Reactions, or Crossover via Social Interaction? Human Relations, 51, 137-156.

Wethington, E., \& Kessler, R. C. (1986). Perceived support, received support, and adjustment to stressful life events. Journal of Health and Social Behavior, 27, 7889.

Wexler, H. K., \& McGrath, E. (1991). Family member stress reactions to military involvement separation. Psychotherapy, 28, 515-519.

Whisman, M. A., Uebelacker, L. A., \& Weinstock, L. M. (2004). Psychopathology and marital satisfaction: The importance of evaluating both partners. Journal of Consulting and Clinical Psychology, 72, 830-838. 
White, M.A., Baker, H. G., \& Wolosin, D. A. (1999). Quality of life in the Marine Corps: A comparison between 1993 and 1998. San Diego, CA: Navy Personnel Research and Development Center.

Wilcove, G. L., Schwerin, M. J., \& Wolosin, D. G. (2003). An exploratory model of quality of life in the U.S. Navy. Military Psychology, 15, 133-152.

Williams, K. (2003). Has the future of marriage arrived? A contemporary examination of gender, marriage, and psychological well-being. Journal of Health and Social Behavior, 44, 470-487.

Wills, T. A. (1985). Supportive functions of interpersonal relationships. In S. Cohen \& S. S. Leonard (Eds.), Social support and health (pp. 61-82). San Diego, CA: Academic Press, Inc.

Wisecarver, M. M., Cracraft, M. L., \& Heffner, T. S. (2006). Deployment consequences: a review of the literature and integration of findings into a model of retention. U.S. Army Research Institute for the Behavioral and Social Sciences.

Wood, M. (2005). Bootstrapped confidence intervals as an approach to statistical inference. Organizational Research Methods, 8, 454-470.

Wood, S., Scarville, J., \& Gravino, K. S. (1995). Waiting wives: Separation and reunion among army wives. Armed Forces and Society, 21, 217-232.

Wright, K. M., Burrell, L. M., Schroeder, E. D., \& Thomas, J. L. (2006). Military spouses: Coping with the fear and the reality of service member injury and death. In C.A. Castro, A. B. Adler, \& C. A. Britt (Eds.), Military life: The psychology of serving in peace and combat. Vol 3: The military family, (pp. 64-90). Westport, CT: Praeger Security International. 
Ysseldyk, R., Matheson, K., \& Anisman, H. (2009). Forgiveness and the appraisal-coping process in response to relationship conflicts: Implications for depressive symptoms. The International Journal on the Biology of Stress, 12, 152-166.

Yueng-Hsiang, H., Shaw, W. S., \& Chen, P. Y. (2004). Worker perceptions of organizational support and return-to-work policy: Associations with post-injury job satisfaction. Work, 23, 225-232. 


\section{Appendix A: Study 1 Measures \\ Relationship satisfaction}

To what extent do you agree or disagree that the following statements describe your current marriage or intimate partnership.

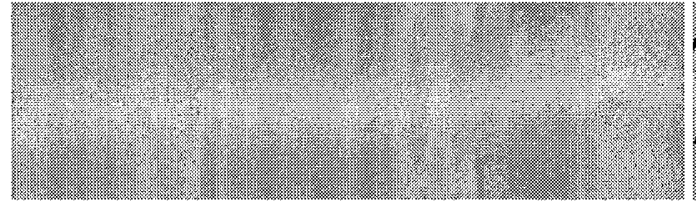

We have a good marriage/partnership.

My relationship with my spouse/partner

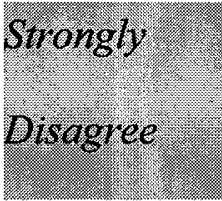

O

$\mathrm{O}$

$\mathrm{O}$
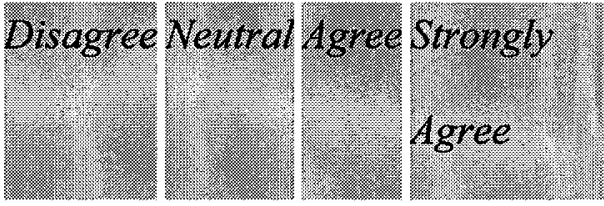

O

O $\quad 0$

O

$\mathrm{O}$

$\mathrm{O}$

$\mathrm{O}$ is very stable.

Our marriage/partnership is strong.

My relationship with my spouse/partner

makes me happy.
$\mathrm{O}$

$\mathrm{O}$
$\mathrm{O}$

$\mathrm{O}$
$\mathrm{O}$

O

$\mathrm{O} \quad \mathrm{O}$
0

$\mathrm{O}$
I really feel like a part of a team with

o my spouse/partner.

Everything considered, I am happy in my marriage/partnership. 
Perceived spousal (emotional) support

Each of the following statements might describe your spouse or partner and the nature of your relationship. To what extent do you agree or disagree that each statement describes your partner's behaviour with you.

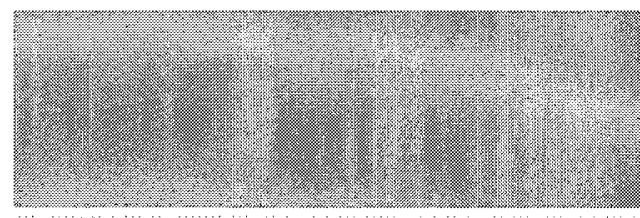

Talks over his/her problems with me

Is always trying to change me

Respects my opinions

Gives me as much freedom as I want

Acts as though I am in the way

Takes time to be romantic with me

Wants to have the last word on how we spend our time

Makes fun of me

O

0

o

O

o

$\mathrm{O}$

o

$\mathrm{O}$ o

o

O

O

$\mathrm{O}$
Strongly

Agree

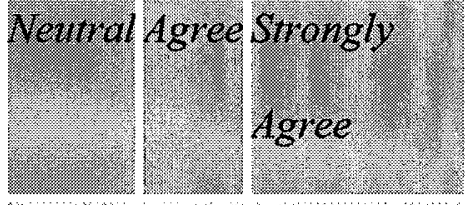

o $\quad 0$

O

$\mathrm{O}$

O
O

$\mathrm{O}$

O $\quad 0 \quad 0$

O

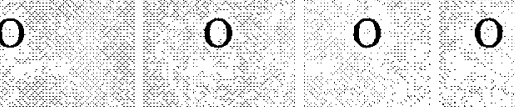

$\sqrt{2}$

$\mathrm{O}$

$\mathrm{O}$

$\mathrm{O}$

Has a good time with me

O

Finds fault with me

$\mathrm{O}$

o

o

O 
Perceived spousal support for member's military career

How supportive is your spouse or intimate partner toward each of the following?

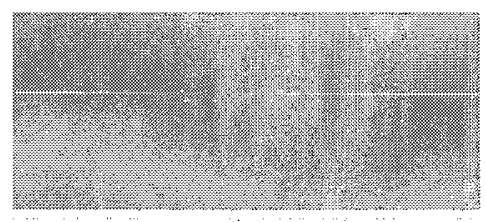

Your current service in the

CF

You pursuing a long-term career in the $\mathrm{CF}$

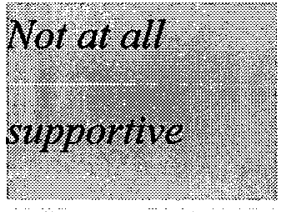

O

$\mathrm{O}$
$\mathrm{O}$

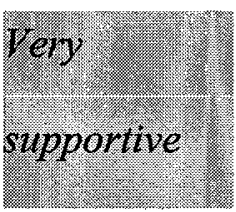

$\mathrm{O}$

.

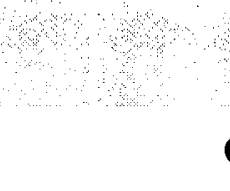

$\mathrm{O}$

$\mathrm{O}$

O

O

O

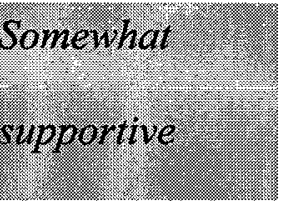

as

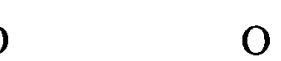


General Health Questionnaire (GHQ-12)

Have you recently:
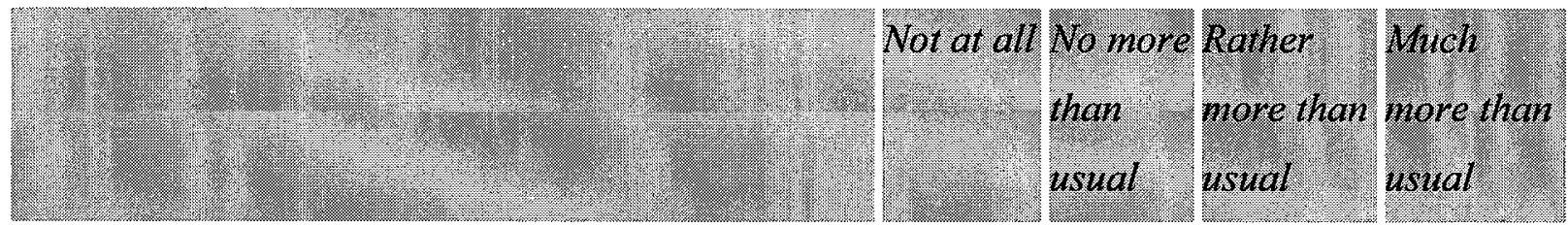

been able to concentrate on what you're doing?

O

\begin{abstract}
$\mathrm{O}$
\end{abstract}
$\mathrm{O}$

$\mathrm{O}$

lost much sleep over worry?

O

$\mathrm{O}$

$\mathrm{O}$

$\mathrm{O}$

felt that you are playing a useful part in things?

0

0

$\mathbf{O}$

felt capable of making decisions about things?

O O

$\mathrm{O}$

$\mathrm{O}$

felt constantly under strain?

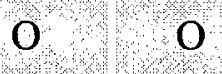

\title{
$\mathrm{O}$
}

$\mathrm{O}$

felt that you couldn't overcome your difficulties?

$\mathrm{O}$

o

O

O

been able to enjoy your normal day-to-day

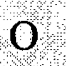

$\mathrm{O}$

$\mathrm{O}$

$\mathrm{O}$ activities?

been able to face up to your problems?

O $\quad \mathrm{O}$

O

$\mathrm{O}$

been feeling unhappy and depressed?

O

0.0

been losing confidence in yourself?

$\mathrm{O}$

$\mathrm{O}$

$\mathrm{O}$

$\mathrm{O}$

been thinking of yourself as a worthless person?

0

$\mathrm{O}$

$\mathrm{O}$

been feeling reasonably happy, all things

$\mathbf{O}$

\begin{abstract}
$\mathrm{O}$
\end{abstract}
O

$\mathrm{O}$ considered? 


\section{Satisfaction with Life Scale (SWLS)}

To what extent do you agree or disagree that each of the following statements describes you.
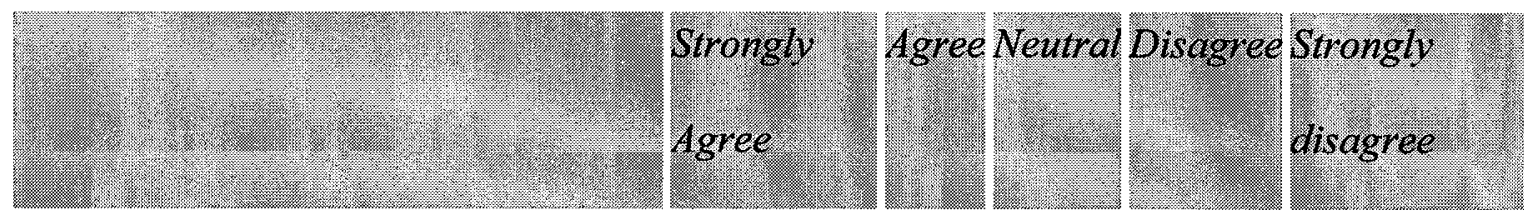

In most ways my life is close to my

0

$\mathrm{O} \quad \mathrm{O}$

$\mathrm{O}$

$\mathrm{O}$

ideal.

The conditions of my life are

$\mathrm{O}$ excellent.

I am satisfied with my life.

So far I have gotten the important things I want in my life.

If I could live my life over, I would change almost nothing. $\begin{array}{llll}0 & 0 & 0 & 0\end{array}$

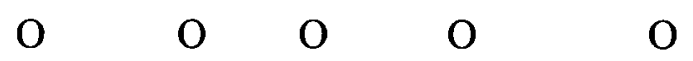

$\mathrm{O}$

O
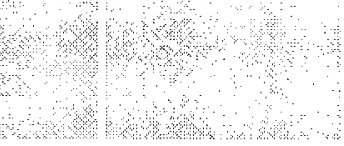


\section{Soldier Commitment Scale}

To what extent do you agree or disagree with the following statements about military service.

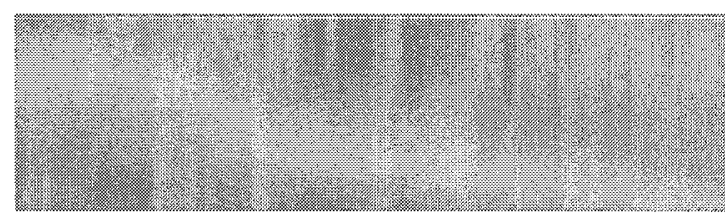

I am proud to be in the Canadian Forces.

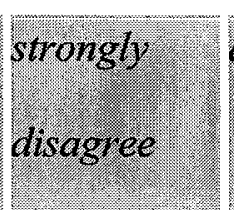

O

$\mathrm{O}$

$\mathrm{O}$

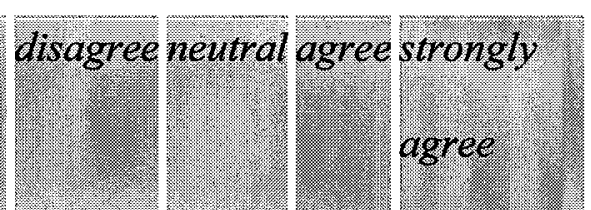

o o

00

O O O

$\mathrm{O}$
I identify with my field of duties.

I am making an essential contribution to my unit's performance of its function. o

$\mathrm{O}$

I am supporting the CF's mission.

I would recommend to my friends that they join the CF.

If it were possible, I would leave the CF immediately,

Above all, service in the $\mathrm{CF}$ is a declaration of loyalty to my country. o

o

o

o

O

0 0

O

o

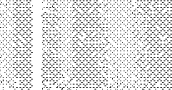

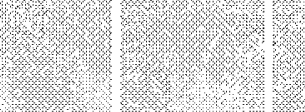

O
O 0

$\mathrm{O}$

$\mathrm{O}$

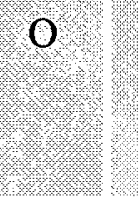

O

O 


\section{Personal Morale}

How would you describe each of the following:
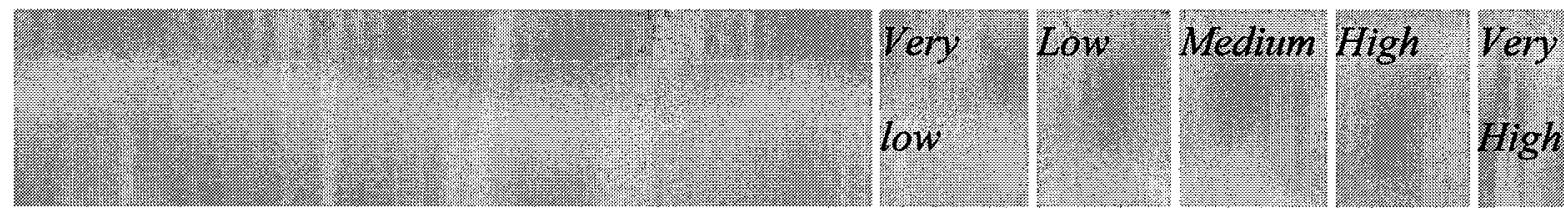

Your personal morale.

o

$\mathrm{O}$

o

$\mathrm{O}$

$\mathrm{O}$

Your level of burnout.

$\mathrm{O}$

$\mathrm{O}$

$\mathrm{O}$

$\mathrm{O}$

$\mathrm{O}$

Your level of motivation.

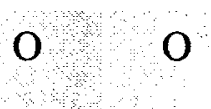

0

o

$\mathrm{O}$

Your level of energy.

$\mathrm{O}$

O

O

o

O 


\section{Willingness to deploy}

Which of the following best describes your willingness to deploy on international operations or missions? Please read all the responses before you select the one that most closely reflects your position today.

O I am ready and willing to deploy

O I would deploy if ordered to do so

O I would try to avoid deploying

O I would refuse to deploy 


\section{Turnover intentions}

Which of the following best describes your current military career intentions?

O Definitely stay in until retirement if I can

O Probably stay in until retirement

O Stay in until my 20 years are up

O Definitely stay in beyond my present term of service, but not necessarily until retirement

O Undecided about whether to stay after completion of my current term of service

O Probably leave upon completion of my current term of service

O Definitely will get out of the $\mathrm{CF}$ as soon as possible 
Appendix B: Measures New to Study 2

\section{Parenting Stressors}

Children respond to deployment in different ways. Have you observed the following in your child or among one or more of your children during a deployment?
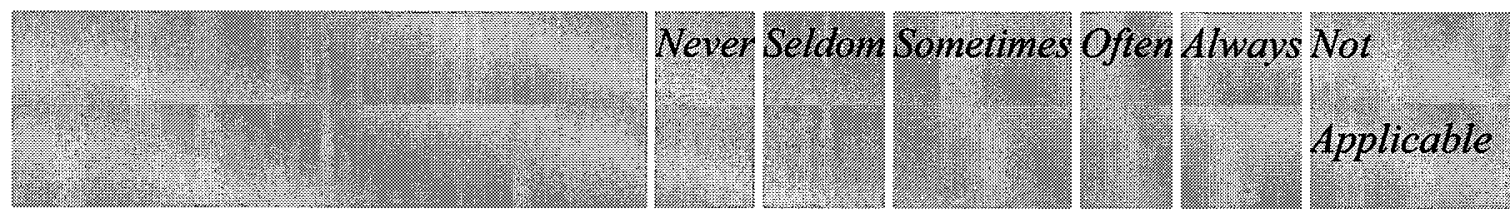

"Acting out"

0.0

$\mathrm{O}$

o

$\mathrm{O}$

o

Decline in school performance

O O

O

O O

O

Improvement in school performance

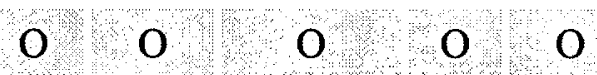

More "clingy"

O O

O

O O

O

Greater independence

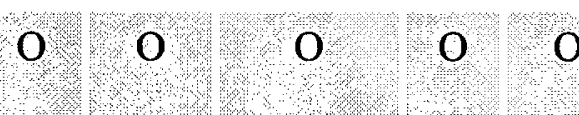

Anxiety

O O

O

O 0

O

Fearfulness
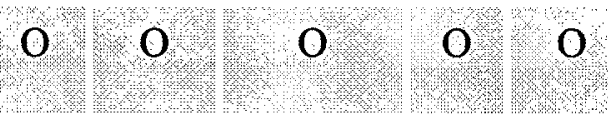

o

Overall behaviour changes

o $\mathrm{O}$

$\mathrm{O}$

O O

O

Accepts more responsibility

$\begin{array}{llllll}0 & 0 & 0 & 0 & 0\end{array}$

Unhappiness/sadness

O O

o

O O

O

Nightmares

$\begin{array}{lllll}0 & 0 & 0 & 0\end{array}$

0

Disruptions in friendships

O $\mathrm{O}$

O

O O

o

An increase in sibling rivalry

$0 \quad 0$

$0 \quad 0 \quad 0$

o 
Emotional withdrawal
o $\mathrm{O}$

O

O O

$\mathrm{O}$

Young children sleeping with parent

O 0

O

O O

$\mathrm{O}$

Contributes more to cleaning and

O O

O

O O

O

maintaining house

More outgoing

$\begin{array}{llllll}0 & 0 & 0 & 0 & 0 & 0\end{array}$

Anger

o $\quad 0$

O

O O

$\mathrm{O}$

Aggression

$\begin{array}{llllll}0 & 0 & 0 & 0 & 0\end{array}$

Violence

O $\mathrm{O}$

o

$\mathrm{O} \quad \mathrm{O}$

O

Running away

$0 \quad 0$

$\mathrm{O}$

0

O

Irrational guilt

$\begin{array}{llllll}0 & 0 & 0 & 0 & 0 & 0\end{array}$

Pride in deployed parent

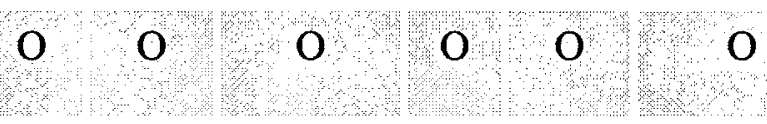

Constantly thinking about the

O $\mathrm{O}$

O

O O

O

deployed parent

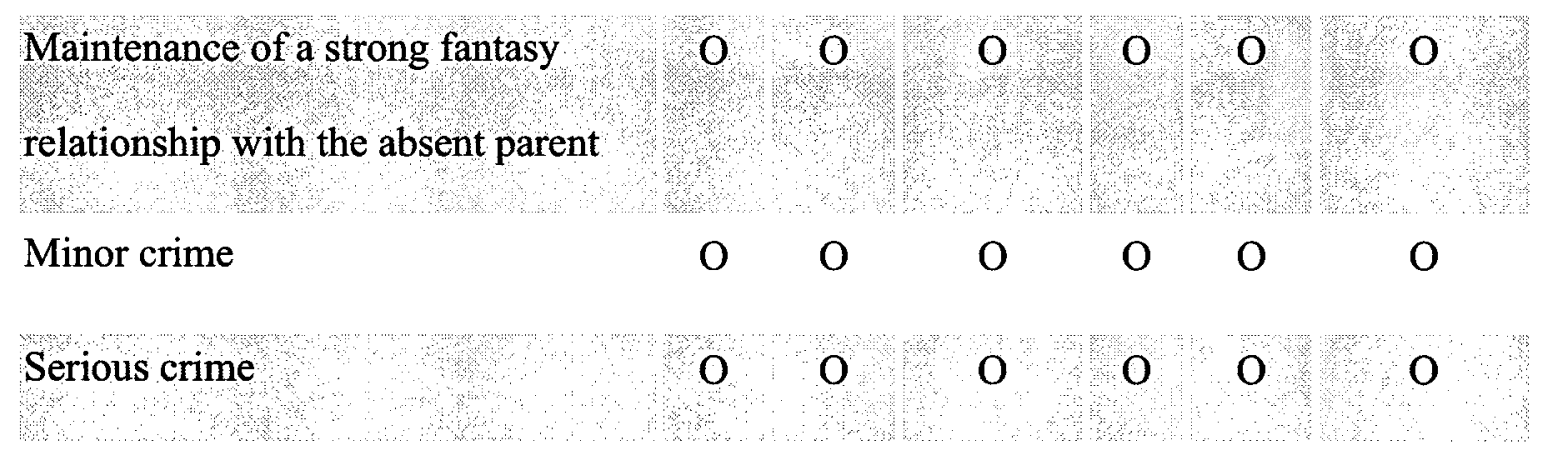




\section{Relationship stressors}

Which of the following statements apply to your experiences after a deployment?
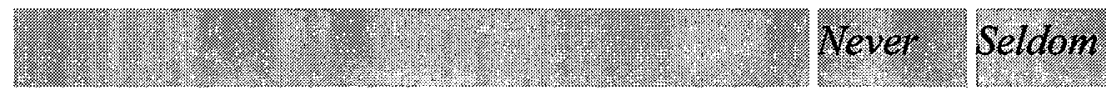

Sometimes

Often Always

I try to talk with my spouse/partner about

$\mathrm{O}$

O

O

$\mathrm{O} \quad \mathrm{O}$

his/her activities while he/she was away.

My spouse/partner has difficulty

O O

$\mathrm{O}$

$\mathrm{O}$

$\mathrm{O}$

compromising.

My spouse/partner is violent after a

0

$\mathrm{O}$

0

$\mathrm{O}$

0 deployment.

I want my spouse/partner to "take care of me"

$\mathrm{O} \quad \mathrm{O}$

$\mathrm{O}$

$\mathrm{O} \quad \mathrm{O}$

after a deployment.

My spouse/partner regains control of the

$0 \quad 0$

o

o

O household.

My spouse/partner asks about things that

$\mathrm{O} \quad \mathrm{O}$

$\mathrm{O}$

$\mathrm{O} \quad \mathrm{O}$ happened while he/she was away.

My spouse/partner does not ask about family

O

o

O

$0 \quad 0$ activities that happened during his/her absence.

My spouse/partner and I argue about finances

O O

$\mathrm{O}$

$\mathrm{O} \quad \mathrm{O}$

after a deployment.

My spouse/partner and I argue about spousal

o

o

o

o

O roles at this time.

My spouse/partner and I argue about child

o $\quad \mathrm{O}$

$\mathrm{O}$

$\mathrm{O}$

$\mathrm{O}$ discipline when he/she returns.

My spouse/partner and I plan a special

0

o

O

0

o vacation away together alone soon after a deployment. 
My spouse/partner and I take the children

$\mathrm{O}$

O

$\mathrm{O}$

$\mathrm{O}$

$\mathrm{O}$ away on a holiday after a deployment.

My spouse/partner and I visit family and

o
O

$\mathrm{O}$

$\mathrm{O}$

$\mathrm{O}$ friends after a deployment.

I take the children away so that my

o $\quad 0$

O

$\mathrm{O} \quad \mathrm{O}$ spouse/partner can rest after a deployment.

My spouse/partner and I spend more money

$\mathrm{O}$

0

O

O $\quad 0$

after a deployment.
$\begin{array}{lllllll}\text { My spouse/partner and I buy new things after a } & \mathrm{O} & \mathrm{O} & \mathrm{O} & \mathrm{O} & \mathrm{O}\end{array}$ deployment.
My spouse/partner and I "treat" ourselves after
a deployment. $\begin{array}{llllll}\text { My spouse/partner and I argue about spending } & \mathrm{O} & \mathrm{O} & \mathrm{O} & \mathrm{O} & \mathrm{O}\end{array}$ money after a deployment. $\begin{array}{llllll}\text { My spouse/partner and I resume our sexual } & \mathrm{O} & \mathrm{O} & \mathrm{O} & \mathrm{O} & \mathrm{O}\end{array}$ relationship soon after he/she returns.
My spouse/partner acts in ways that indicate
$\begin{array}{lllll}\mathrm{O} & \mathrm{O} & \mathrm{O} & \mathrm{O} & \mathrm{O}\end{array}$ that he/she forgets that our household is sometimes noisy, confused and cluttered.
My spouse/partner acts in ways that indicate
$\mathrm{O}$
O
0
O $\quad 0$ that he/she is threatened by the independence $I$ experienced while he/she was deployed.
My spouse/partner discusses the deployment
$\mathrm{O}$
$\mathrm{O}$
$\mathrm{O}$
$\mathrm{O} \quad \mathrm{O}$ within the family.

My spouse/partner will not talk about his/her

o

o

O

o

o experiences during the deployment. 


\section{Coping styles}

People deal with stress in different ways. How often do you do the following when you feel stressed?

\begin{tabular}{|c|c|c|c|c|c|}
\hline & Never & Seldom & Sometin & & Always \\
\hline Change what's causing the stress & 0 & 0 & $\mathrm{O}$ & $\mathrm{O}$ & $\mathrm{O}$ \\
\hline Try to do new things & $\mathrm{O}$ & $\mathrm{O}$ & $\mathrm{O}$ & $\mathrm{O}$ & $\mathrm{O}$ \\
\hline $\begin{array}{l}\text { Look for information about } \\
\text { possible choices }\end{array}$ & 0 & 0 & 0 & 0 & 0 \\
\hline Feel responsible for the outcome & $\mathrm{O}$ & $\mathrm{O}$ & $\mathrm{O}$ & $\mathrm{O}$ & $\mathrm{O}$ \\
\hline Decide what needs to be done & O & 0 & $\mathrm{O}$ & 0 & O \\
\hline Become apathetic or just don't care & $\mathrm{O}$ & $\mathrm{O}$ & $\mathrm{O}$ & $\mathrm{O}$ & $\mathrm{O}$ \\
\hline Drink alcohol & 0 & O & 0 & O & $\mathrm{O}$ \\
\hline $\begin{array}{l}\text { Withdraw physically from the } \\
\text { situation }\end{array}$ & $\mathrm{O}$ & $\mathrm{O}$ & $\mathrm{O}$ & $\mathrm{O}$ & $\mathrm{O}$ \\
\hline Eat more & 0 & $\mathrm{O}$ & 0 & 0 & 0 \\
\hline Just try to ignore it & $\mathrm{O}$ & $\mathrm{O}$ & $\mathrm{O}$ & $\mathrm{O}$ & $\mathrm{O}$ \\
\hline Daydream & 0 & 0 & $\mathrm{O}$ & 0 & $\mathrm{O}$ \\
\hline Smoke cigarettes & $\mathrm{O}$ & $\mathrm{O}$ & $\mathrm{O}$ & $\mathrm{O}$ & $\mathrm{O}$ \\
\hline Complain to others & 0 & O & $\mathrm{O}$ & $\mathrm{O}$ & 0 \\
\hline Avoid thinking about the problem & $\mathrm{O}$ & $\mathrm{O}$ & $\mathrm{O}$ & $\mathrm{O}$ & $\mathrm{O}$ \\
\hline Turn to my religious beliefs & 0 & 0 & 0 & 0 & O \\
\hline Turn to prayer or spiritual thoughts & $\mathrm{O}$ & $\mathrm{O}$ & $\mathrm{O}$ & $\mathrm{O}$ & $\mathrm{O}$ \\
\hline Seek religious guidance & 0 & 0 & 0 & 0 & 0 \\
\hline Do physical exercise & $\mathrm{O}$ & $\mathrm{O}$ & $\mathrm{O}$ & $\mathrm{O}$ & $\mathrm{O}$ \\
\hline Use illicit drugs (marijuana, etc.) & $\mathrm{O}$ & 0 & 0 & 0 & $\mathrm{O}$ \\
\hline $\begin{array}{l}\text { Use over-the-counter or } \\
\text { prescription drugs }\end{array}$ & $\mathrm{O}$ & $\mathrm{O}$ & $\mathrm{O}$ & $\mathrm{O}$ & $\mathrm{O}$ \\
\hline
\end{tabular}


Threat Appraisals: The Work to Family Conflict scale

The following statements describe aspects of the connection between the demands of service life, work, and personal or family life in general. Please rate how much you agree or disagree with each.

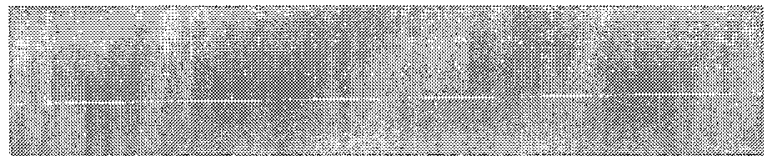

The demands of the military interfere with my home and family life.

The amount of time my spouse or partner's duty takes up makes it difficult to fulfill family responsibilities.

Things I want to do at home do not get done because of the demands my spouse or partner's military service puts on me.

My spouse or partner's job produces strain that makes it difficult to fulfill family duties.

Due to my spouse or partner's servicerelated duties, I have to make changes in my plans for family activities.
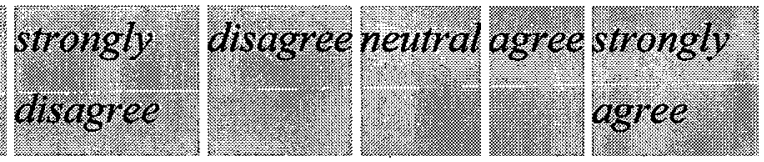

$\begin{array}{lllll}0 & 0 & 0 & 0 & 0\end{array}$
$\mathrm{O}$

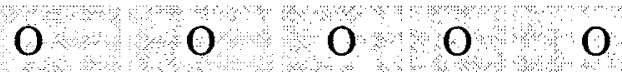

$\mathrm{O}$

Threat Appraisals (two items added to the scale)

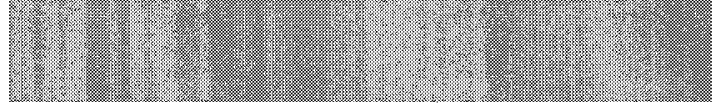

My marriage or partnership is stronger because of frequent time apart

My employment or career has suffered as a result of my spouse/partner's service in CF

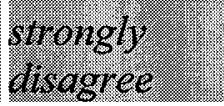
disagree

$\mathrm{O}$

$\mathrm{O}$

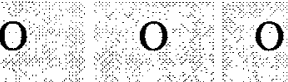

\author{
, 13
}

O

17 tons 
Support for member's military career

How supportive are you toward each of the following?

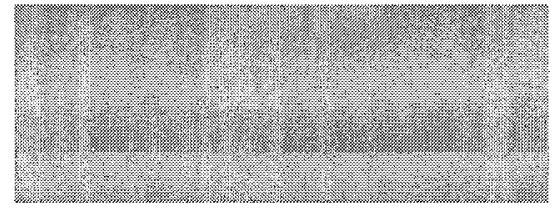

Your spouse or partner's current service in the CF

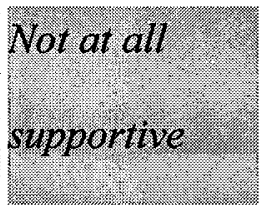

o

$0 \times 0$ $\frac{2}{2+3}$
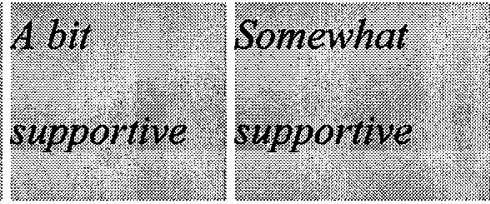

o

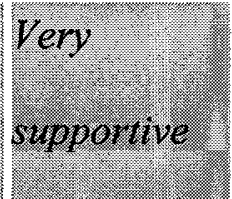

o

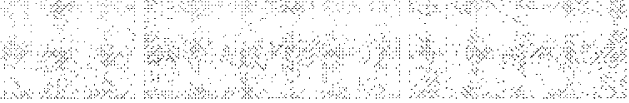
Your spouse or partner $\mathrm{O}$

O $\mathrm{O}$ $\mathrm{O}$

pursuing a long-term career in the $\mathrm{CF}$ 
Appendix C: Descriptive statistics for the variables in Study 2

Table C1

Descriptive statistics for the variables in Study 2

\begin{tabular}{lccccc}
\hline Scale & Possible & $M$ & $S D$ & Skewness & Kurtosis \\
& Range & & & & \\
\hline Parenting stressors & $1-5$ & 2.40 & 0.76 & 0.23 & -0.41 \\
Relationship stressors & $1-5$ & 1.91 & 0.72 & 0.83 & 0.22 \\
Threat & $1-5$ & 3.10 & 0.89 & -0.25 & -0.59 \\
Controllability & $1-5$ & 4.11 & 0.71 & -0.51 & -0.24 \\
Problem-solving coping & $1-5$ & 3.36 & 0.63 & -0.18 & 0.77 \\
Emotional coping & $1-5$ & 2.45 & 0.73 & 0.15 & -0.77 \\
Avoidant coping & $1-5$ & 2.21 & 0.68 & 0.12 & -0.39 \\
Religious coping & $1-5$ & 1.89 & 0.98 & 1.04 & 0.39 \\
Support for member's military & $1-4$ & 3.38 & 0.71 & -1.06 & 0.32 \\
career & & & & & \\
Perceived spousal support & & & & & 0.39 \\
Perceived organizational support & $1-5$ & 4.07 & 0.64 & -0.72 & 0.35 \\
Satisfaction with life & $1-5$ & 2.33 & 0.94 & 0.03 & -0.96 \\
Psychological distress & $1-4$ & 2.21 & 0.39 & 0.29 & 1.39 \\
\hline & & & & & \\
\hline
\end{tabular}


$\Phi$

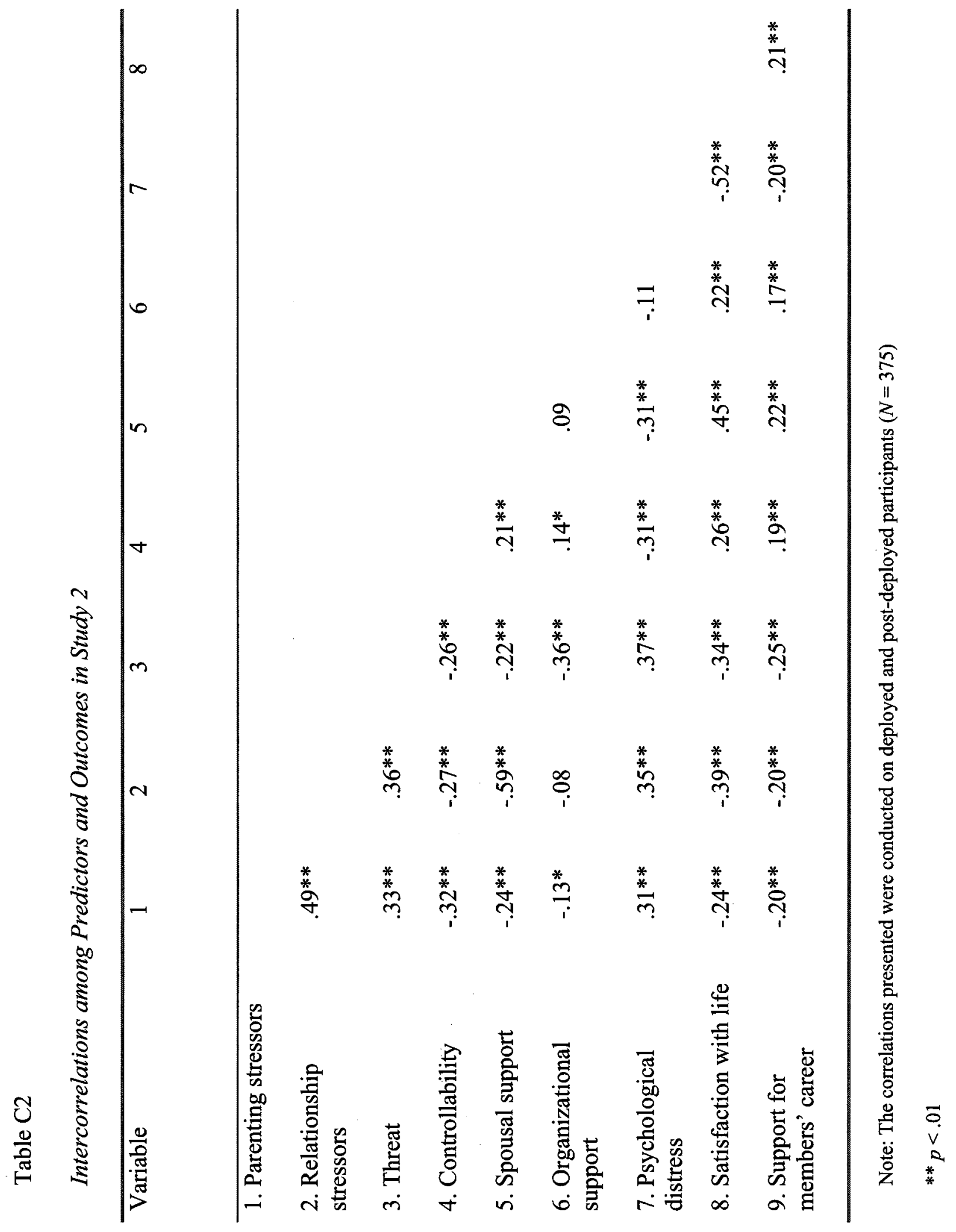

